\title{
ESTUDO ESPECTROSCÓPICO IN SITU E ESPECTROMÉTRICO ON LINE DA ELETRO-OXIDAÇÃO OSCILATÓRIA DE ÁLCOOIS SIMPLES SOBRE PLATINA
}

Tese apresentada ao Instituto de Química de São Carlos da Universidade de São Paulo como parte dos requisitos para a obtenção do título de Doutor em Química.

Área de concentração: Físico-Química

Orientador: Prof. Dr. Hamilton Varela

São Carlos

2013 


\section{Exemplar revisado}

O exemplar original encontra-se em acervo reservado na biblioteca do IQSC-USP

Este exemplar foi revisado e alterado em relação à versão original, sob a exclusiva responsabilidade do autor.

São Carlos, 04 de setembro de 2013.

Emerson Paulinho Boscheto 
Aos meus queridos pais, Euclides $\mathcal{L}$. Boscheto e Vani M. Boscheto 


\section{AGRADECIMENTOS}

Ao Prof. Dr. Hamilton pelo interessante tema do projeto e por ter proporcionado muito boas condições para realizá-lo.

Aos membros do Grupo de Eletroquímica do IQSC que, direta ou indiretamente, contribuíram para a conclusão deste trabalho, Jonas, Mauro, Maristela, Valdecir, Gabriel, Roberto, Melke, Raphael, Bruno, Maurício, Emília, Daniel, Liliane, Elton, Eduardo Machado, Eduardo Ciapina, Adriano, Manuel, Hyrla, Paulo, Natália, Andressa, Nickson, Marcelo, Cristiane, Graziela, Débora, Amanda, Orlando, Thairo, Elenice, Adriana, Vanessa, Aniélli, Waldemir, Jairo, Edivan, Wanderson, Drielly, Nyccolas, Alana, André, Gustavo, Pietro, José, Luiz, Janaína, Murilo, Emerson, Márcia, Patrícia, entre outros que me esqueci de registrar aqui.

Aos funcionários da secretaria de pós-graduação e das oficinas mecânica e de vidraria, sempre solícitos em ajudar.

Ao Prof. Rolf J. Behm e a todos os membros do Grupo de Eletrocatálise do Intituto de Química de Superfície e Catálise da Universidade de Ulm, em Ulm - Alemanha, principalmente, ao Dr. Zenonas Jusys pela ajuda com os experimentos.

Ao Otávio por toda a ajuda com minha estadia em Ulm.

À María, ao Konstantin e à Zezé pela ajuda e pelos momentos de descontração em Ulm.

Ao Bruno Batista pela ajuda nos experimentos e pelas muitas interessantes discussões.

Aos meus pais e à minha família pelo incentivo e apoio.

À Joana pelo companheirismo e suporte.

Ao povo brasileiro que por meio do CNPq financiou este trabalho. 

Embora a entropia do universo evolua para um máximo, localmente, sistemas podem se ordenar às custas do maior desordenamento de suas vizinhanças. Assim, a formação espontânea de padrões temporais e espaciais tem sido observada em diferentes sistemas, incluindo os eletroquímicos. Neste trabalho foram estudadas as dinâmicas oscilatórias temporais de potencial desenvolvidas durante a eletro-oxidação galvanostática de metanol e etanol em meio ácido sobre eletrodos de platina. Como a técnica galvanostática informa apenas sobre a totalidade dos processos a ocorrer na interface eletrodo/solução, técnicas auxiliares devem ser empregadas em conjunto para obter informações a respeito dos processos individuais. Desta forma, as técnicas de espectroscopia de infravermelho in situ, em configuração de reflexão interna, e de espectrometria de massas on line foram utilizadas e permitiram alcançar as seguintes conclusões. Para a eletro-oxidação oscilatória de metanol, os resultados mostraram que (i) em média, o grau de recobrimento de monóxido de carbono linearmente adsorvido $\left(\theta_{\mathrm{CO}_{L}}\right)$ decai continuamente ao longo do experimento oscilatório, sugerindo que um acúmulo de espécies oxigenadas adsorvidas desenvolve-se ao longo das oscilações de potencial e é o responsável pela deriva que age sobre o sistema; (ii) a variação negativa da posição da banda de $\mathrm{CO}_{\llcorner}$com o aumento do potencial durante o período de indução sugere que não há tendência para formação de padrões ou ilhas de $\mathrm{CO}_{\text {ads }}$ previamente à observação de oscilações. Já os resultados da eletro-oxidação oscilatória de etanol mostraram (i) também uma queda contínua, em média, em $\theta_{C O_{L}}$ ao longo do tempo bem como um crescimento, em média, da população de acetato adsorvido; (ii) para a condição oscilatória estudada, a produção de $\mathrm{CO}_{2}$ seguiu a mesma dinâmica temporal das oscilações de potencial, já a corrente iônica associada à produção de acetaldeído permaneceu estacionária dentro do regime oscilatório. 
Although the entropy of the universe evolves to a maximum, locally systems can become ordered at the expense of greater disordering of their neighborhoods. Thus, the spontaneous formation of temporal and spatial patterns have been observed in different systems, including electrochemical ones. In this thesis, the temporal dynamics of potential oscillations developed during the galvanostatic electro-oxidation of methanol and ethanol in acid medium on platinum electrodes were studied. As the galvanostatic technique informs just about all the processes occurring at the interface electrode/solution auxiliary techniques should be employed together to obtain information about individual processes. Thus the techniques of in situ infrared spectroscopy, in configuration of internal reflection, and online mass spectrometry were used and allowed to reach at the following conclusions. For the oscillatory electro-oxidation of methanol the results showed that (i) on average, the coverage degree of linearly adsorbed carbon monoxide $\left(\theta_{C O_{L}}\right)$ decays continuously throughout the oscillatory experiment, suggesting that an accumulation of adsorbed oxygen species develops along the oscillations and causes the drift in the system, (ii) the negative change in the band position of $\mathrm{CO}_{\mathrm{L}}$ with potential increasing during the induction period suggests that there is no tendency to pattern formation or islands formation of $\mathrm{CO}_{\text {ads }}$ prior to the observation of oscillations. Concerning the oscillatory electro-oxidation of ethanol the results showed that (i) there is also a continuous drop on average in $\theta_{C O_{L}}$ over time as well as an increase on average in the population of adsorbed acetate, (ii) for the oscillatory condition studied the production of $\mathrm{CO}_{2}$ followed the same temporal dynamics of the oscillations of potential, while the ionic current associated with the production of acetaldehyde remained stationary inside the oscillatory regime. 
Figura 1 - Esquema ilustrando uma cadeia linear de influências (a) e um ciclo de retro-alimentação (b) entre variáveis internas de um sistema.

Figura 2 - Ilustração de curvas estacionárias de corrente faradaica vs. potencial da dupla camada que apresentam ramos instáveis em forma de $\mathrm{N}$ (a) e de S (b). Em (a) círculos abertos representam estados estacionários estáveis e o preenchido um estado estacionário instável; a linha reta representa a variação da corrente total, $\mathrm{I}_{\mathrm{T}}$, para um potencial aplicado, $\mathrm{U}$, com resistência, $R_{\Omega}$, não nula.

Figura 3 - llustração do mecanismo oscilatório simplificado em modo galvanostático através do acoplamento entre ciclos de retro-alimentação positiva e negativa. $\phi$ denota o potencial da dupla camada, $U$ o potencial externamente medido e $\theta_{\mathrm{OH}}$ e $\theta_{\mathrm{CO}}$ os graus de recobrimento de espécies oxigenadas e de monóxido de carbono, respectivamente. Figura adaptada da referência [22].

Figura 4 - Diagrama de bifurcação (a) no plano de parâmetros adimensionais resistência, $\rho$, versus potencial aplicado, $U$, e (b) no plano de máximos da corrente faradaica, $I_{F}$, versus $U$, para $\rho=106,63$. Os dados correspondem a simulações em um modelo genérico para um oscilador eletroquímico. Figura adaptada da referência [23].

Figura 5 - Oscilações de potencial observadas durante aplicação de 0,77 mA $\mathrm{cm}^{-2}$ a sistema contendo $\mathrm{HCHO} 0,1 \mathrm{M}+\mathrm{H}_{2} \mathrm{SO}_{4}$ 0,5 M em contato com eletrodo de platina. Regiões destacadas em (a2) e (a3) correspondem a padrões com período-1 e em (a1) e (a4) para período-2. Figura adaptada da referência [24].

Figura 6 - Representações esquemáticas de células espectroeletroquímicas em configuração de reflexão (a) externa e (b) interna. ET: eletrodo de trabalho, EC: contra-eletrodo e ER: eletrodo de referência. Figura adaptada da referência [32].

Figura 7 - Uma ilustração típica dos componentes de um instrumento de EMED. Figura adaptada da referência [39].

Figura 8 - Esquema de célula espectro-eletroquímica utilizada para monitoramento in situ da interface eletrodo/solução pela técnica de espectroscopia de infravermelho EAIVIS em configuração RTA.

Figura 9 - Diagrama esquemático da célula de fluxo utilizada para medidas simultâneas de EMED on line e EAIVIS-RTA in situ. Ent-1 e Ent-2 denotam duas entradas de solução possíveis. CE denota contra-eletrodo e ER eletrodo de referência. Flechas azuis indicam o sentido do fluxo de solução. Figura 
Figura 10 - Voltamograma cíclico, a $25 \mathrm{mV} \mathrm{s}^{-1}$, do eletrodo de trabalho (filme de Pt) em contato com solução de (a) $\mathrm{H}_{2} \mathrm{SO}_{4} 0,5 \mathrm{M} \mathrm{e} \mathrm{(b)} \mathrm{H}_{2} \mathrm{SO}_{4} 0,5 \mathrm{M}+\mathrm{CH}_{3} \mathrm{OH}$ $0,1 \mathrm{M}$. As correntes foram normalizadas pela área real de $74 \mathrm{~cm}^{2}$.

Figura 11 - Esquema reacional simplificado para eletro-oxidação de metanol sobre eletrodos de Pt. Figura adaptada da referência [54].

Figura 12 - (a) Oscilações de potencial durante a eletro-oxidação galvanostática de $\mathrm{CH}_{3} \mathrm{OH} 0,1 \mathrm{M}$ em meio de $\mathrm{H}_{2} \mathrm{SO}_{4}$ 0,5 $\mathrm{M}$ sob densidade de corrente de $0,2 \mathrm{~mA} \mathrm{~cm}^{-2}$; (b) intensidade integrada das bandas de $\mathrm{CO}_{\mathrm{L}}(\bullet), \mathrm{CO}_{\mathrm{B}}$ (\) e formato (•); (c) visão detalhada de duas regiões diferentes das oscilações de potencial dadas em (a).

Figure 13 - Evolução temporal de espectros EAIVIS, obtidos a partir da média de $60 \mathrm{~s}$ de coleta de interferogramas adquiridos com resolução temporal de $0,2 \mathrm{~s}$ e com resolução espacial de $8 \mathrm{~cm}^{-1}$, resultando em 300 varreduras por espectro. Eletrólito: $\mathrm{H}_{2} \mathrm{SO}_{4} 0,5 \mathrm{M}+\mathrm{CH}_{3} \mathrm{OH} 0,1 \mathrm{M}$. Corrente aplicada: 0,20 mA $\mathrm{cm}^{-2}$.

Figura 14 - Série de espectros, em unidades de absorvância, registrados simultaneamente às oscilações de potencial. Linhas tracejadas conectam máximos de ciclos de potencial com seus respectivos espectros. As resoluções espaciais e temporais foram $8 \mathrm{~cm}^{-1}$ e $500 \mathrm{~ms}$, respectivamente. Eletrólito: $\mathrm{H}_{2} \mathrm{SO}_{4}$ 0,5 M $+\mathrm{CH}_{3} \mathrm{OH} \mathrm{0,1} \mathrm{M.} \mathrm{Corrente} \mathrm{aplicada:} \mathrm{0,18} \mathrm{mA} \mathrm{cm}^{-2}$.

Figura 15 - Oscilações (a) de potencial durante eletro-oxidação galvanostática de metanol; (b) da posição da banda; e (c) do recobrimento de $\mathrm{CO}_{\mathrm{L}}$, registrados simultaneamente com o experimento eletroquímico. Dados extraídos da Fig. 14.

Figura 16 - (a) Voltamograma base do filme de platina, depositado sobre o prisma de $\mathrm{Si}$, em contato com $\mathrm{HClO}_{4}$ 0,5 M. Velocidade de varredura $=10 \mathrm{mV}$ $\mathrm{s}^{-1}$. Corrente normalizada pela área real de $4 \mathrm{~cm}^{2}$. Velocidade de fluxo de eletrólito $\approx 50 \mu \mathrm{L} \mathrm{s}^{-1}$; (b) Espectro obtido com o eletrodo saturado com $\mathrm{CO}_{\text {ads }} \mathrm{e}$ polarizado a $50 \mathrm{mV}$ em contato apenas com eletrólito, $\mathrm{HClO}_{4}$ 0,5 M. A soma entre a área da banda de $\mathrm{CO}_{\mathrm{L}}$ com duas vezes a de $\mathrm{CO}_{\mathrm{B}}$ resultou ser $4,44 \mathrm{~cm}^{-1}$. $O$ espectro de referência foi coletado com o eletrodo polarizado a $60 \mathrm{mV}$ na presença apenas de eletrólito de suporte.

Figura 17: Evolução temporal do potencial (preto), posição da banda de $\mathrm{CO}$ (azul) e intensidades integradas de $\mathrm{CO}_{\mathrm{L}}$ (vermelho), $\mathrm{CO}_{\mathrm{B}}$ (verde) e formato (laranja) adsorvidos durante eletro-oxidação galvanostática de $\mathrm{CH}_{3} \mathrm{OH}$ 0,1 $\mathrm{M}+$ $\mathrm{HClO}_{4} 0,5 \mathrm{M} \mathrm{a} \mathrm{0,62} \mathrm{mA} \mathrm{cm}{ }^{-2}$ (aplicada em $\mathrm{t}=50 \mathrm{~s}$ ). 
Figura 18 - (a) Visão ampliada da Fig. 17 e respectivos espectros na região de número de onda de (b) $\mathrm{CO}_{\mathrm{L}}$ e (c) formato entre 130 e $140 \mathrm{~s}$.

Figura 19 - (a) Visão ampliada da Fig. 17 e respectivos espectros na região de número de onda de (b) $\mathrm{CO}_{\mathrm{L}}$ e (c) formato entre 180 e $190 \mathrm{~s}$.

Figura 20 - Perfis temporais das oscilações de potencial (preto) observadas na Fig. 17 e suas derivadas (vermelho) com resolução temporal considerada (rtc) de (a) 60 e (b) $240 \mathrm{~ms}$.

Figura 21 - Perfis temporais das oscilações de potencial (preto) observadas na Fig. 17 e do negativo de suas derivadas (laranja) com resolução temporal considerada de (a) 60 e (b) 240 ms.

Figura 22 - Representação da posição da banda de $\mathrm{CO}_{\mathrm{L}}$ em função do potencial em três diferentes intervalos de tempo, no período de indução (verde), após o início (azul) e próximo do fim (vermelho) das oscilações. 0 coeficiente angular da reta pontilhada é de $-111.4 \mathrm{~cm}^{-1} \mathrm{~V}^{-1}$ e o coeficiente angular das linhas tracejadas é de $29 \mathrm{~cm}^{-1} \mathrm{~V}^{-1}$.

Figura 23 - Esquema ilustrando efeito da repulsão lateral na força de vibração de moléculas de CO adsorvidas. O tamanho das setas em verde indica a magnitude relativa da energia de vibração.

Figura 24 - Varreduras positivas a $50 \mathrm{mV} / \mathrm{s}$ do potencial do eletrodo de Pt em contato com $\mathrm{H}_{2} \mathrm{SO}_{4} 0,5 \mathrm{M}+\mathrm{H}_{2} \mathrm{O}_{2} \times \mathrm{mM}, \mathrm{x}=0,1,2,3,4$, 5. Potencial limite superior ou de reversão da voltametria $\left(U_{\text {rev }}\right)=0,8 \mathrm{~V}$.

Figura 25 - Varreduras, a $25 \mathrm{mV} / \mathrm{s}$, de ida (a) e volta (b) do potencial do eletrodo de Pt na presença de $\mathrm{H}_{2} \mathrm{SO}_{4} 0,5 \mathrm{M}$ (linha tracejada) e de $\mathrm{H}_{2} \mathrm{SO}_{4} 0,5 \mathrm{M}$ $+\mathrm{H}_{2} \mathrm{O}_{2} 1 \mathrm{mM}$ (linha contínua).

Figura 26 - Voltamogramas a $25 \mathrm{mV} / \mathrm{s}$ do eletrodo de platina em contato com (a) $\mathrm{H}_{2} \mathrm{SO}_{4} 0,5 \mathrm{M}+\mathrm{H}_{2} \mathrm{O}_{2}$ 0,001 M, (b) $\mathrm{H}_{2} \mathrm{SO}_{4} 0,5 \mathrm{M}+\mathrm{CH}_{3} \mathrm{OH} 0,1 \mathrm{M}$ e varredura positiva, a $25 \mathrm{mV} / \mathrm{s}$, prevista e experimental (ver texto) do sistema misto $\mathrm{H}_{2} \mathrm{SO}_{4} 0,5 \mathrm{M}+\mathrm{H}_{2} \mathrm{O}_{2} 0,001 \mathrm{M}+\mathrm{CH}_{3} \mathrm{OH}$ 0,1 M.

Figura 27 - Oscilações de potencial sob corrente aplicada de $140 \mu \mathrm{A}$ para (a)

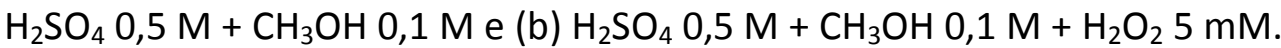

Figura 28 - Amplitude máxima e número de ciclos para oscilações obtidas com os sistemas $\mathrm{H}_{2} \mathrm{SO}_{4} 0,5 \mathrm{M}+\mathrm{CH}_{3} \mathrm{OH} \mathrm{0,1} \mathrm{M}$ (círculos cheios) e $\mathrm{H}_{2} \mathrm{SO}_{4} 0,5 \mathrm{M}+$ $\mathrm{CH}_{3} \mathrm{OH} 0,1 \mathrm{M}+\mathrm{H}_{2} \mathrm{O}_{2}$ 0,005 $\mathrm{M}$ (círculos vazios) em função de corrente aplicada.

Figura 29 - Ilustração de isotermas de adsorção de espécies oxigenadas sem (a) e com (b) a presença de peróxido de hidrogênio (linha tracejada) durante a eletro-oxidação de metanol. Isotermas do recobrimento de CO (linha mais 
grossa) também foram incluídas.

Figura 30 - Esquema simplificado das vias paralelas presentes na eletrooxidação de etanol sobre eletrodos de platina [95, 103-106].

Figura 31 - Voltamograma cíclico do eletrodo de platina em contato com (a) $\mathrm{H}_{2} \mathrm{SO}_{4} \quad 0,5 \mathrm{M}$ e (b) $\mathrm{H}_{2} \mathrm{SO}_{4} 0,5 \mathrm{M}+\mathrm{CH}_{3} \mathrm{CH}_{2} \mathrm{OH}$ 0,05 M. A corrente foi normalizada pela área real, $4,36 \mathrm{~cm}^{2}$, encontrada pela região de dessorção de hidrogênio, região hachurada em (a). Velocidade de varredura de potencial: $10 \mathrm{mV} \mathrm{s}^{-1}$.

Figura 32 - Perfil do potencial em função do tempo registrado durante eletrooxidação de $\mathrm{H}_{2} \mathrm{SO}_{4} 0,5 \mathrm{M}+\mathrm{CH}_{3} \mathrm{CH}_{2} \mathrm{OH} 0,05 \mathrm{M}$ sobre platina. Densidade de corrente aplicada: 0,183 $\mathrm{mA} \mathrm{cm}^{-2}$.

Figura 33 - Amplitude (azul) e potenciais de máximo (preto) e de mínimo (vermelho) das oscilações exibidas na Fig. 32 em função do tempo.

Figura 34 - Frequência das oscilações exibidas na Fig. 32 em função do número de ciclos.

Figura 35 - Representação de ciclos de potencial no início (a) e próximo do fim (b) da série temporal mostrada na Fig. 32. Os pontos vermelhos delimitam a região em que foram calculadas as taxas de variação do potencial, cujos valores estão indicados na figura.

Figura 36 - Representação do potencial médio em função do tempo com os coeficientes angulares aproximados para as regiões de período-1 e período-2. A razão entre elas é de 4,1.

Figura 37 - Espectro de radiação infravermelha da interface eletrodo/solução coletado aos $20 \mathrm{~s}(\mathrm{U}=0,56 \mathrm{~V})$ do experimento da Fig. 32. As linhas tracejadas marcam o centro, em média, das bandas referentes aos adsorbatos $\mathrm{CO}_{L}, 2046$ $\mathrm{cm}^{-1}, \mathrm{CO}_{\mathrm{M}}, 1829 \mathrm{~cm}^{-1}$, acetato, $1407 \mathrm{~cm}^{-1}$, e espécies sulfato, 1207 e $1113 \mathrm{~cm}^{-}$ ${ }^{1}$. A resolução espectral utilizada foi de $0,5 \mathrm{~cm}^{-1}$ e o espectro de referência foi coletado com o eletrodo polarizado a $70 \mathrm{mV}$ e em contato apenas com eletrólito suporte. Resolução temporal: 0,302 s.

Figura 38 - Intensidades integradas das bandas de $\mathrm{CO}_{\mathrm{L}}$ (vermelho), $\mathrm{CO}_{\mathrm{M}}$ (verde), acetato adsorvido (laranja) e sulfato adsorvido (azul) ao longo dos ciclos de potencial (preto) em diferentes intervalos de tempo, $9-30 \mathrm{~s}$ (a1) e (a2), $29-130 \mathrm{~s}$ (b1) e (b2), $129-230 \mathrm{~s}$ (c1) e (c2) e $230-390 \mathrm{~s}$ (d1) e (d2) do experimento da Fig. 32.

Figura 39 - Perfil temporal das correntes iônicas associadas à produção de $\mathrm{CO}_{2}$ (azul) e acetaldeído (vermelho) ao longo das oscilações da Fig. 32 (a); região ampliada no começo da série temporal (b). 
Figura 40 - Representação de oscilações de potencial (preto) da Fig. 32 juntamente com as variações temporais na corrente iônica de $\mathrm{CO}_{2}$ (azul), na intensidade integrada da banda de $\mathrm{CO}_{\mathrm{L}}$ (vermelho) e do negativo da derivada do potencial (laranja) no início das oscilações (a) e no intervalo de tempo compreendendo a bifurcação espontânea de período-1 para período-2 (b).

Figura 41 - Variação temporal de $\mathrm{U}(\mathrm{a})$ e das posições das bandas de $\mathrm{CO}_{\mathrm{L}}(\mathrm{b})$, $\mathrm{CO}_{\mathrm{B}}$ (c) e acetato adsorvido (d), cujas posições médias tomadas entre 100 e $300 \mathrm{~s}$ são, respectivamente, $2046 \mathrm{~cm}^{-1}, 1829 \mathrm{~cm}^{-1}$ e $1407 \mathrm{~cm}^{-1}$ durante experimento apresentado na Fig. 32.

Figura 42 - Variação temporal das posições das bandas das espécies sulfato (a) e bi-sulfato (b) cujas posições médias tomadas entre 100 e 300 s são, respectivamente, $1207 \mathrm{~cm}^{-1}$ e $1113 \mathrm{~cm}^{-1}$ durante o experimento apresentado na Fig. 32. 
LISTA DE ABREVIATURAS E SIGLAS

\author{
RDN Resistência Diferencial Negativa \\ RDN-NE Resistência Diferencial Negativa- com N Escondido \\ IV Infravermelho \\ EAIVIS Espectroscopia de Absorvância no Infravermelho Intensificada pela Superfície \\ RTA Reflexão Total Atenuada \\ ER Eletrodo de Referência \\ ET Eletrodo de Trabalho \\ CE Contra-eletrodo \\ ERH Eletrodo Reversível de Hidrogênio \\ EPH Eletrodo Padrão de Hidrogênio \\ EMED Espectrometria de Massas Eletroquímica Diferencial \\ rtc Resolução temporal considerada
}


LISTA DE SÍMBOLOS

$\begin{array}{ll}\mathrm{I}_{\mathrm{T}} & \text { Corrente total } \\ \mathrm{I}_{\mathrm{F}} & \text { Corrente faradaica } \\ \mathrm{I}_{\mathrm{C}} & \text { Corrente capacitiva } \\ \mathrm{I}_{\mathrm{ap}} & \text { Corrente aplicada } \\ \mathrm{C} & \text { Capacitância da dupla-camada elétrica } \\ \mathrm{U} & \text { Potencial externo } \\ \phi & \text { Potencial da dupla-camada } \\ \phi_{\mathrm{ee}} & \text { Potencial da dupla-camada em condição estacionária } \\ \delta \phi & \text { Pequena perturbação no potencia da dupla-camada } \\ \mathrm{R}_{\Omega} & \text { Resistência total do sistema } \\ \mathrm{Z} & \text { Impedância faradaica } \\ \mathrm{A} & \text { Área ativa do catalisador } \\ \mathrm{c} & \text { Concentração da espécie eletroativa } \\ \mathrm{k} & \text { Constante eletroquímica de reação } \\ \theta_{\mathrm{OH}} & \text { Grau de recobrimento de espécies oxigenadas adsorvidas } \\ \theta_{\mathrm{CO}} & \text { Grau de recobrimento de monóxido de carbono adsorvido } \\ \bar{U} & \text { Potencial médio }\end{array}$




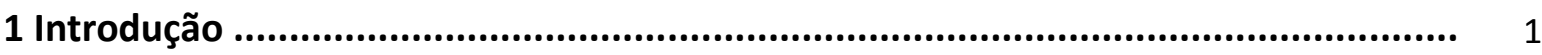

1.1 Oscilações em sistemas eletroquímicos ........................................................... 2

1.1.1 Introdução de alguns conceitos e problemática de oscilações não compensadas ........................................................................................... 10

1.2 Espectroscopia de absorção no infravermelho intensificada pela superfície (EAIVIS) .............................................................................................. 12

1.3 Espectrometria de massas eletroquímica diferencial (EMED) ......................... 15

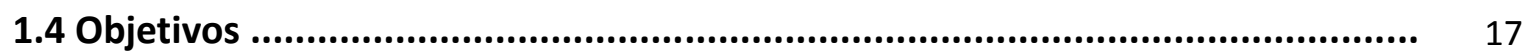

2 Procedimento experimental e materiais utilizados ............................................ 18

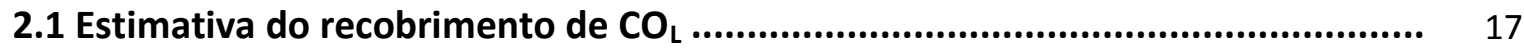

2.2 Experimentos eletroquímicos combinados com espectroscopia de infravermelho in situ ............................................................................................ 19

2.3 Experimentos puramente eletroquímicos .................................................... 21

2.4 Experimentos espectro-eletroquímicos em célula de fluxo com dois

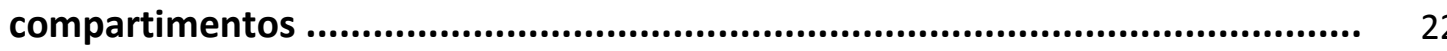

3. Resultados e discussão ....................................................................................... 25

3.1 Eletro-oxidação oscilatória de metanol sobre Pt estudada por espectroscopia de absorção de infravermelho intensificada pela superfície (EAIVIS) in situ em configuração de reflexão total atenuada (RTA) e por perturbação com peróxido de hidrogênio

3.1.1 Estudo da eletro-oxidação oscilatória de metanol por espectroscopia de infravermelho in situ sob condições de eletrólito estagnado

3.1.2 Estudo da eletro-oxidação oscilatória de metanol por espectroscopia de infravermelho in situ utilizando eletrólito em fluxo

3.1.3 Influência da presença extra de espécies oxigenadas sobre a eletrooxidação oscilatória de metanol sobre platina

3.2 Eletro-oxidação oscilatória de etanol estudada por espectroscopia de infravermelho in situ e espectrometria de massas on line ................................. 61

4 Conclusões ........................................................................................... 78

5 Referências Bibliográficas .............................................................................. 80

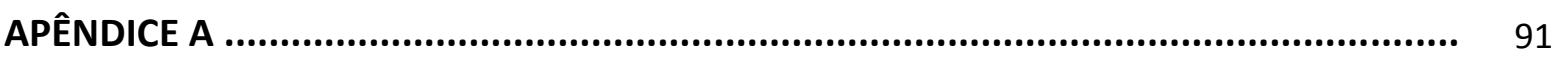




\section{Introdução}

Os estudos de cinética química tratam, geralmente, de casos em que variáveis como concentração ou velocidade de reação tendem, após algum transiente, para um estado estacionário ou de equilíbrio. Um comportamento menos explorado é aquele em que propriedades do sistema oscilam autonomamente ao longo do tempo, isto é, seus valores avançam e recuam entre certos limites, passando inúmeras vezes por estados intermediários. Ressalte-se que esta auto-organização dinâmica dá-se de forma espontânea, ou seja, sem requerer informação das vizinhanças que dite este comportamento. Além de importantes para o funcionamento de organismos vivos [1, 2], especula-se que os padrões dinâmicos tenham desempenhado algum papel na transição da matéria inanimada para a animada [3]. Eles também seriam relevantes para processamento de informações, como recentemente proposto por Sadeghi e Thompson [4] ao sugerirem que a formação de padrões poderia fazer parte do funcionamento do cérebro e que sistemas eletroquímicos que apresentam padrões poderiam agir como sistemas cognitivos artificiais. Efetivamente, este interessante fenômeno tem sido observado não apenas em sistemas químicos [5-11], mas também em outras áreas do conhecimento, como economia [12] e biologia [2, 13-15], e, em eletroquímica, vêm recebendo progressivamente mais atenção nas décadas recentes $[8,16-21]$.

Esta tese trata de sistemas eletroquímicos que apresentam comportamento temporal auto-organizado, mais especificamente, na forma de oscilações de potencial durante a eletro-oxidação dos álcoois simples metanol e etanol, em meio ácido, sobre eletrodos de platina. Como estes processos envolvem múltiplas etapas elementares e espécies intermediárias, o uso isolado de técnicas eletroquímicas, as quais informam apenas sobre a totalidade dos processos ocorrendo sobre a superfície, é insuficiente para determinar sem ambiguidade o mecanismo a nível molecular. Diante disto, outras técnicas devem ser acopladas ao experimento eletroquímico para acessar informações sobre espécies/processos individuais que estão presentes na interface eletrodo/solução e, assim, possibilitar inferir sobre o mecanismo oscilatório. Neste estudo, foram utilizadas as técnicas 
auxiliares de espectroscopia de infravermelho in situ e de espectrometria de massas on line, as quais serão apresentadas adiante nas Seções 1.2 e 1.3, respectivamente, após apresentação das condições necessárias para observação de oscilações em sistemas eletroquímicos bem como do mecanismo simplificado da eletro-oxidação oscilatória de moléculas orgânicas pequenas sobre platina (Seção 1.1). Finalmente, os objetivos específicos são apresentados na Seção 1.4, encerrando o capítulo.

\subsection{Oscilações em sistemas eletroquímicos}

Diante dos fenômenos de auto-organização dinâmica, um primeiro questionamento se coloca: qual seria o mecanismo de formação espontânea destes padrões de ordem? Estando a manifestação deles nas variáveis internas, algum mecanismo intrínseco que impulsione e limite seus valores deve operar. De modo geral, as variáveis internas de um sistema interagem entre si podendo, eventualmente, formar cadeias de dependências/influências (mútuas). Quando acontece de elos, não necessariamente extremos, de uma destas cadeias se unirem de forma a fechá-la em si mesma, ciclos são criados e com eles a possibilidade de restrições internas, ver esquema na Fig. 1. A depender do efeito do ciclo sobre uma determinada variável participante ele será classificado, em relação a ela, como sendo de retro-alimentação positiva, se ela é produzida nele, ou de retro-alimentação negativa, se ela é consumida nele. Do acoplamento entre ciclos de retroalimentação positiva e negativa, em relação a uma mesma variável $i$, ou seja, $i$ participa dos dois ciclos, abre-se a possibilidade de impulsionar e restringir o intervalo de valores que ela pode assumir. Segundo Strasser et al. [17], oscilações são esperadas quando um ciclo que contém apenas variáveis cuja formação é rápida acopla-se a outro com ao menos uma variável de formação rápida em comum e que possui ao menos uma variável cuja produção seja lenta. 
(a)

$$
A_{1} \rightarrow A_{2} \rightarrow A_{3} \rightarrow A_{4} \rightarrow A_{5} \rightarrow A_{6}
$$

(b)

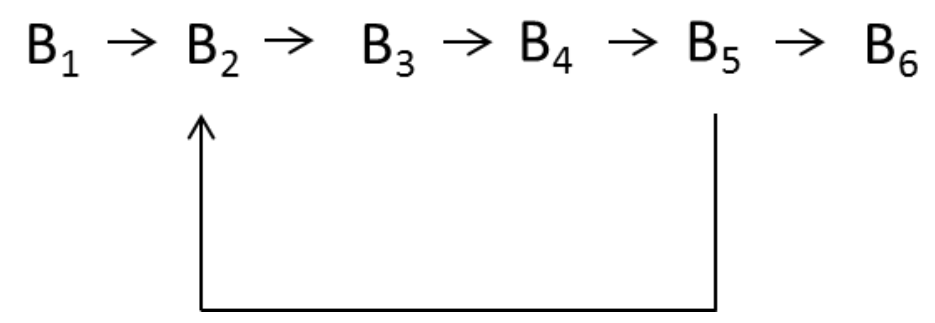

Figura 1 - Esquema ilustrando uma cadeia linear de influências (a) e um ciclo de retro-alimentação (b) entre variáveis internas de um sistema.

Em estudos de cinética eletroquímica o sistema pode ser facilmente afastado de seu estado de equilíbrio através do controle elétrico externo, cumprindo, assim, o requisito mais elementar necessário para apresentação de comportamentos auto-organizados, uma vez que estes são marcados pela visita dinâmica a diferentes estados do sistema, o que não seria permitido no equilíbrio, onde qualquer flutuação é atenuada. Quando se fixa o potencial ou a corrente em um sistema eletroquímico, uma resposta comum do transiente correspondente é a tendência para atingir um valor (quase) estacionário; no entanto, se a resposta é, ou se torna, oscilatória, isto implica que o estado estacionário perdeu estabilidade em favor de um ciclo limite ${ }^{1}$. Desta forma, condições necessárias para a observação de oscilações poderiam ser encontradas por meio da análise de estabilidade do estado estacionário, a qual é realizada a seguir. O primeiro passo consiste em encontrar uma expressão para a variação temporal do potencial da dupla camada, $\phi$, o que se consegue introduzindo a equação de continuidade da corrente elétrica através da interface eletrodo/solução:

\footnotetext{
${ }^{1}$ Ciclo limite é um regime de estabilidade de um sistema caracterizado por uma curva fechada no espaço de fases, isto é, no espaço em que os eixos correspondem às variáveis essenciais do sistema.
} 


$$
I_{T}=I_{F}+I_{C}
$$

onde a corrente total, $I_{T}$, é igual a soma das correntes faradaica, $I_{F}$, e capacitiva, $I_{C}$, lembrando que a corrente capacitiva é o produto da capacitância da dupla camada, $C$, pela derivada temporal de $\phi$, e que o potencial aplicado, $U$, distribui-se entre o potencial da dupla camada, $\phi$, e a queda ôhmica $\left(U=\phi+I_{T} R_{\Omega}\right)$ :

$$
\frac{U-\phi}{R_{\Omega}}=C \frac{d \phi}{d t}+I_{F}(\phi)
$$

onde $R_{\Omega}$ é a resistência total do sistema. O segundo passo é analisar a evolução de uma pequena perturbação, $\delta \phi$, realizada sobre o potencial da dupla camada em estado estacionário, $\phi_{\text {ee: }}$

$$
C \frac{d}{d t}\left(\phi_{e e}+\delta \phi\right)=\frac{U-\left(\phi_{e e}+\delta \phi\right)}{R_{\Omega}}-I_{F}\left(\phi_{e e}+\delta \phi\right)
$$

Expandindo a eq. (3) fica-se com

(4)

$$
C \frac{d \phi_{e e}}{d t}+C \frac{d \delta \phi}{d t}=\frac{U-\phi_{e e}}{R_{\Omega}}-\frac{\delta \phi}{R_{\Omega}}-I_{F}\left(\phi_{e e}+\delta \phi\right)
$$

Para prosseguir com a análise é preciso encontrar uma expressão para a corrente faradaica, que é função de $\phi_{\mathrm{ee}}$ e da pequena perturbação $\delta \phi$. Consegue-se isto expandindo $I_{F}$ em uma 
série de Taylor $^{2}$ e desprezando termos em que a perturbação está elevada a expoentes iguais ou superiores a dois:

$$
I_{F}\left(\phi_{e e}+\delta \phi\right)=I_{F}\left(\phi_{e e}\right)+\frac{d I_{F}\left(\phi_{e e}\right)}{d \phi} \delta \phi
$$

Substituindo a eq. (5) na eq. (4) e lembrando que no estado estacionário a corrente capacitiva é nula e, portanto, a corrente total se iguala à faradaica, se encontra a expressão que rege a evolução temporal da perturbação $\delta \phi:$

$$
C \frac{d \delta \phi}{d t}=-\left(\frac{1}{R_{\Omega}}+\frac{1}{Z}\right) \delta \phi
$$

onde $Z$ é a impedância faradaica, definida como o inverso de $\frac{d I_{F}(\phi)}{d \phi}$. Por causa do sinal negativo, quando o termo entre parêntesis do lado direito da eq. (6) for positivo $\delta \phi$ decrescerá com o tempo e o estado estacionário será restabelecido. Por outro lado, o estado estacionário se tornará instável, possibilitando a observação de oscilações, quando o termo entre parênteses for inferior a zero, levando à amplificação da perturbação, o que acontecerá quando a impedância faradaica for negativa e seu valor absoluto for menor do que o da resistência total do sistema:

(7)

$$
Z<0 \quad \text { e } \quad|Z|<R_{\Omega}
$$

\footnotetext{
${ }^{2}$ A série de Taylor

$$
f(x+h)=f(x)+\frac{d f(x)}{d x} h+\frac{d^{2} f(x)}{d x^{2}} \frac{h^{2}}{2}+\frac{d^{3} f(x)}{d x^{3}} \frac{h^{3}}{6}+O\left(h^{4}\right)
$$

é uma aproximação para uma função, $f$, num ponto desconhecido $x+h$, para $h$ sendo suficientemente pequeno, em termos de $f(x)$ e suas derivadas.
} 
Assim, de acordo com estas condições, a observação de oscilações é esperada em regiões da curva estacionária de $I_{F}$ versus $\phi$ (a qual pode ser obtida por meio de saltos potenciostáticos) em que a corrente faradaica é decrescente, ou seja, em regiões de resistência diferencial negativa, $\mathrm{RDN}^{3}$, as quais podem ocorrer em curvas com formato de $\mathrm{S}$ ou de $\mathrm{N}$, como aquelas esquematicamente mostradas na Fig. 2, em que $\phi$ desempenha, respectivamente, papel de variável essencial lenta e rápida (autocalítica) [17].

(a)

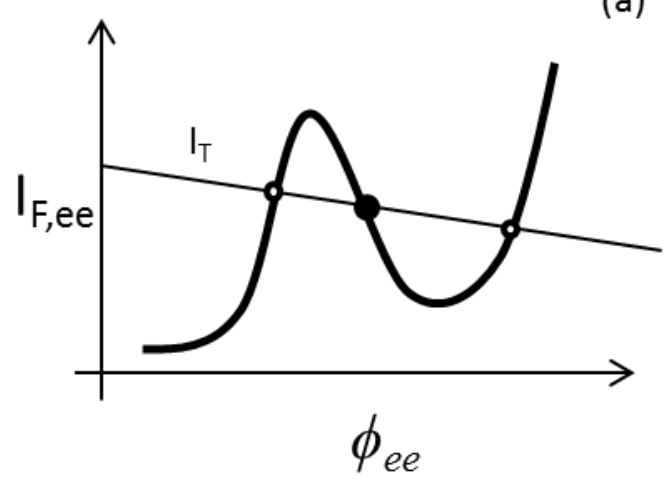

(b)

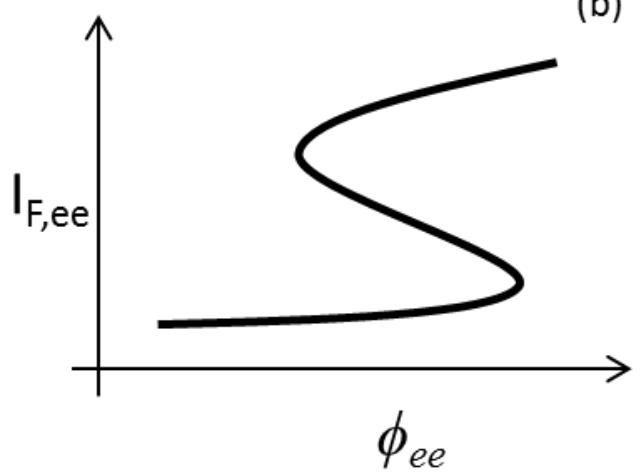

Figura 2 - llustração de curvas estacionárias de corrente faradaica vs. potencial da dupla camada que apresentam ramos instáveis em forma de $\mathrm{N}(\mathrm{a})$ e de $\mathrm{S}(\mathrm{b})$. Em (a) círculos abertos representam estados estacionários estáveis e o preenchido um estado estacionário instável; a linha reta representa a variação da corrente total, $I_{T}$, para um potencial aplicado, $U$, com resistência, $R_{\Omega}$, não nula.

Para casos de controle potenciostático, a corrente total, $\mathrm{I}_{\mathrm{T}}$, diminui linearmente com o aumento do potencial da dupla camada a uma taxa determinada por $\left(-1 / R_{\Omega}\right)$. A representação desta variação da corrente total sobre a curva estacionária, por exemplo, em forma de N, Fig. 2a, é útil para se determinar graficamente os pontos de estado estacionário do sistema, uma vez que nas intersecções tem-se $\mathrm{I}_{\mathrm{T}}=\mathrm{I}_{\mathrm{F}} \mathrm{e}$, portanto, $\mathrm{I}_{\mathrm{C}}=0$ e $\mathrm{d} \phi / \mathrm{dt}=0$. Os pontos de intersecção extremos são estados estacionários estáveis, uma vez que na vizinhança à direita deles $I_{F}$ é maior que $I_{T}$, o que, pela eq. (2), implica em $d \phi / d t<0$, ou seja, perturbações positivas suficientemente pequenas serão atenuadas de volta ao estado estacionário; por outro lado, na vizinhança à esquerda deles tem-se $\mathrm{I}_{\mathrm{T}}>\mathrm{I}_{\mathrm{F}}$, logo, $d \phi / d t>0,0$

\footnotetext{
${ }^{3}$ Esta região é amplamente conhecida na literatura em língua inglesa pelo acrônimo NDR, iniciais de "negative differential resistance".
} 
que fará perturbações negativas suficientemente pequenas crescerem até que o estado estacionário seja restabelecido. Uma análise similar leva à conclusão de que o ponto interceptado no centro da curva em $\mathrm{N}$, dentro da região RDN, é instável, e qualquer flutuação conduzirá o sistema para um dos outros dois estados estacionários estáveis. A mesma determinação gráfica da posição e estabilidade dos estados estacionários pode ser feita também para o caso galvanostático, o qual pode ser visto como uma extrapolação do caso potenciostático para $\mathrm{U}$ e $\mathrm{R}_{\Omega}$ tendendo ao infinito.

A primeira condição expressa em (7) implica na diminuição de $I_{F, e e}$ com o aumento de $\phi_{\text {ee. }}$ Assumindo que a corrente faradaica é função da área ativa do catalisador, $A$, da concentração da espécie eletroativa, c, e da constante eletroquímica de reação, k, todas estas funções de $\phi$, ter-se-ia:

$$
I_{F}(\phi)=n F A(\phi) c(\phi) k(\phi)
$$

onde $n$ é o número de elétrons envolvidos e $\mathrm{F}$ a constante de Faraday. Então, utilizando a definição da impedância faradaica, chega-se que, à parte de $R_{\Omega}$ ser suficientemente grande, o sistema possuirá um estado estacionário instável quando a soma entre parênteses na eq. (9) for negativa:

(9)

$$
\frac{I_{F}(\phi)}{d \phi}=n F\left(c(\phi) k(\phi) \frac{d A(\phi)}{d \phi}+k(\phi) A(\phi) \frac{d c(\phi)}{d \phi}+c(\phi) A(\phi) \frac{d k(\phi)}{d \phi}\right)<0
$$

Isto poderá acontecer quando, por exemplo, a produção de espécies bloqueadoras de sítios reativos crescer com o aumento de $\phi$, ou a concentração superficial da espécie eletroativa decair com incrementos em $\phi$, ou a constante eletroquímica variar negativamente para maiores valores de $\phi$. Exemplos para estes casos podem ser encontrados na referência [19]. 
Contudo, não basta, para a observação de oscilações, a instabilidade no estado estacionário do potencial da dupla camada, pois isto levaria apenas a uma variação exponencial de $\phi$ até o estado estacionário estável mais próximo. É preciso também que um ciclo de retroalimentação negativa esteja presente, ou seja, se requer uma variável que aja negativamente, e com certo atraso, sobre o crescimento de $\phi$, controlando-o. Sob regime galvanostático, abordado neste estudo, o mecanismo oscilatório aproximado durante a eletro-oxidação de pequenas moléculas orgânicas pode ser entendido com a ajuda do diagrama da Fig. 3.

\section{retro-alimentação positiva}

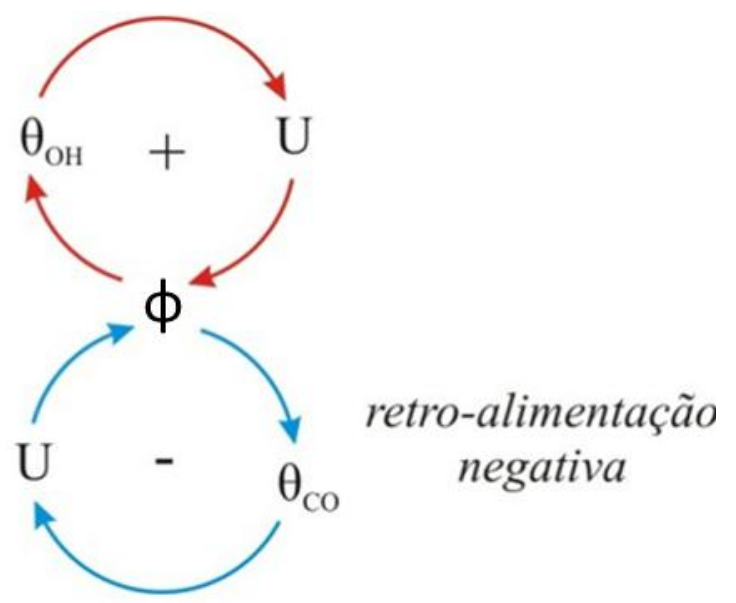

Figura 3 - llustração do mecanismo oscilatório simplificado em modo galvanostático através do acoplamento entre ciclos de retro-alimentação positiva e negativa. $\phi$ denota o potencial da dupla camada, $U$ o potencial externamente medido e $\theta_{\mathrm{OH}}$ e $\theta_{\mathrm{CO}}$ os graus de recobrimento de espécies oxigenadas e de monóxido de carbono, respectivamente. Figura adaptada da referência [22].

Supondo que o potencial da dupla camada sofra uma perturbação positiva, isto acarretará num aumento da quantidade de espécies oxigenadas adsorvidas, $\mathrm{OH}_{\mathrm{ads}}$, e diminuição dos sítios livres para reações de transferência de carga, o que, sob controle galvanostático implicará em maior aumento do potencial externo $U$ e, em consequência, de $\phi$ (ciclo de retro-alimentação positivo). Contudo, o aumento em $\phi$ também é acompanhado pela desidrogenação das moléculas orgânicas para monóxido de carbono adsorvido, $\mathrm{CO}_{\mathrm{ads}}$, com um certo atraso porque a formação destas espécies é mais lenta do que a das espécies $\mathrm{OH}$. As duas espécies adsorvidas, então, podem reagir promovendo uma limpeza superficial: 
$\mathrm{Pt}-\mathrm{OH}_{\mathrm{x}}+\mathrm{Pt}-\mathrm{CO} \rightarrow 2 \mathrm{Pt}+\mathrm{CO}_{2}+\mathrm{xH}^{+}+\mathrm{xe}^{-}$

Com isto, o número de sítios superficiais livres, Pt, aumenta e o potencial necessário para manter a corrente imposta diminui. Assim, através deste controle do crescimento do potencial da dupla camada oscilações podem se desenvolver, podendo ser interpretadas como um processo de autolimpeza da superfície, que é envenenada por espécies carbonáceas e oxigenadas e liberada delas pela reação (10).

Uma característica interessante da eletro-oxidação de metanol, ácido fórmico e etanol, entre outras moléculas orgânicas pequenas, é que possuem regiões de instabilidade tanto de potencial como de corrente acessíveis experimentalmente, conforme seja o controle elétrico (e adição de resistência externa em série com o eletrodo de trabalho em alguns casos), ou em outras palavras, podem apresentar oscilações de potencial e de corrente [16]. Estes sistemas exibem oscilações de potencial numa região da curva de polarização $\mathrm{I}_{\mathrm{F}, \mathrm{ee}}$ vs. $\phi_{\text {ee }}$ com coeficiente angular positivo, mas as instabilidades ainda estão ligadas a uma RDN, nada mais que ela está escondida a baixos potenciais pela relativamente lenta formação de $\mathrm{CO}_{\text {ads }}$. Para perturbações rápidas, obtidas, por exemplo, em frequências suficientemente altas durante medidas de impedância, é possível detectar a RDN, pois quando o potencial varia rapidamente a variável $\mathrm{OH}_{\text {ads }}$ responde antes do que $\mathrm{CO}_{\text {ads }}$ e se observa uma diminuição na corrente entre um determinado valor de potencial $U_{1}$ e outro maior $U_{2}$, causando a RDN [18]. Assim, estes osciladores são classificados como do tipo que apresenta curva estacionária em forma de $\mathrm{N}$ com região de resistência diferencial negativa parcialmente escondida, RDN-NE [19]. 


\subsubsection{Introdução de alguns conceitos e problemática de oscilações não compensadas}

Sistemas dinâmicos podem apresentar diferentes padrões oscilatórios, isto é, oscilações com diferentes períodos morfológicos ${ }^{4}$, a observação dos quais depende dos valores dos parâmetros fixados. Assim, pode-se construir um espaço de parâmetros e identificar regiões que correspondem a padrões morfológicos específicos. Cada um destes domínios é conhecido como bacia de atração e, quando há uma variação de parâmetros que transfere o estado do sistema de uma bacia para outra, há uma mudança qualitativa no comportamento do sistema e diz-se que o mesmo sofreu uma bifurcação. Estes conceitos podem ser visualizados na Fig. 4, extraída da referência [23], onde é apresentado um diagrama de bifurcação no espaço de parâmetros adimensionais de resistência ( $\rho$ ) versus potencial aplicado (U), Fig. 4a, construído via simulação de um modelo genérico para um oscilador eletroquímico, em que as cores correspondem a diferentes períodos morfológicos, ou seja, diferentes regimes de estabilidade. Fixando o parâmetro $\rho$ em 106,63 (linha azul horizontal na Fig. 4a) e variando-se o valor de $U$, obtém-se diferentes respostas na corrente faradaica, $I_{F}$, como pode ser visualizado na Fig. $4 \mathrm{~b}$ em que os máximos de $I_{F}$ são representados em função de $U$ aplicado. A região de cor branca na Fig. 4a corresponde ao domínio caótico.

\footnotetext{
${ }^{4}$ O período morfológico de uma região oscilatória é caraterizado pelo número total de mínimos, locais e ínfimo, presentes em cada ciclo; assim, para $n$ mínimos diz-se que o padrão morfológico é de período-n. Quando mais de um mínimo está presente em um ciclo, diz-se que a oscilação é mista. Quando o comportamento é caótico existem infinitos mínimos.
} 
(a) 100

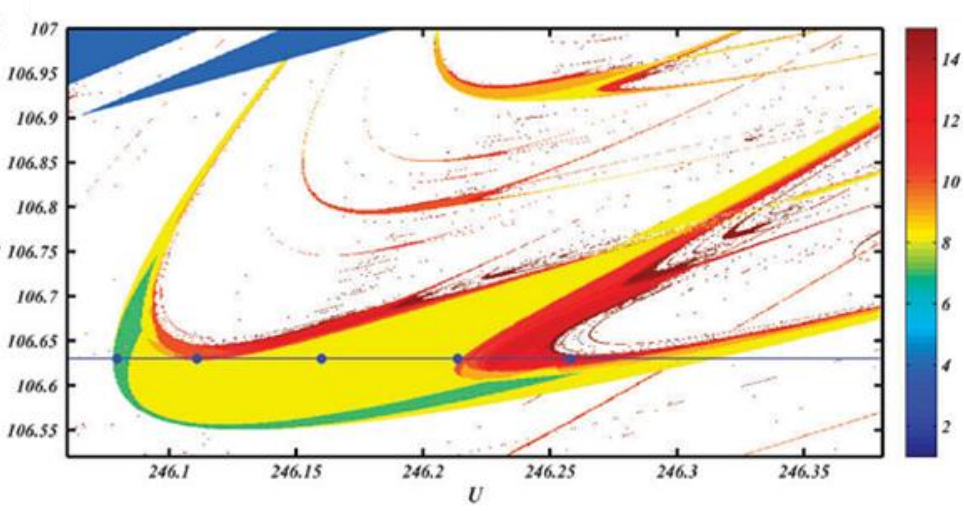

(b)

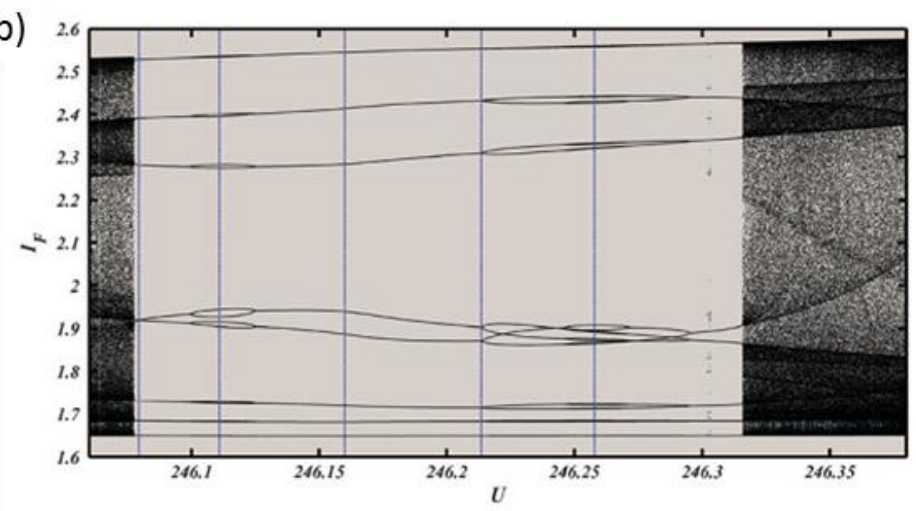

Figura 4 - Diagrama de bifurcação (a) no plano de parâmetros adimensionais resistência, $\rho$, versus potencial aplicado, $U$, e (b) no plano de máximos da corrente faradaica, $I_{F}$, versus $U$, para $\rho=106,63$. Os dados correspondem a simulações em um modelo genérico para um oscilador eletroquímico. Figura adaptada da referência [23].

Em geral, experimentalmente, é possível encontrar a faixa de parâmetros, como intervalo de concentração do orgânico e potencial e/ou corrente aplicados, em que as oscilações podem ser observadas, mas não se consegue achar condições em que elas sejam estáveis indefinidamente, ainda que todos os parâmetros experimentais controláveis sejam mantidos constantes. A Fig. 5, extraída da referência [24], traz um exemplo típico de oscilações de potencial obtidas durante a eletro-oxidação galvanostática de moléculas orgânicas pequenas sobre $\mathrm{Pt}$, neste caso para $0,1 \mathrm{M}$ de formaldeído dissolvido em $0,5 \mathrm{M}$ de $\mathrm{H}_{2} \mathrm{SO}_{4}$. É possível observar que, após um certo período de indução, as oscilações nascem com período simples (período-1) mas, cerca de 23 minutos depois, sofrem uma bifurcação espontânea para ondas que apresentam um pequeno mínimo antes de passar pelo mínimo ínfimo (período-2), então, após mais 60 minutos o sistema volta a passar por um ponto de bifurcação e a apresentar oscilações de período-1. A interpretação deste comportamento é 
de que, inclusive quando as restrições experimentais são bem controladas ainda existe uma variação de algum parâmetro intrínseco, cuja velocidade irá ditar o tempo que o sistema passará exibindo um determinado padrão morfológico.

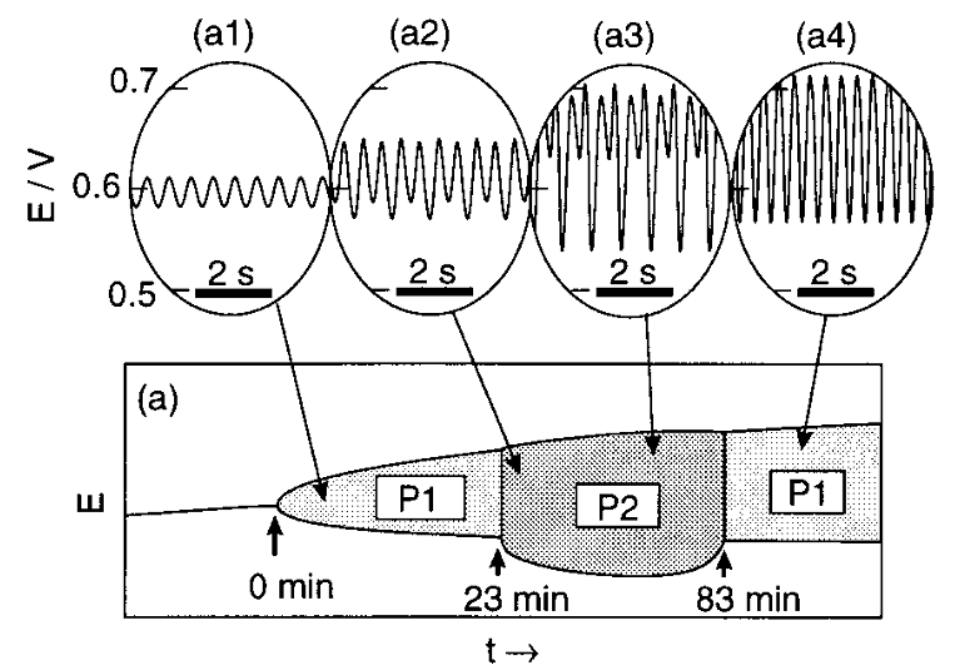

Figura 5 - Oscilações de potencial observadas durante aplicação de $0,77 \mathrm{~mA} \mathrm{~cm}^{-2}$ a sistema contendo $\mathrm{HCHO} 0,1 \mathrm{M}+\mathrm{H}_{2} \mathrm{SO}_{4}$ 0,5 $\mathrm{M}$ em contato com eletrodo de platina. Regiões destacadas em (a2) e (a3) correspondem a padrões com período-1 e em (a1) e (a4) para período-2. Figura adaptada da referência [24].

Ademais, pode-se observar nas regiões a2 e a3 da Fig. 5 que, mesmo numa região de período morfológico equivalente, a forma das ondas de cada ciclo vão mudando com o tempo, a este fenômeno tem sido referido como não compensação das oscilações [25]. Este tema será abordado nas Seções 3.1 e, mais profundamente, 3.3 desta tese.

\subsection{Espectroscopia de absorção no infravermelho intensificada pela superfície (EAIVIS)}

Os átomos de uma molécula não guardam posição estritamente fixa uns em relação aos outros, em vez disso, estão em permanente movimento de aproximação e afastamento. Ademais, as frequências que estes movimentos podem assumir são quantizadas e estão 
associadas a energias que dependem da força da ligação e das massas dos átomos envolvidos [26]. Quando a molécula interage com radiação de energia equivalente, neste caso abaixo do vermelho visível, com números de onda, aproximadamente, entre 100 e 5000 $\mathrm{cm}^{-1}$, os modos vibracionais podem entrar em ressonância com a radiação, absorver energia dela e passar a vibrar com amplitude maior [27]. Contudo, nem todas as transições podem ser ativadas pela radiação infravermelha (IV). Para determinar as que são possíveis existem regras de seleção, que definem as condições necessárias para uma transição acontecer, como aquela que diz que o momento dipolar da molécula deve variar durante o movimento vibracional [26], excluindo, assim, por exemplo, espécies diatômicas homonucleares de serem detectadas em espectros IV.

Desta forma, a radiação infravermelha pode ser usada como ferramenta de acesso a estruturas moleculares de amostras desconhecidas. A partir da década de 1980, a técnica de espectroscopia de infravermelho passou a ser usada in situ em experimentos eletroquímicos [28-31], visando identificar os intermediários e produtos da eletro-oxidação de moléculas orgânicas pequenas sobre platina. Uma representação esquemática da configuração, conhecida como de reflexão externa, do sistema espectroeletroquímico utilizada nestes primeiros experimentos é dada na Fig. 6a, extraída da referência [32]. Com o eletrodo de trabalho (ET) consistindo de um disco de metal maciço, o feixe de radiação infravermelha é direcionado através de espelhos para passar pela janela prismática, feita de um material transparente à radiação $\mathrm{IV}$, como $\mathrm{CaF}_{2}$, refletir no $\mathrm{ET}$ e ser direcionado para o detector. Nesta configuração o feixe atravessa duas vezes a solução aquosa, o que pode atenuar grandemente o sinal IV devido à absorção por parte das moléculas de água. Para minimizar este problema, o ET é pressionado contra o prisma até tocá-lo, visando reduzir à ordem de micrômetros a camada de água no caminho do feixe IV [33, 34]. Mas esta solução acaba por criar outros problemas, como acesso dificultado de reagentes à superfície reacional e aumento da queda ôhmica, uma vez que o transporte dos íons do eletrólito de suporte também fica dificultado. Como será discutido na Subseção 3.1.1 estes problemas descartam o uso da técnica de reflexão externa para o estudo de oscilações. 
(a)

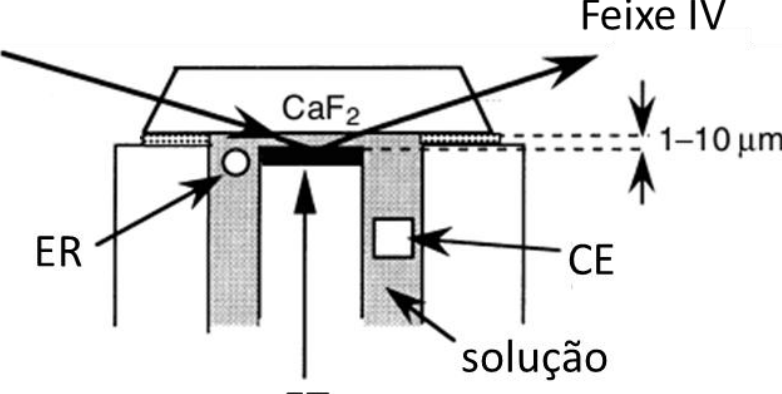

ET

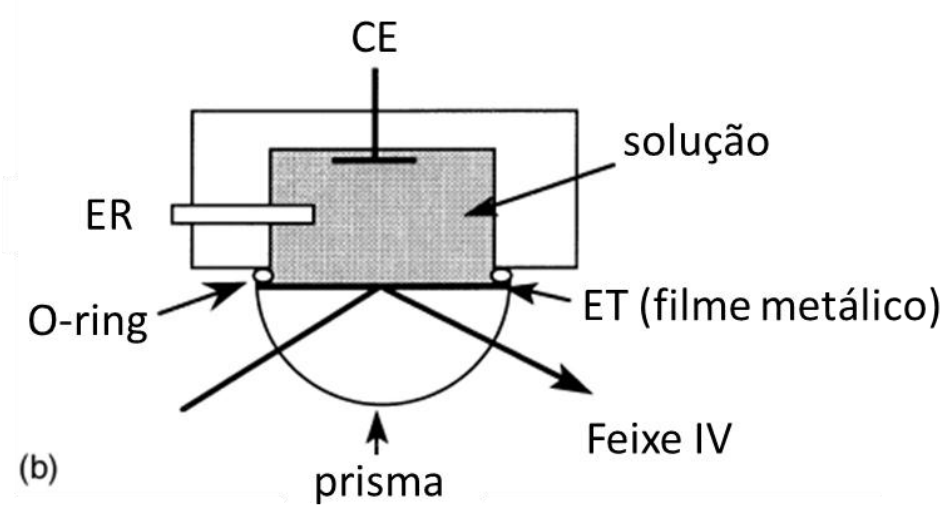

Figura 6 - Representações esquemáticas de células espectroeletroquímicas em configuração de reflexão (a) externa e (b) interna. ET: eletrodo de trabalho, EC: contra-eletrodo e ER: eletrodo de referência. Figura adaptada da referência [32].

Uma configuração alternativa que não apresenta estas limitações é a de reflexão interna ou de reflexão total atenuada, RTA, (em inglês ATR, Attenuated Total Reflection), ver Fig. 6 b. Nela o eletrodo de trabalho consiste de um filme de metal depositado sobre um prisma transparente à radiação infravermelha com alto índice de refração, como Ge ou Si [35], onde o feixe IV sofre reflexão total ao tocar pelas costas o eletrodo de trabalho. Nos pontos em que o feixe IV toca o eletrodo uma onda evanescente, com intensidade exponencialmente decrescente, se propaga na direção perpendicular à superfície e interage com os adsorbatos [35], não sendo necessário, portanto, que o feixe IV atravesse a solução, o que já é uma grande vantagem mas ainda uma outra é observada nesta configuração. $A$ absorção de radiação por moléculas adsorvidas sobre filmes de metais consistindo de ilhas metálicas nanométricas é muito mais forte do que a observada sobre superfícies planas de metais maciços [36], este efeito tem sido referido na literatura como absorção no infravermelho intensificada pela superfície, AIVIS, (em inglês SEIRA, Surface Enhanced 
Infrared Absorption) [32, 35-37]. Assim, o modo RTA-AIVIS de monitoramento in situ de interfaces eletroquímicas permite estudar a dinâmica de eletrodos com alta resolução temporal, pois graças à maior sensibilidade mais interferogramas podem ser coletados por unidade de tempo para uma mesma relação sinal/ruído quando comparada com a configuração de reflexão externa. Desvantagens da configuração de reflexão interna incluem baixa capacidade de detectar espécies em solução e a dificuldade em preparar filmes metálicos estáveis sobre os prismas, o que foi a principal causa da adoção tardia da configuração de reflexão interna para a investigação da interface eletrodo/solução.

\subsection{Espectrometria de massas eletroquímica diferencial (EMED)}

Outra técnica auxiliar empregada em conjunto com experimentos eletroquímicos é a de espectroscopia de massas, a qual consiste em fracionar moléculas em fragmentos carregados caracterizados por uma razão massa/carga $(\mathrm{m} / \mathrm{c})$ que é então detectada. A ionização se dá por bombardeamento da amostra num sistema de baixa pressão para que os fragmentos realmente correspondam apenas à(s) molécula(s) que se queira investigar, o que envolve a volatilização das amostras quando estas não são gasosas ou suficientemente voláteis [38]. A aplicação em conjunto com sistemas eletroquímicos torna-se possível através da utilização de uma membrana hidrofóbica, por exemplo, de teflon, mediando a célula e o sistema de vácuo, para impedir a passagem de solução mas permitir o acesso de moléculas gasosas e voláteis ao espectrômetro [39-41]. Seguindo este raciocínio, Bruckenstein e Gadde [42] foram os primeiros a acoplar um espectrômetro de massas a um experimento eletroquímico visando seguir a produção de oxigênio a partir de uma solução de $\mathrm{HClO}_{4}$ 0,1 M. Contudo, o aparato original destes autores era caracterizado por um atraso da ordem de 10 s entre a produção da espécie gasosa no sistema eletroquímico e sua deteç̧ão no espectrômetro. 
Uma significativa redução deste tempo de atraso, para a ordem de milissegundos, foi conseguida por Wolter e Heitbaum $[43,44]$ ao introduzirem um sistema de baixa pressão com duas câmaras, uma de médio vácuo $\left(10^{-3} \mathrm{mbar}\right)$ em contato com a célula eletroquímica e uma segunda com alto vácuo $\left(10^{-5} \mathrm{mbar}\right)$ em que a análise dos fragmentos é realizada. Como o tempo entre a produção e detecção de uma espécie é quase instantânea este aparato foi chamado de Espectrometria de Massas Eletroquímica Diferencial (EMED), no sentido de que não apenas a quantidade total da espécie produzida num intervalo de tempo é detectada como também sua velocidade de produção. Um diagrama esquemático do acoplamento entre as técnicas eletroquímica e de espectrometria de massas on line, extraído da referência [39], é apresentado na Fig. 7.

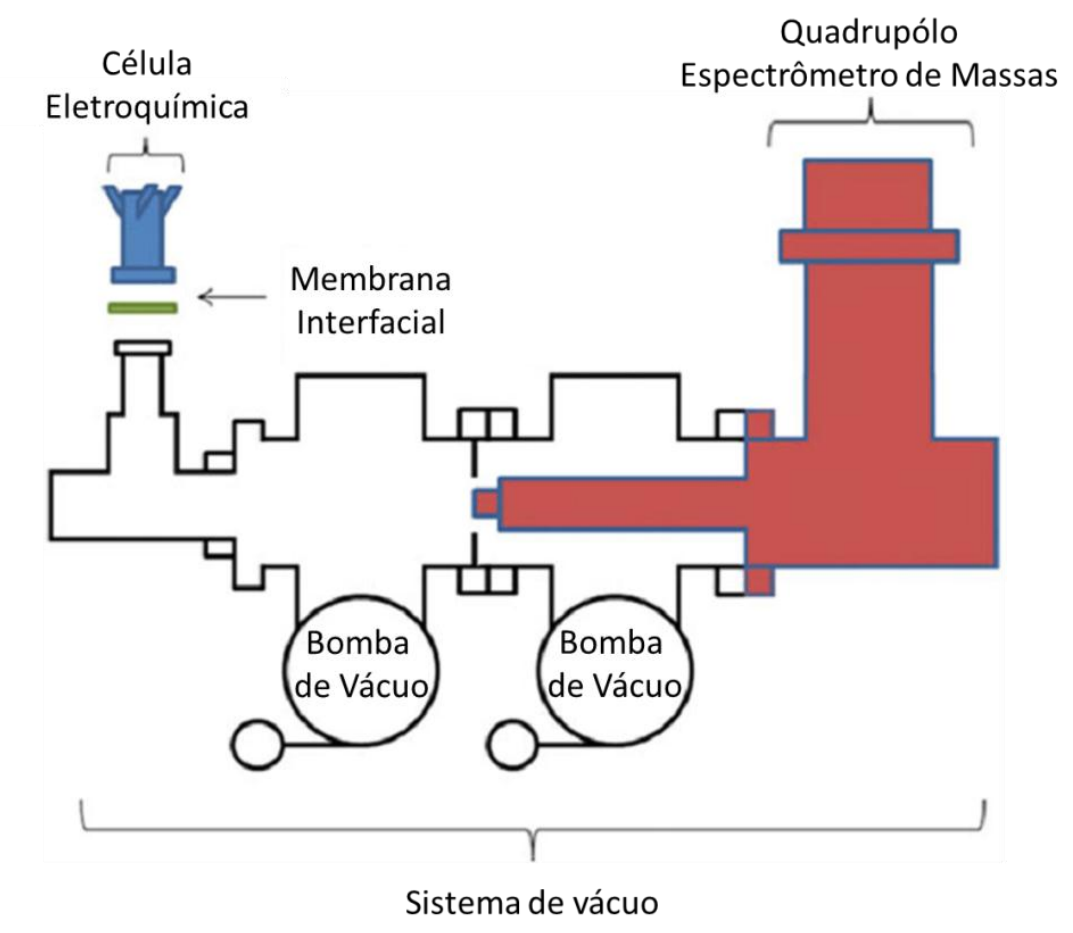

Figura 7 - Uma ilustração típica dos componentes de um instrumento de EMED. Figura adaptada da referência [39]. 


\subsection{Objetivos}

No âmbito geral, este trabalho tem como objetivo estudar a dinâmica de intermediários e produtos de reação que se desenvolvem simultaneamente às oscilações de potencial observáveis durante a eletro-oxidação galvanostática de metanol e de etanol sobre eletrodos de platina. Mais especificamente para o caso de metanol pretende-se:

(i) Acompanhar com o auxílio da técnica espectroscópica EAIVIS in situ a dinâmica de adsorbatos, como formato adsorvido em ponte e monóxido de carbono linearmente adsorvido, presentes durante a eletro-oxidação oscilatória de metanol em meio ácido sobre platina em regime galvanostático e inferir sobre o mecanismo oscilatório a nível molecular;

(ii) Perturbar a cinética oscilatória desenvolvida durante a eletro-oxidação de metanol sobre platina via adição de peróxido de hidrogênio, um fornecedor de espécies oxigenadas, visando investigar o papel destas na desestabilização das oscilações.

E para o caso de etanol:

(i) Acompanhar com o auxílio das técnicas EAIVIS in situ e EMED on line a dinâmica de espécies químicas envolvidas na eletro-oxidação oscilatória de etanol sobre platina, como acetato adsorvido, monóxido de carbono adsorvido, acetaldeído e dióxido de carbono, em modo galvanostático e inferir sobre o mecanismo oscilatório a nível molecular. 


\section{Procedimento experimental e materiais utilizados}

\subsection{Estimativa do recobrimento de $\mathrm{CO}_{\mathrm{L}}$}

A considerar que a quantidade máxima de espécies $\mathrm{CO}$ adsorvidas sobre eletrodos de platina é alcançada quando estes são polarizados em potenciais tão baixos quanto $50 \mathrm{mV}$ e

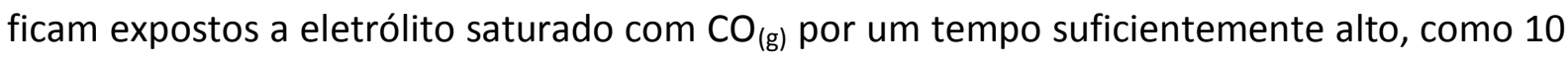
minutos, um espectro obtido nestas condições conteria bandas referentes a $\mathrm{CO}$ adsorvido de forma linear, $\mathrm{CO}_{\mathrm{L}}$, e em ponte, $\mathrm{CO}_{\mathrm{B}}$, com a máxima intensidade observável para aquela superfície. Visto que as espécies $\mathrm{CO}_{\mathrm{B}}$ ocupam dois sítios superficiais, a intensidade integrada máxima referente às espécies $\mathrm{CO}, I_{C O \text {,máx }}$ poderia ser assumida como a soma da área integrada da banda de $\mathrm{CO}_{\mathrm{L}}$ mais duas vezes a área integrada da banda de $\mathrm{CO}_{\mathrm{B}}$ :

$$
I_{C O, m a ́ x}=I_{C O_{L}}^{s a t}+2 I_{C O_{B}}^{s a t}
$$

onde o índice superior "sat" refere-se à condição de superfície saturada com $\mathrm{CO}_{\mathrm{ads}}$. Desta forma, a intensidade integrada da banda de $\mathrm{CO}_{\mathrm{L}}$ a qualquer tempo e condição, $I_{C O_{L}}$, poderia ser transformada em grau de recobrimento de $\mathrm{CO}_{\mathrm{L}}$ superficial relativo à intensidade máxima de $\mathrm{CO}_{\text {ads }}$ :

$$
\theta_{C O_{L}, \text { rel. }}=\frac{I_{C O_{L}}}{I_{C O, m a ́ x}}
$$

Contudo, este procedimento fornece apenas uma estimativa aproximada do verdadeiro grau de recobrimento visto que a intensidade da banda de uma espécie pode não variar de forma linear com sua quantidade na superfície; além disso, os diferentes coeficientes de absorção 
para os diferentes números de coordenação [45] bem como a transferência de intensidade entre um e outro [46] são ignorados. Mas, de forma geral, a aproximação tende a ganhar validade para valores intermediários de grau de recobrimento [47].

\subsection{Experimentos eletroquímicos combinados com espectroscopia de infravermelho in situ} (Subseção 3.1.1)

Uma célula espectroeletroquímica de compartimento único anexada a uma janela prismática de silício com forma trapezoidal foi utilizada para obter os resultados da Subseção 3.1.1. Foram empregados como contra-eletrodo e eletrodo de referência, respectivamente, uma folha de platina de alta área superficial e um eletrodo reversível de hidrogênio preparado na mesma solução do eletrólito de suporte. O eletrodo de trabalho consistiu de um filme de Pt depositado sobre o prisma utilizado de Si, não-dopado, com área geométrica exposta para a solução de, aproximadamente, $7,3 \mathrm{~cm}^{2}$. Uma visão lateral esquemática da célula espectroeletroquímica é apresentada na Fig. 8; observe-se que para o prisma utilizado, em configuração de reflexão total atenuada, o feixe de radiação infravermelho (IV) sofre múltiplas reflexões totais em seu interior.

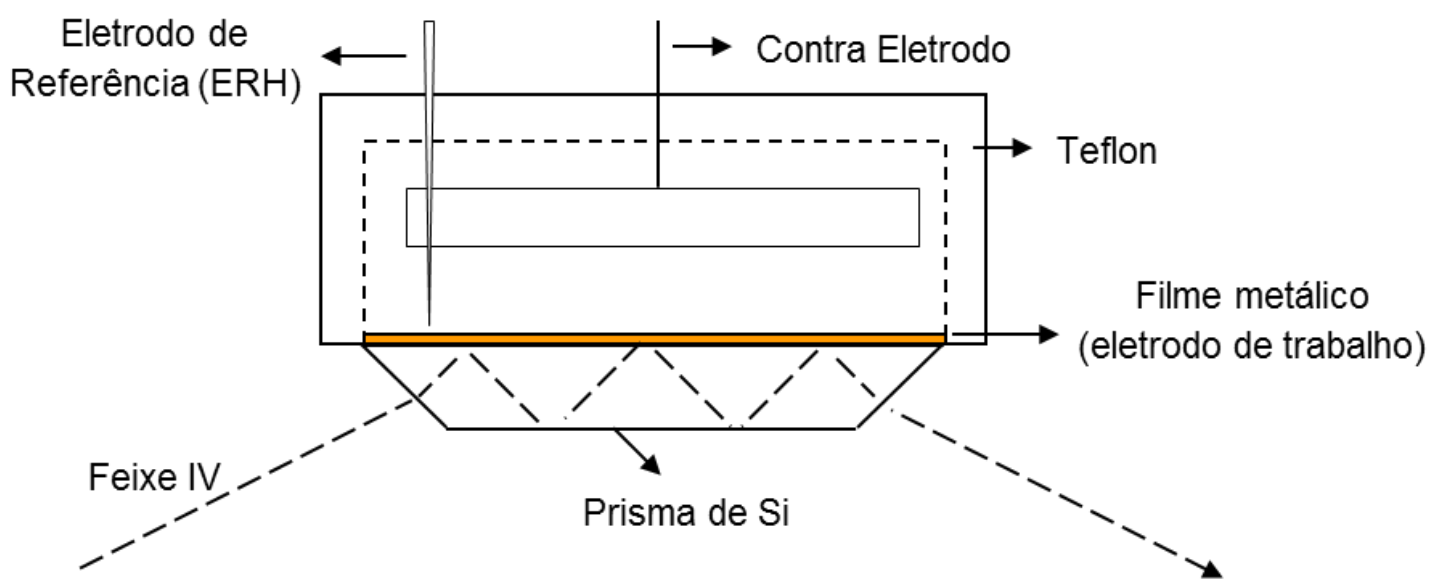

Figura 8 - Esquema de célula espectro-eletroquímica utilizada para monitoramento in situ da interface eletrodo/solução pela técnica de espectroscopia de infravermelho EAIVIS em configuração RTA. 
A preparação do filme metálico seguiu o procedimento descrito por Miyake e Osawa [48] e envolveu três etapas: limpeza e preparação da superfície do prisma de Si, deposição química de um filme de $A u$ e, então, deposição eletroquímica do filme de platina de interesse. Assim, primeiramente, o plano refletor do prisma sobre o qual o metal é depositado foi polido em pastas de diamante com granulações gradativamente menores desde 9 até 0,25 $\mu \mathrm{m}$; então, seguiu-se limpeza por sonificação durante 20 minutos, alternadamente, em acetona e em água, e, finalmente, aquecimento a $60^{\circ} \mathrm{C}$ em solução piranha $\left(\mathrm{H}_{2} \mathrm{SO}_{4}: \mathrm{H}_{2} \mathrm{O}_{2}, 3: 1\right)$. Na sequência, o prisma foi anexado ao corpo da célula feito de Teflon, ver Fig. 8, e uma solução aquosa de $\mathrm{NH}_{4} \mathrm{~F} 40 \%$ foi posta em contato com o prisma a fim de remover a camada de óxido da superfície do silício e terminá-la com hidrogênio. Após todas as etapas de limpeza e preparação do prisma, um filme de Au foi depositado quimicamente sobre ele a partir de um banho composto por $\mathrm{NaAuCl}_{4} \cdot 2 \mathrm{H}_{2} \mathrm{O} 0,015 \mathrm{M}+$ $\mathrm{Na}_{2} \mathrm{SO}_{3} 0,15 \mathrm{M}+\mathrm{Na}_{2} \mathrm{~S}_{2} \mathrm{O}_{3} \cdot 5 \mathrm{H}_{2} \mathrm{O} 0,05 \mathrm{M}+\mathrm{NH}_{4} \mathrm{Cl}$ 0,05 $\mathrm{M}$ mais uma solução aquosa de $\mathrm{HF} 2 \%$, aquecidos a $60^{\circ} \mathrm{C}$, na proporção $2: 1$. A deposição do Au dá-se em paralelo à dissolução do silício:

$$
\begin{aligned}
& \mathrm{Si}^{0}(\mathrm{~s})+6 \mathrm{~F}^{-}(\mathrm{aq}) \rightarrow \mathrm{SiF}_{6}{ }^{2-}(\mathrm{aq})+4 \mathrm{e}^{-} \\
& \mathrm{AuCl}_{4}^{-}(\mathrm{aq})+3 \mathrm{e}^{-} \rightarrow \mathrm{Au}^{0}(\mathrm{~s})+4 \mathrm{Cl}^{-}(\mathrm{aq})
\end{aligned}
$$

Finalmente, o filme de platina de interesse foi depositado eletroquimicamente sobre o ouro a partir de uma solução de $\mathrm{H}_{2} \mathrm{PtCl}_{6} 0,006 \mathrm{M}$, em regime potenciostático a $250 \mathrm{mV}$ por cerca de 3 minutos.

Os reagentes empregados na prepação dos filme de Au e Pt e nas medidas de eletrooxidação de metanol incluíram: água de alta pureza $(18,2 \mathrm{M} \Omega \mathrm{cm}$, sistema Milli-Q, Millipore), ácido fluorídrico (Riedel-de Haen, 40 \%), fluoreto de amônio (Sigma-Aldrich, 99,99 \%), cloreto de amônio (Sigma-Aldrich 99,998 \%), sulfito de sódio (Sigma-Aldrich, 98 \%), tiossulfato de sódio penta-hidratado (Sigma-Aldrich, 99,999 \%), ácido cloro-platínico hexahidratado (Sigma-Aldrich, 37,5 \%), cloroaudrato de sódio di-hidratado (Alfa Aesar, 49-50 \%), ácido sulfúrico (Mallinckrodt, 99,8\%) e metanol (J.T. Baker, 99,9\%) e foram utilizados como 
recebidos. Gás argônio de alta pureza (White Martins, 99,99\%) foi usado para desaerar as soluções.

Todas as vidrarias utilizadas foram limpas deixando-as imersas por uma noite em solução de permanganato de potássio levemente básica; então, lavadas em água de alta pureza, deixadas imersas em solução levemente acidificada de peróxido de hidrogênio por cerca de 15 minutos, para novamente serem lavadas e fervidas três vezes em água de alta pureza.

Os experimentos eletroquímicos foram realizados com um potenciostato Solartron 1286 e as medidas de infravermelho in situ foram registradas com um espectrômetro Nicolet Nexus 670, equipado com um acessório de reflexão desenvolvido na oficina mecânica do IQSC para realização das medidas em configuração RTA e com um detector HgCdTe. Os dados espectrais foram adquiridos na forma de interferogramas com resolução de $8 \mathrm{~cm}^{-1} \mathrm{e}$ resolução temporal de 0,5 s. Para estimar a intensidade integrada relacionada ao recobrimento máximo de monóxido de carbono, $I_{C O, m a ́ x}$ o seguinte procedimento foi adotado. Primeiramente, uma monocamada de CO foi formada sobre a superfície do filme polarizada em 0,05 V ao se borbulhar $\mathrm{CO}_{(\mathrm{g})}$ através da solução durante 20 minutos, então, após o excesso de $\mathrm{CO}_{(\mathrm{g})}$ ser purgado da solução via fluxo de $\operatorname{Ar}$ por 40 minutos, um espectro foi coletado, a partir do qual $I_{C o, m a ́ x}$ foi estimada adotando-se a eq(11). 0 espectro de referência foi registrado com o eletrodo polarizado em $1,4 \mathrm{~V}$, ou seja, numa condição em que a superfície está livre de $\mathrm{CO}_{\mathrm{ads}}$.

\subsection{Experimentos puramente eletroquímicos (Subseção 3.1.3)}

As medidas cujos resultados são apresentados na Subseção 3.1.3 foram realizadas com um potenciostato Autolab ${ }^{\circledR}$ PGSTAT302 em uma célula de vidro com compartimento único utilizando um eletrodo reversível de hidrogênio como referência, uma folha de platina como eletrodo de trabalho (área $=0,47 \mathrm{~cm}^{2}$ ) e outra folha de platina cerca de cinco vezes maior (área $=2,23 \mathrm{~cm}^{2}$ ) como contra-eletrodo. Para o preparo das soluções utilizou-se além 
dos reagentes já citados na Sec. 2.2, peróxido de hidrogênio (Synth, 30\%). Previamente a cada medida estacionária foram executados três ciclos de potencial a $100 \mathrm{mV} / \mathrm{s}$ entre a região de adsorção de hidrogênio e a de formação de óxido visando reproduzir sempre as mesmas condições iniciais.

\subsection{Experimentos espectroeletroquímicos em célula de fluxo com dois compartimentos (Subseção 3.1 .2 e Seção 3.2) ${ }^{5}$}

Os resultados apresentados na Subseção 3.1 .2 e na Seção 3.2 foram obtidos utilizando-se uma célula de fluxo de solução, como a esquematicamente representada na Fig. 9, extraída da referência [49]. Nela é possível trocar o fluxo de uma solução para outra graças à existência de duas entradas, Ent-1 e Ent-2. O fornecimento de solução à célula deuse por gravidade, a partir de reservatórios (garrafas) posicionados no alto do sistema experimental. Ao adentrar a célula a solução em fluxo é direcionada por capilar para, primeiramente, entrar em contato com o eletrodo de trabalho (um filme de platina depositado sobre um prisma de silício hemicilíndrico) onde espécies adsorvidas podem ser detectadas pela técnica de EAIVIS in situ; então, os intermediários solúveis e produtos de reação formados são transportados para um segundo compartimento onde as espécies voláteis e gasosas podem permear uma membrana porosa de Teflon (Scimat, com poros de 0,2 $\mu \mathrm{m}$ de diâmetro), e passar para o interior do espectrômetro de massas, sendo, portanto, detectadas pela técnica de EMED on line. Desta forma, a célula de fluxo com dois compartimentos possui a vantagem de permitir a combinação, simultânea, das técnicas de EAIVIS in situ e EMED on line a um experimento eletroquímico. Na Seção 3.2 são apresentados resultados para eletro-oxidação oscilatória de etanol em combinação com ambas técnicas auxiliares enquanto que na Subseção 3.1.2 apenas a técnica EAIVIS in situ foi acoplada para estudo da eletro-oxidação oscilatória de metanol.

\footnotetext{
${ }^{5}$ Estes experimentos foram realizados no laboratório do Professor R. J. Behm, durante estágio na Universidade de Ulm, em Ulm - Alemanha, entre fevereiro e junho de 2012.
} 


\section{Vista lateral}

Ent-1

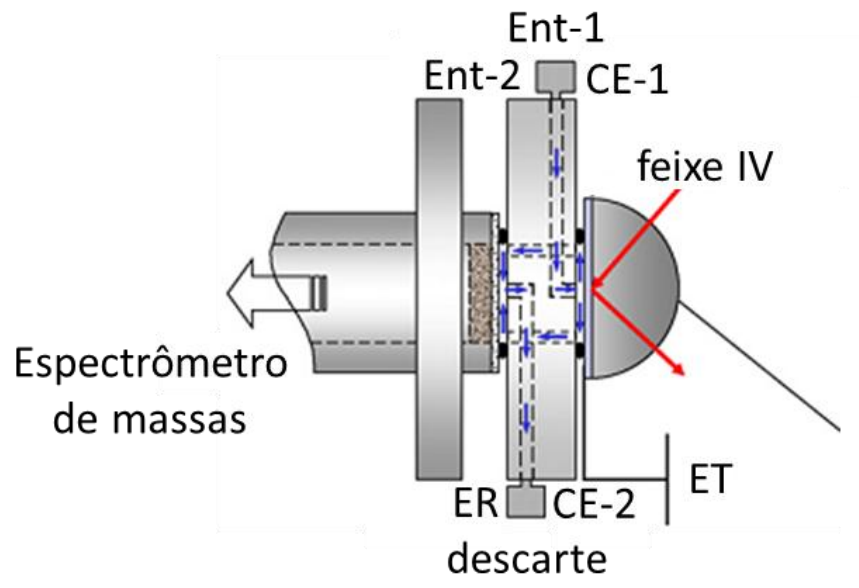

Vista superior

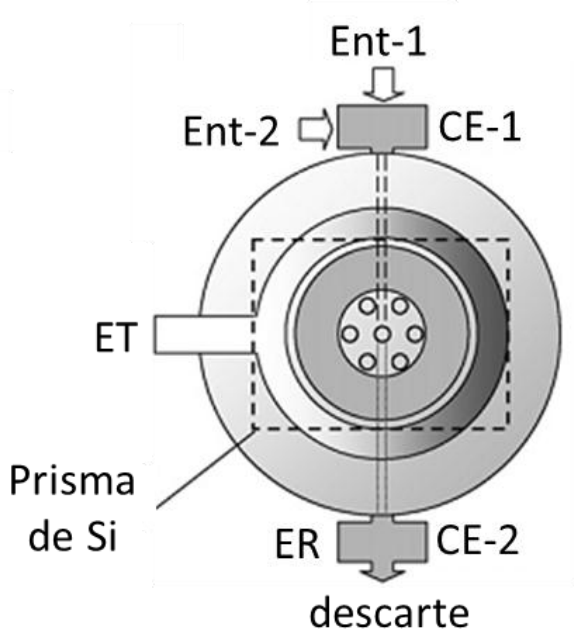

Figura 9 - Diagrama esquemático da célula de fluxo utilizada para medidas simultâneas de EMED on line e EAIVIS-RTA in situ. Ent-1 e Ent-2 denotam duas entradas de solução possíveis. CE denota contra-eletrodo e ER eletrodo de referência. Flechas azuis indicam o sentido do fluxo de solução. Figura adaptada da referência [49].

O volume da célula em fluxo utilizada foi determinado por um espaçador circular, feito de Parafilm, com $100 \mu \mathrm{m}$ de espessura, o qual expôs cerca de $1 \mathrm{~cm}^{2}$ de área geométrica do filme metálico, portanto, a $10 \mu \mathrm{L}$ de solução. O contato elétrico do filme metálico ao circuito elétrico foi realizado com a ajuda de uma folha circular de cobre com diâmetro maior que aquele do espaçador. Um eletrodo de calomelano saturado comercial (Schott B2910) foi utilizado como eletrodo de referência, mas os valores de potencial neste trabalho são todos apresentados na escala do eletrodo reversível de hidrogênio, somando-se $260 \mathrm{mV}$ ao valor experimental medido.

Um espectrômetro BioRad modelo FTS-6000 foi utilizado para coletar os espectros da Seção 3.2 enquanto os espectros da Subseção 3.1.2 foram coletados utilizando-se um espectrômetro Varian modelo 670-IR. Os experimentos eletroquímicos foram realizados com um potenciostato/galvanostato Pine modelo AFRDE5 com uma interface programada em LabView para aquisição dos dados. Os reagentes utilizados incluíram água de alta pureza 
(Milli Q, $18 \mathrm{M \Omega} \mathrm{cm}$ ), $\mathrm{HClO}_{4}$ (Merck, supra puro), $\mathrm{H}_{2} \mathrm{SO}_{4}$ (Merck, supra puro), Metanol (Merck, 99,9\%) e Etanol (Merck, 99,9\%). Os resultados apresentados na Seção 3.2 foram obtidos utilizando-se soluções purgadas com $\operatorname{Ar}$ (MTI Gase, N 6.0).

A preparação do filme de platina sobre o prisma de silício seguiu o seguinte procedimento. Após polimento em pasta de diamante ( $1 \mu \mathrm{m}-0,25 \mu \mathrm{m})$ e limpeza em ultrassom em meio de propanona e de água, o plano refletor do prisma foi colocado em contato com uma solução de $\mathrm{PdCl}_{2}$ 0,001 $\mathrm{M}$ dissolvido em solução aquosa contendo $0,5 \%$ de HF por cerca de um minuto, com o objetivo de crescer núcleos de Pd sobre o Si e aumentar a adesão do filme de Pt, o qual foi formado expondo-o a um banho formado por água e duas soluções comerciais, lectroless PT 100 B (Ethone GmbH) e lectroless PT 100 Reducer (Ethone $\mathrm{GmbH}$ ) na proporção em volume de 0,9:1:0,02 por, aproximadamente, dois minutos. 


\section{Resultados e discussão}

3.1 Eletro-oxidação oscilatória de metanol sobre Pt estudada por espectroscopia de absorção de infravermelho intensificada pela superfície (EAIVIS) in situ em configuração de reflexão total atenuada (RTA) e por perturbação com peróxido de hidrogênio

Nesta seção apresentam-se, em subseções separadas, resultados de eletro-oxidação oscilatória de metanol sobre eletrodos de platina realizados em três sistemas experimentais distintos. Em dois deles, visando aprofundar o entendimento da dinâmica de adsorbatos durante o desenvolvimento das oscilações de potencial, utilizou-se células espectroeletroquímicas acopladas a espectrômetros de radiação infravermelha, sendo uma delas convencional de solução estagnada, com ácido sulfúrico como eletrólito suporte (Subseção 3.1.1), enquanto a outra era uma célula de fluxo, com experimentos realizados em meio de ácido perclórico (Subseção 3.1.2). ${ }^{6}$ No terceiro sistema utilizou-se uma célula eletroquímica comum para explorar as consequências de se perturbar a eletro-oxidação oscilatória de metanol ao se forçar uma presença extra de espécies oxigenadas ao sistema, conseguida através da adição de peróxido de hidrogênio (Subseção 3.1.3).

\subsubsection{Estudo da eletro-oxidação oscilatória de metanol por espectroscopia de infravermelho in situ sob condições de eletrólito estagnado}

A observação de oscilações de potencial durante a eletro-oxidação de metanol sobre platina tem sido relatada na literatura [50-52]; contudo, em geral, os estudos não foram beneficiados pelo uso de técnicas espectroscópicas in situ. Uma exceção é o trabalho de Martins et al. [53], mas, como se discutirá adiante, a configuração de reflexão externa

\footnotetext{
${ }^{6}$ A utilização dos eletrólitos empregados nos dois sistemas espectro-eletroquímicos foi mais contingencial do que planejada.
} 
utilizada é inadequada para acompanhar as mudanças que ocorrem na interface eletrodo/solução em condições oscilatórias. Recentemente, acoplando a técnica EMED on line à técnica galvanostática, Nagao et al. [54] conseguiram observar pela primeira vez, separadamente, diferentes vias paralelas de oxidação de metanol em regime oscilatório.

Esta subseção inicia-se com a análise do voltamograma base da platina porque, ao definir a região de potencial onde uma das variáveis oscilantes, os óxidos superficiais, se forma, ela será útil para a interpretação dos resultados de oscilação. A seguir, se apresentará o voltamograma obtido durante a eletro-oxidação de metanol bem como se discutirá o mecanismo em que esta opera, proporcionando, assim, elementos para se pensar tentativas de explicação/interpretação para os fenômenos complexos que serão expostos posteriormente.

Antes das medidas de eletro-oxidação do composto orgânico a superfície do eletrodo de trabalho (filme de platina), ainda em contato apenas com o eletrólito de suporte, $\mathrm{H}_{2} \mathrm{SO}_{4}$ 0,5 M, foi limpa eletroquimicamente ciclando-se seu potencial entre 0,05 e 1,4 V até a definição de um voltamograma estável, como aquele exibido na Fig. 10a. Isto indica remoção de contaminantes eventualmente presentes no eletrodo e maximização da quantidade de sítios de platina disponíveis para adsorção. Três regiões distinguem-se neste conhecido voltamograma $[55,56]$ :

(i) abaixo de 0,4 V observam-se dois processos reversíveis com picos em, aproximadamente, 0,260 e 0,125 V, atribuídos a processos de adsorção (varredura negativa)/dessorção (varredura positiva) de hidrogênio:

$$
\mathrm{Pt}+\mathrm{H}^{+}+\mathrm{e}^{-} \rightleftharpoons \mathrm{Pt}-\mathrm{H}
$$

que ocorrem em regimes de subtensão em sítios de platina energeticamente diferentes. Embora a energia de adsorção do metanol seja menor do que a de hidrogênio sobre eletrodos de platina [57], quando na presença do composto orgânico, à medida que o potencial avança durante a primeira varredura anódica, a reação (15), no sentido inverso, se vai processando e sítios superficiais vão sendo liberados, possibilitando a adsorção de 
moléculas de metanol. Como a eletro-oxidação destas produz adsorbatos com energia de adsorção maior do que a de hidrogênio [57], os picos presentes no voltamograma base nesta faixa de potencial são inibidos já após a primeira varredura positiva em presença de metanol;

(ii) na região entre 0,4 e 0,75 V, aproximadamente, ocorrem processos capacitivos de carregamento da dupla camada elétrica durante a varredura positiva e, na varredura negativa, ocorre também redução de óxidos superficiais ainda remanescentes da formação promovida durante a varredura positiva:

$$
\mathrm{H}_{2} \mathrm{O}_{\text {sol }}+\mathrm{Pt} \rightleftharpoons \mathrm{Pt}-\underline{\mathrm{OH}}_{\mathrm{x}}+(2-\mathrm{x}) \mathrm{H}^{+}+(2-\mathrm{x}) \mathrm{e}^{-}
$$

onde o átomo sublinhado indica que a adsorção à superfície realiza-se por ele e x =0, 1 ou 2 . Para $x=1$ a reação no sentido direto iniciar-se-ia em torno de $0,56 \mathrm{~V}$ na presença de metanol [58];

(iii), na varredura positiva por volta de $0,75 \mathrm{~V}$ inicia-se a formação de óxidos superficiais, reação (16) $c o m x=0$, a qual se estende até o potencial de inversão, enquanto que na negativa, por causa do deslocamento para valores mais positivos do potencial de equilíbrio do sistema eletrodo/óxido/solução, inicia-se, em potenciais onde na varredura positiva havia formação de óxidos, a redução dos mesmos, finalizada em potenciais mais negativos. É oportuno ressaltar aqui que as espécies oxigenadas adsorvidas $\mathrm{OH}_{\mathrm{x}}$ são variáveis essenciais do mecanismo oscilatório, participantes do ciclo de retroalimentação positiva (ver Cap.1). 

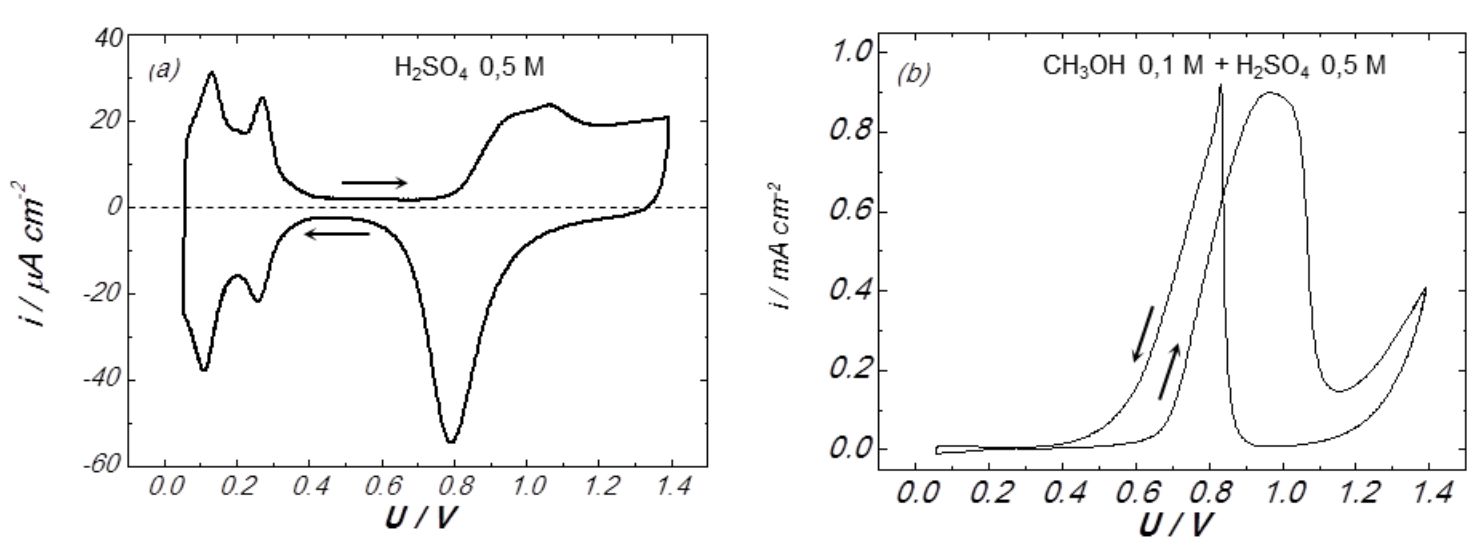

Figura 10 - Voltamograma cíclico, a $25 \mathrm{mV} \mathrm{s}^{-1}$, do eletrodo de trabalho (filme de Pt) em contato com solução de (a) $\mathrm{H}_{2} \mathrm{SO}_{4} 0,5 \mathrm{M}$ e (b) $\mathrm{H}_{2} \mathrm{SO}_{4} 0,5 \mathrm{M}+\mathrm{CH}_{3} \mathrm{OH} 0,1 \mathrm{M}$. As correntes foram normalizadas pela área real de $74 \mathrm{~cm}^{2}$.

Ao se adicionar metanol à concentração de interesse, $\mathrm{CH}_{3} \mathrm{OH} 0,1 \mathrm{M}$, a resposta voltamétrica, Fig. 10b, passou a exibir as características comumente encontradas durante a eletro-oxidação deste orgânico sobre eletrodos de platina [57]. Entre elas inclui-se o bloqueio inicial da superfície em baixos potenciais por $\mathrm{CO}_{\mathrm{ads}}$, um intermediário estável cuja principal via de formação aceita é a sucessiva desidrogenação da molécula de metanol adsorvida [59-61]:

$$
\begin{aligned}
& \mathrm{H}_{3} \mathrm{COH}_{(\text {sol })}+\mathrm{Pt} \rightarrow \mathrm{Pt}-\mathrm{H}_{2} \mathrm{COH}_{\mathrm{ads}}+\mathrm{H}^{+}+\mathrm{e}^{-} \\
& \mathrm{Pt}_{-} \mathrm{H}_{2} \mathrm{COH}_{\mathrm{ads}}+\mathrm{Pt} \rightarrow \mathrm{Pt}_{2}-\mathrm{HCOH}_{\mathrm{ads}}+\mathrm{H}^{+}+\mathrm{e}^{-} \\
& \mathrm{Pt}_{2}-\mathrm{HCOH}_{\mathrm{ads}}+\mathrm{Pt} \rightarrow \mathrm{Pt}-\mathrm{HCO}_{\mathrm{ads}}+\mathrm{H}^{+}+\mathrm{e}^{-}+2 \mathrm{Pt} \\
& \mathrm{Pt}_{-} \mathrm{HCO}_{\mathrm{ads}}+\mathrm{Pt} \rightarrow \mathrm{Pt}_{1+\mathrm{x}}-\mathrm{CO}_{\mathrm{ads}}+(1-\mathrm{x}) \mathrm{Pt}+\mathrm{H}^{+}+\mathrm{e}^{-}, \quad \mathrm{x}=0 \text { ou } 1
\end{aligned}
$$

Os sítios livres, Pt, extras na etapa (20) indicam a essencialidade da presença de um sítio adjacente para o rompimento da ligação $\mathrm{C}-\mathrm{H}$ e a imediata liberação deste sítio na sequência. A forte interação atrativa entre CO e Pt impede a adsorção de novas moléculas de metanol e, por conseguinte, sua oxidação e a observação de correntes apreciáveis na varredura 
positiva até que o potencial seja alto o suficiente para promover a formação de espécies oxigenadas adsorvidas sobre a superfície, sentido direto da etapa (16), as quais reagem com $\mathrm{CO}_{\mathrm{ads}}$ produzindo dióxido de carbono e disponibilizando sítios livres para a adsorção de novas moléculas:

$$
\mathrm{Pt}-\underline{\mathrm{OH}}_{\mathrm{x}}+\mathrm{Pt}-\underline{\mathrm{CO}}_{\mathrm{ads}} \rightarrow \mathrm{CO}_{2}+\mathrm{xH}^{+}+\mathrm{x} \mathrm{e}^{-}+2 \mathrm{Pt}
$$

A combinação de sítios livres com presença moderada de espécies oxigenadas propicia as condições para a observação da maior atividade do eletrodo, que durante a varredura positiva acontece, aproximadamente, entre 0,67 e 1,0 V. Em valores mais positivos de potencial, o bloqueio superficial causado pela formação de óxidos inibe a corrente de oxidação, contudo, ela ainda é bem maior do que a observada no voltamograma base, Fig. 10a, na região de potenciais elevados. Este fenômeno pode estar relacionado a uma atividade catalítica dos óxidos de platina em altos sobrepotenciais e ser auxiliado pelo consumo dos óxidos superficiais pelo orgânico em solução [62]. Na varredura negativa a redução dos óxidos disponibiliza sítios livres para a adsorção de metanol, o qual ao ser oxidado gera resíduos que aceleram o consumo dos óxidos e a produção de mais sítios livres, resultando na eletro-oxidação auto-catalítica de metanol que se observa a partir de, aproximadamente, $0,85 \mathrm{~V}$. No entanto, à medida que a população superficial de espécies oxigenadas decresce, com a redução na velocidade de sua formação que acompanha a diminuição do potencial, um acúmulo de $\mathrm{CO}_{\mathrm{ads}}$ volta a se estabelecer fazendo a corrente diminuir até atingir valores muito pequenos no final da varredura negativa.

A via que produz dióxido de carbono passando pelas etapas (20) e (21) não é, contudo, a única responsável pela oxidação completa do metanol. Rotas paralelas, cujo número é incerto $[57,63-66]$, também podem levar a $\mathrm{CO}_{2}$ e a espécies parcialmente oxidadas. Neste contexto, a denominação caminho indireto tem sido utilizada para se referir à(s) rota(s) que envolve(m) a formação de $\mathrm{CO}_{\mathrm{ads}}$, dado o bloqueio superficial mencionado acima que esta espécie pode causar, enquanto que as demais rotas ficam agrupadas sob a denominação de caminho direto [60]. A multiplicidade de possíveis etapas reacionais 
ocorrendo em paralelo na superfície do eletrodo torna o mecanismo de eletro-oxidação do metanol assaz complexo. Nas últimas décadas se tem avançado no esclarecimento deste mecanismo e, embora ainda não seja possível afirmar com segurança todas as etapas elementares que realmente operam e em que faixa de potencial predominam, na Fig. 11 foram reunidas algumas das rotas mais citadas na literatura [57, 64-69].

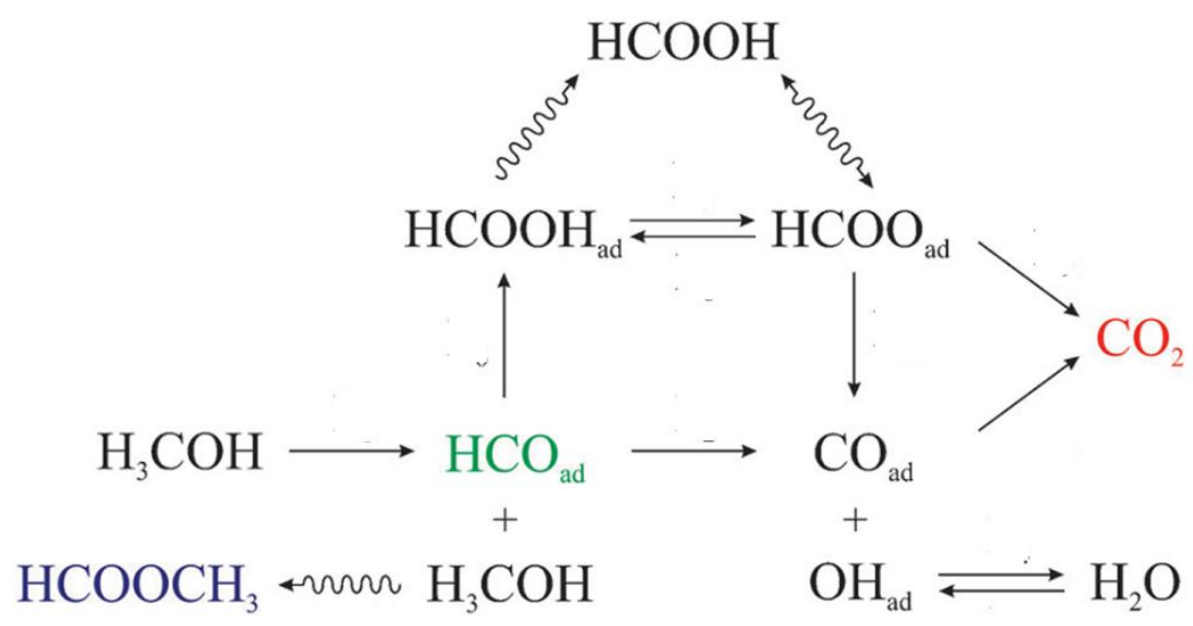

Figura 11 - Esquema reacional simplificado para eletro-oxidação de metanol sobre eletrodos de Pt. Figura adaptada da referência [54].

Entre as vias de caminho direto propostas incluem-se aquelas que envolvem a formação de ácido fórmico, a qual dar-se-ia de três maneiras:

(i) Via ataque nucleofílico de uma molécula de água a um intermediário adsorvido pelo carbono, Pt-HCO [69]:

$$
\mathrm{Pt}-\mathrm{HCO}_{\mathrm{ads}}+\mathrm{H}_{2} \mathrm{O} \rightarrow \mathrm{Pt}-\mathrm{HCOOH}_{\mathrm{ads}}+\mathrm{H}^{+}+\mathrm{e}^{-}
$$

A espécie Pt- $\mathrm{HCOOH}_{\mathrm{ads}}$, então, dessorver-se-ia para a solução onde tenderia a estabelecer, rapidamente, um equilíbrio com sua forma desprotonada adsorvida [70]: 
(23) $\mathrm{HCOOH}_{\mathrm{sol}}+2 \mathrm{Pt} \rightleftharpoons \mathrm{Pt}_{2}-\mathrm{HCOO}_{\mathrm{ads}}+\mathrm{H}^{+}+\mathrm{e}^{-}$

por sua vez, o formato adsorvido, $\mathrm{Pt}_{2}-\mathrm{HCOO}_{\mathrm{ads}}$, poderia ser reduzido a monóxido de carbono adsorvido [68]:

$$
\mathrm{Pt}_{2}-\mathrm{HCOO}_{\mathrm{ads}}+\mathrm{H}^{+}+\mathrm{e}^{-} \rightarrow \mathrm{Pt}-\mathrm{CO}_{\mathrm{ads}}+\mathrm{H}_{2} \mathrm{O}+\mathrm{Pt}
$$

ou ser eletro-oxidado, gerando $\mathrm{CO}_{2}$ e desenvenenando a superfície [71-73]:

$$
\mathrm{Pt}_{2}-\mathrm{HCOO}_{\mathrm{ads}}[+\mathrm{Pt}] \rightarrow \mathrm{CO}_{2}+2 \mathrm{Pt}+\mathrm{H}^{+}+\mathrm{e}^{-}[+\mathrm{Pt}]
$$

onde os sítios livres de platina adicionais entre colchetes em ambos os lados representam a incerteza sobre a necessidade de um sítio livre adjacente para a decomposição do formato, frente às diferentes propostas feitas [71-73]. Recentemente, Cuesta et al. [67, 71] propuseram que dímeros de ácido fórmico em solução adsorver-se-iam como espécie formato adjacentes:

(26) $(\mathrm{HCOOH})_{2, \text { sol }}+4 \mathrm{Pt} \rightarrow 2 \mathrm{Pt}_{2}-\mathrm{HCOO}_{\mathrm{ads}}+2 \mathrm{H}^{+}+\mathrm{e}^{-}$

os quais sofreriam processo de decomposição química para gerar $\mathrm{CO}_{2}$ e $\mathrm{H}_{2}$, sendo que este último seria eletro-oxidado ao se adsorver:

(27) $2 \mathrm{Pt}_{2}-\mathrm{HCOO}_{\mathrm{ads}} \rightarrow 2 \mathrm{CO}_{2}+\mathrm{H}_{2}+4 \mathrm{Pt}$

(28) $\mathrm{H}_{2}+2 \mathrm{Pt} \rightarrow 2 \mathrm{H}^{+}+2 \mathrm{e}^{-}+2 \mathrm{Pt}$ 
(ii) Pelo ataque nucleofílico de uma molécula de água ao metóxi adsorvido, $\mathrm{Pt}-\mathrm{H}_{2} \mathrm{CO}$, um intermediário decorrente da adsorção da molécula de metanol pelo átomo de oxigênio, na forma de metóxi adsorvido, $\mathrm{Pt}-\mathrm{H}_{3} \mathrm{CO}$ [74]:

$$
\begin{aligned}
& \mathrm{CH}_{3} \mathrm{OH}_{(\text {sol) }}+\mathrm{Pt} \rightarrow \mathrm{Pt}-\mathrm{H}_{3} \mathrm{CO}_{\text {ads }}+\mathrm{H}^{+}+\mathrm{e}^{-} \\
& \text {Pt- } \mathrm{H}_{3} \mathrm{CO}_{\text {ads }} \rightarrow \mathrm{Pt}-\mathrm{H}_{2} \mathrm{CO}_{\mathrm{ads}}+\mathrm{H}^{+}+\mathrm{e}^{-} \\
& \text {Pt- } \mathrm{H}_{2} \mathrm{CO}_{\mathrm{ads}}+\mathrm{H}_{2} \mathrm{O} \rightarrow \mathrm{Pt}-\mathrm{HCOOH}_{\mathrm{ads}}+2 \mathrm{H}^{+}+2 \mathrm{e}^{-}
\end{aligned}
$$

É interessante notar que o caminho via metóxi envolveria a ocupação, por parte da molécula de metanol, de apenas um sítio reacional enquanto que no caminho via hidroximetil três deles seriam requeridos [75]. Isto sugere que, em condições de baixa disponibilidade de sítios livres, o caminho via metóxi poderia predominar sobre as demais rotas.

(iii) Pela dessorção de formaldeído para a solução, onde adquiriria uma forma hidratada que ao se readsorver produziria formato adsorvido [66]

$$
\mathrm{H}_{2} \mathrm{C}(\mathrm{OH})_{2, \text { sol }}+2 \mathrm{Pt} \rightarrow \mathrm{Pt}_{2}-\mathrm{HCOO}+3 \mathrm{H}^{+}+3 \mathrm{e}^{-}
$$

e, então, $\mathrm{Pt}_{2}-\mathrm{HCOO}$ poderia tomar algum dos caminhos sugeridos acima, reações (23) a (27).

Este cenário geral da eletro-oxidação de metanol, mesmo incompleto, fornece elementos para se discutir, em termos de etapas reacionais, o que está acontecendo na interface eletrodo/solução durante as oscilações, as quais passam a ser consideradas a seguir. 
Como já adiantado no Cap.1, oscilações de potencial podem se desenvolver quando uma corrente constante é exigida de um sistema RDN-NE. As oscilações apresentadas na Fig. 12a (e em detalhe na Fig. 12c), iniciadas após um período de indução de cerca de cem segundos, confirmam esta potencialidade. Elas são observadas durante eletro-oxidação galvanostática de $\mathrm{CH}_{3} \mathrm{OH} 0,1 \mathrm{M}+\mathrm{H}_{2} \mathrm{SO}_{4}$ 0,5 $\mathrm{M}$ via aplicação de uma densidade de corrente de $0,2 \mathrm{~mA} \mathrm{~cm}^{-2}$. A amplitude baixa ${ }^{7}$ com a qual nascem experimenta um crescimento próximo do exponencial, inicialmente, o qual se desacelera para uma forma aparentemente logarítmica e, então, praticamente linear. O acelerado aumento inicial pode estar ligado à própria dinâmica do sistema que deixa o estado-estacionário, o qual se tornou instável no momento da bifurcação, rumo ao atrator mais próximo, neste caso um ciclo limite (ver Cap. 1). Em princípio, uma vez atingido o ciclo limite o sistema deveria oscilar indefinidamente, mantendo os mesmos valores de amplitude e período bem como seu perfil morfológico. Entretanto, mesmo quando as oscilações da Fig. 12a se estabelecem, evento indicado pela aparente estabilização de sua amplitude, pode-se detectar ainda uma lenta variação, sugerindo que mesmo conservando constantes todos os parâmetros externos controláveis (como, por exemplo, corrente aplicada e concentração do orgânico no seio da solução), a eletro-oxidação oscilatória de metanol é um fenômeno transiente e algum parâmetro intrínseco está a mudar no sistema entre um ciclo e outro. Em outras palavras, poder-se-ia dizer que tudo se passa como se o sistema estivesse à deriva ${ }^{8}$ para outro regime de estabilidade.

\footnotetext{
${ }^{7}$ Apenas para conhecimento, do ponto de vista da teoria dos sistemas dinâmicos o nascimento de oscilações com amplitude pequena indica que a bifurcação que desestabilizou o estado estacionário e lhes deu origem seria uma bifurcação de Hopf supercrítica. À diferença, se as oscilações nascem já com grande amplitude tratarse-ia de uma bifurcação de Hopf subcrítica (SCOTT, S. K. Chemical chaos. Estados Unidos da América: Oxford University Press, 1993. 472 p.).

${ }^{8} \mathrm{Na}$ literatura em língua inglesa esta sina, não controlável por parâmetros externos, dos sistemas reais tem sido identificada pelo termo drift (NAGAO, R.; SITTA, E.; VARELA, H. Stabilizing nonstationary electrochemical time series. Journal of Physical Chemistry C. v. 114, p. 22262-22268, 2010.). Um exemplo é a lenta mudança pela qual passa o corpo humano, um sistema físico-químico afastado do equilíbrio termodinâmico que, apesar da aparente estabilidade numa escala temporal de dias, está evoluindo para seu inelutável fim.
} 

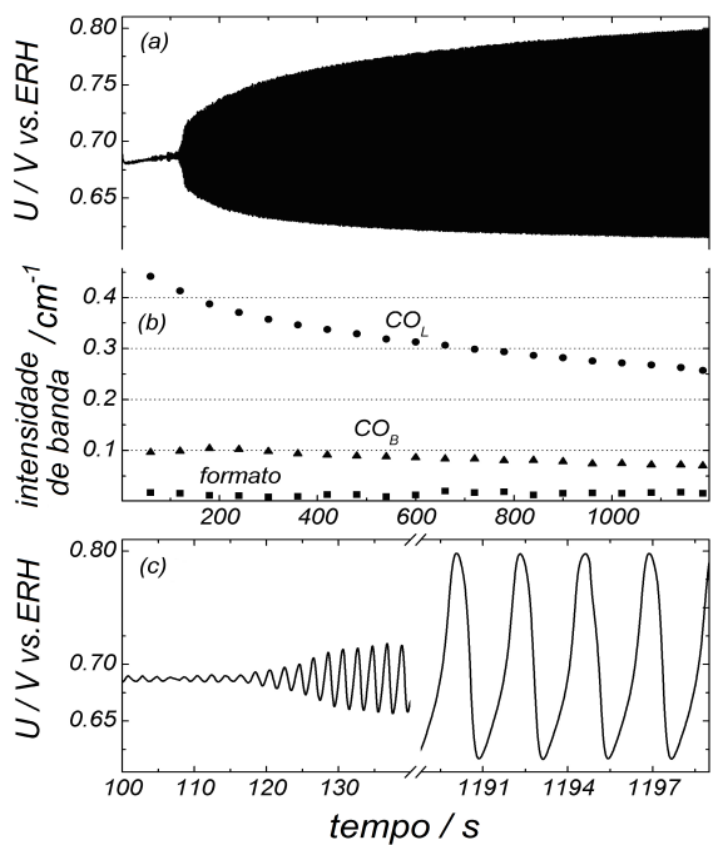

Figura 12 - (a) Oscilações de potencial durante a eletro-oxidação galvanostática de $\mathrm{CH}_{3} \mathrm{OH}$ 0,1 M em meio de $\mathrm{H}_{2} \mathrm{SO}_{4}$ 0,5 M sob densidade de corrente de 0,2 mA $\mathrm{cm}^{-2}$; (b) intensidade integrada das bandas de $\mathrm{CO}_{\mathrm{L}}(\bullet), \mathrm{CO}_{\mathrm{B}}(\boldsymbol{\Delta})$ e formato (-); (c) visão detalhada de duas regiões diferentes das oscilações de potencial dadas em (a).

A mudança à qual as oscilações da Fig. 12a estão submetidas pode ser percebida também no comportamento do período dos ciclos ao longo do tempo, os quais repetem-se a cada 2,3 s, inicialmente, e após mil segundos dentro do regime oscilatório passam a fazê-lo num tempo ligeiramente maior, a cada $2,5 \mathrm{~s}$, uma variação que além de acusar baixa velocidade na deriva do sistema indica uma relativamente alta estabilidade ou robustez destas oscilações. Esta deriva dos sistemas também é costumeiramente observada em séries temporais experimentais quando, espontaneamente, ocorrem transições (bifurcações) entre diferentes padrões de oscilação [76-78].

Uma importante informação adicional relacionada à lenta mudança experimentada por um sistema oscilatório, e à qual se pode acessar ainda pela análise dos dados eletroquímicos somente, é a diminuição da fração da superfície livre para adsorção, $\theta_{S L}$, ao longo do experimento galvanostático. Esta conclusão pode ser alcançada pela análise do comportamento temporal de uma nova variável dentro da região oscilatória, o potencial 
médio, $\bar{U}$, definida como a área integrada sob a curva de potencial entre dois mínimos adjacentes de um ciclo dividida pelo período deste ciclo, $\mathrm{T}$ :

$$
\bar{U}=\frac{1}{T} \int_{t_{\min }}^{t_{\min }+T} U d t
$$

Durante a série temporal exibida na Fig. 12a o potencial médio calculado pela eq. (33) cresce a uma taxa de, aproximadamente, 0,011 $\mathrm{mV} \mathrm{s}^{-1}$ dentro do regime oscilatório, valor seis vezes menor do que a taxa de variação do potencial observada no período de indução, 0,066 $\mathrm{mV} \mathrm{s}^{-1}$. Assim, assumindo que não há mudança no mecanismo de eletrooxidação do metanol na faixa de potencial em que as instabilidades cinéticas se observam, estes resultados sugerem ser possível identificar as oscilações como um meio para desacelerar a velocidade de envenenamento da superfície, já que, sob condições galvanostáticas, um aumento no potencial indicaria uma redução na área ativa do eletrodo. Isto pode ter consequências práticas para a aplicação de células a combustível diretas de metanol, por exemplo, em movimentação veicular, onde uma corrente constante é requerida do sistema e baixo nível de bloqueio do catalisador é desejável. Nesta direção, existem trabalhos mostrando possibilidades de aumento na potência obtida de células a combustível, alimentadas por hidrogênio contaminado com traços de CO, quando operadas em regime oscilatório em relação ao funcionamento em estado estacionário [79-81]. Apoiando a conclusão destes resultados experimentais existe previsão teórica de maior aproveitamento da energia livre, extraível de células a combustível, quando sua operação se dá em condições bastante afastadas do equilíbrio termodinâmico, ou seja, para além da região linear, onde as oscilações se desenvolvem [51].

Desta forma, um candidato ao papel de parâmetro intrínseco, cuja variação altera as características das oscilações e, potencialmente, o regime de estabilidade do sistema, seria o recobrimento de sítios livres superficiais $\left(\theta_{\mathrm{SL}}\right)$. Assumindo $\theta_{\mathrm{SL}}$ como parâmetro de bifurcação, da análise do comportamento temporal do potencial médio poder-se-ia estabelecer uma metodologia para quantificar a deriva do sistema podendo, inclusive, servir de base para o desenvolvimento de estratégias de compensação artificial desta variação intrínseca do 
sistema. Uma que tem sido adotada $[25,82]$ consiste em tentar compensar a redução na disponibilidade de sítios livres (causada pelo crescente envenenamento superficial) diminuindo gradativamente a corrente exigida ao sistema, o que pode ser realizado via aplicação de varreduras negativas de corrente sobre o sinal galvanostático ou, equivalentemente, e de modo mais prático, apenas aplicação de varredura negativa de corrente partindo de um valor inicial coincidente com aquele de interesse para o experimento galvanostático. Diante do aumento do bloqueio superficial, a diminuição da corrente aplicada tenderia a atenuar a agência da deriva sobre a densidade de corrente, deixando-a constante por mais tempo. Essa estratégia mostrou-se eficaz para a estabilização de oscilações desenvolvidas durante a eletro-oxidação de metanol, aumentando em até vinte vezes o número de ciclos observados em uma determinada série, além de estender a duração de padrões mistos que de outra forma teriam uma existência efêmera [25]. Estes resultados corroboram a hipótese de que o parâmetro de bifurcação intrínseco está mesmo relacionado ao consumo de sítios livres superficiais, uma vez que a atenuação artificial de sua diminuição refletiu-se em estabilização das características do sistema. A compensação da redução de sítios livres poderia ainda ser aperfeiçoada se, em vez de constante, a taxa de diminuição da corrente aplicada, $d i_{a p} / d t$, ajustasse-se a cada ciclo, uma vez que a velocidade de deriva observada durante a eletro-oxidação galvanostática de metanol sobre platina é não linear [83]. Este procedimento exigiria monitorar em tempo real o potencial médio durante a série temporal de modo a permitir alimentar o mecanismo de ajuste com esta informação.

Visando aprofundar o entendimento dos processos interfaciais presentes durante o evento das oscilações de potencial, a técnica espectroscópica de infravermelho in situ EAIVIS-RTA (ver Cap.1 e 2 para detalhes) foi empregada para acessar informações a respeito das espécies adsorvidas, tais como identidade e reatividade. Desta forma, simultaneamente ao experimento galvanostático da Fig. 12a, foram coletados interferogramas entre 1000 e $4000 \mathrm{~cm}^{-1}$ da interface eletrodo/solução, com resolução temporal de 0,2 s e resolução espacial de $8 \mathrm{~cm}^{-1}$. Fazendo-se, então, médias dos interferogramas regularmente adquiridos em intervalos de $60 \mathrm{~s}$ e calculando-se a transformada de Fourier inversa, foram obtidos os espectros apresentados na Fig. 13. Puderam ser detectadas bandas em, aproximadamente, $2060 \mathrm{~cm}^{-1}, 1830 \mathrm{~cm}^{-1}$ e $1320 \mathrm{~cm}^{-1}$ que, por associação a espectros obtidos em condições de 
ultra alto vácuo, tem sido atribuídas, respectivamente, ao modo de estiramento (CO) do monóxido de carbono adsorvido pelo carbono a um único átomo de platina, $\mathrm{CO}_{\mathrm{L}}$, ou a mais de um, $\mathrm{CO}_{\mathrm{B}},[30,84]$ e ao estiramento simétrico (OCO) de formato adsorvido em ponte pelos oxigênios, $\mathrm{HCOO}_{\mathrm{ads}}$, [85-87] além das bandas referentes à água interfacial. ${ }^{9}$

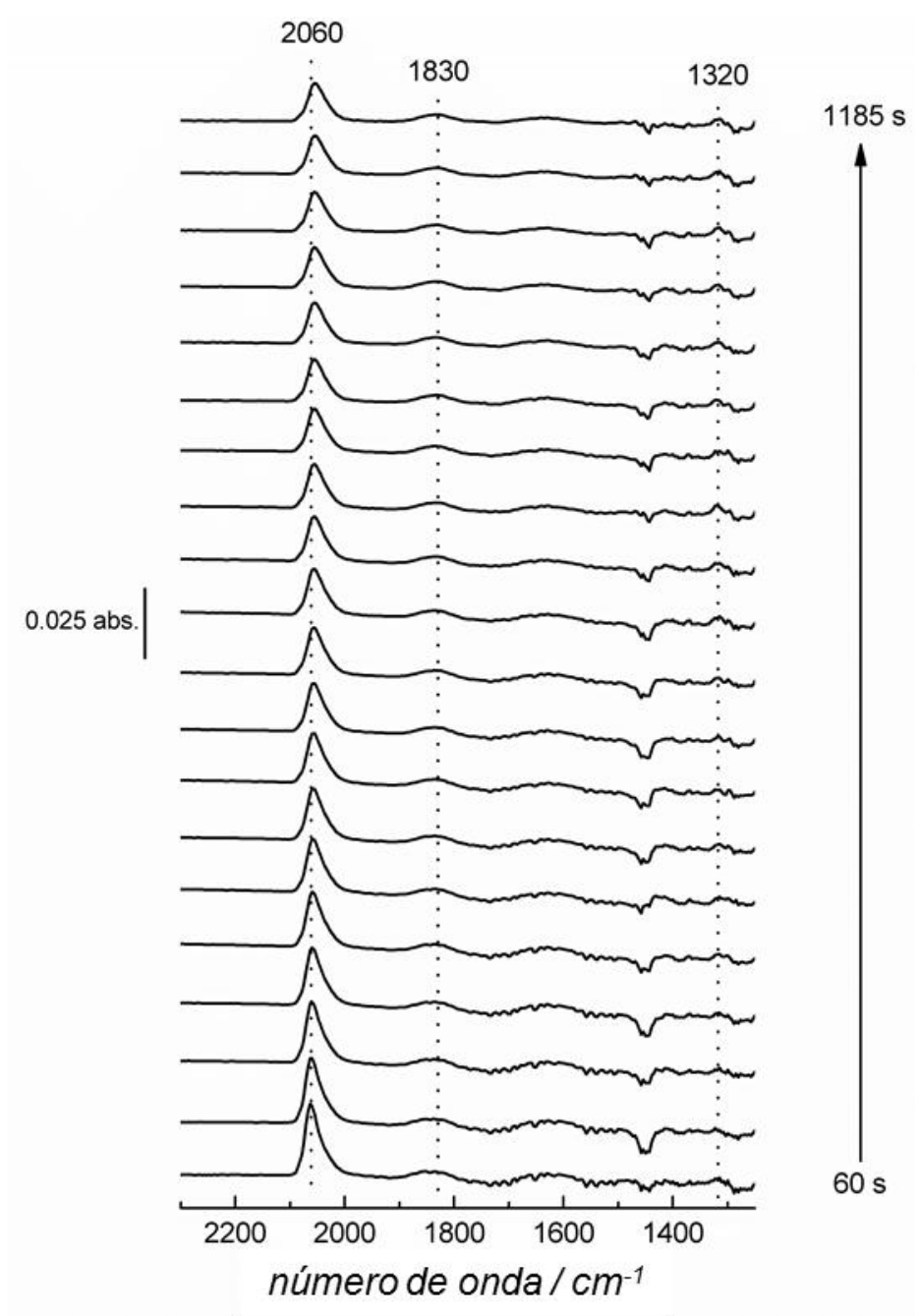

Figure 13 - Evolução temporal de espectros EAIVIS, obtidos a partir da média de $60 \mathrm{~s}$ de coleta de interferogramas adquiridos com resolução temporal de 0,2 s e com resolução espacial de $8 \mathrm{~cm}^{-1}$, resultando em 300 varreduras por espectro. Eletrólito: $\mathrm{H}_{2} \mathrm{SO}_{4} \mathrm{0,5} \mathrm{M}+\mathrm{CH}_{3} \mathrm{OH}$ 0,1 M. Corrente aplicada: 0,20 mA cm${ }^{-2}$.

\footnotetext{
${ }^{9}$ Também pode-se observar duas pequenas bandas em torno de $1450 \mathrm{~cm}^{-1}$, elas se devem à ressonância de Fermi do grupo $\mathrm{CH}_{3}$ (informação fornecida pelo Dr. Renato Garcia de Freitas Sobrinho, em 04 de julho de 2013).
} 
Sendo a absorvância de uma espécie $i, A_{i}$, função linear de sua presença no caminho ótico do feixe da radiação, então, num espectro, que é uma representação da intensidade de absorção versus o correspondente número de onda da radiação incidente, a área integrada da banda atribuída a um adsorbato pode ser usada para estimar, mesmo que relativamente, sua população superficial. A Fig. $12 \mathrm{~b}$ apresenta as áreas integradas das bandas de $\mathrm{CO}_{\mathrm{L}}, \mathrm{CO}_{\mathrm{M}} \mathrm{e}$ $\mathrm{HCOO}_{\mathrm{ads}}$ presentes nos espectros da Fig. 13 para comparação com os dados eletroquímicos, Fig. 12a. O que se observa, em médias de $60 \mathrm{~s}$ dos dados adquiridos, é que as populações superficiais médias de formato e $\mathrm{CO}_{M}$ mantêm-se, aproximadamente, constantes enquanto que a de $\mathrm{CO}_{\mathrm{L}}$ decai continuamente.

Martins et al. [53] desenvolveram um estudo espectroscópico visando acompanhar o recobrimento de $\mathrm{CO}_{\mathrm{L}}$ ao longo da eletro-oxidação oscilatória de metanol e observaram um rápido aumento em $\theta_{C_{L}}$ no início das oscilações seguido por uma estabilização próxima de 0,7 monocamadas. Contudo, este elevado valor de recobrimento de monóxido de carbono para a eletro-oxidação de metanol deve ter sido um artefato da técnica espectroscópica utilizada, a de reflexão externa [33]. Uma vez que nela o feixe de radiação atravessa a solução duas vezes, é essencial inibir a atenuação do sinal infravermelho pelo solvente (água) restringindo a distância entre o eletrodo e a janela prismática para a ordem de micrômetros, o que se consegue pressionando o eletrodo contra a janela (configuração de camada ultrafina). Contudo, isto limita o transporte de massa de reagentes e de íons de suporte e, por conseguinte, o de carga, prejudicando o desenvolvimento pleno da eletrooxidação dos adsorbatos e causando acúmulo de $\mathrm{CO}_{\text {ads }}$. Diante disto, o resultado apresentado na Fig. 12b é o primeiro a mostrar, de maneira minimamente invasiva, o comportamento de $\mathrm{CO}_{\mathrm{ads}}$ ao longo de um experimento oscilatório e descarta a responsabilidade de um contínuo acúmulo de $\mathrm{CO}_{\mathrm{L}}$ pelo gradual bloqueio da superfície e o consequente aumento do potencial médio discutido acima, ou seja, como causa da deriva do sistema e desestabilização das oscilações. Ademais, isto mostra que a técnica de reflexão externa é totalmente inadequada para estudar fenômenos dinâmicos como as oscilações.

A conjunção deste resultado (diminuição temporal, em média, de $\theta_{\text {co }}$ com o conhecimento de que $\mathrm{CO}_{\mathrm{ads}}$ é consumido por espécies oxigenadas, reação (21), sugere que um acúmulo destas poderia estar a desenvolver-se sobre a superfície com o passar do tempo e ser o responsável pela redução na disponibilidade de sítios livres. Recentemente, Cabral et 
al. [82] propuseram que este acúmulo dar-se-ia na forma de oxigênio sub-superficial, isto é, oxigênio acomodado no interior da rede metálica do eletrodo, formado quando ele e o átomo de platina ao qual está adsorvido trocam reversível e simultaneamente de posição:

$$
\mathrm{Pt}-\mathrm{OH}_{\mathrm{x}} \rightleftharpoons \mathrm{O}_{\text {sub }}-\mathrm{Pt}+\mathrm{xH}^{+}+\mathrm{xe}^{-}
$$

Este processo diminuiria a fração da área superficial disponível para adsorção, uma vez que ambos os átomos perdem reatividade. Entretanto, a formação e crescimento de ilhas de espécies oxigenadas poderiam, a princípio, também ser conjecturadas como possíveis responsáveis pela deriva, uma vez que as moléculas no interior das ilhas não teriam acesso às espécies carbonáceas e, por isso, permaneceriam estáveis. A ilha cresceria se, ao fim de cada ciclo, a formação de $\mathrm{OH}_{\text {ads }}$ sobrepujasse a de $\mathrm{CO}_{\text {ads }}$, o que não seria inconcebível visto que a concentração da água, em torno de cinquenta e cinco molar, ser cerca de quinhentas vezes maior do que a de metanol no presente caso.

Ao se calcular a velocidade de diminuição do recobrimento de $\mathrm{CO}_{\mathrm{L}}$ médio, $\bar{\theta}_{C O}$, apresentado na Fig. 12b, obtém-se uma taxa de decréscimo em torno de $4,510^{-4} \mathrm{~cm}^{-1} \mathrm{~s}^{-1}$ no período de indução frente a $0,910^{-4} \mathrm{~cm}^{-1} \mathrm{~s}^{-1}$ dentro da região oscilatória, um valor cinco vezes menor. A comparável desaceleração, em torno de 5 a 6 vezes, tanto no aumento do potencial médio quanto na queda do recobrimento médio de $\mathrm{CO}_{\mathrm{ads}}$, quando se passa do período de indução para as oscilações sustentadas, corrobora a hipótese de que uma mesma variável, possivelmente o recobrimento de espécies oxigenadas adsorvidas, $\theta_{\mathrm{OH}}$, intermediaria os dois fenômenos. 


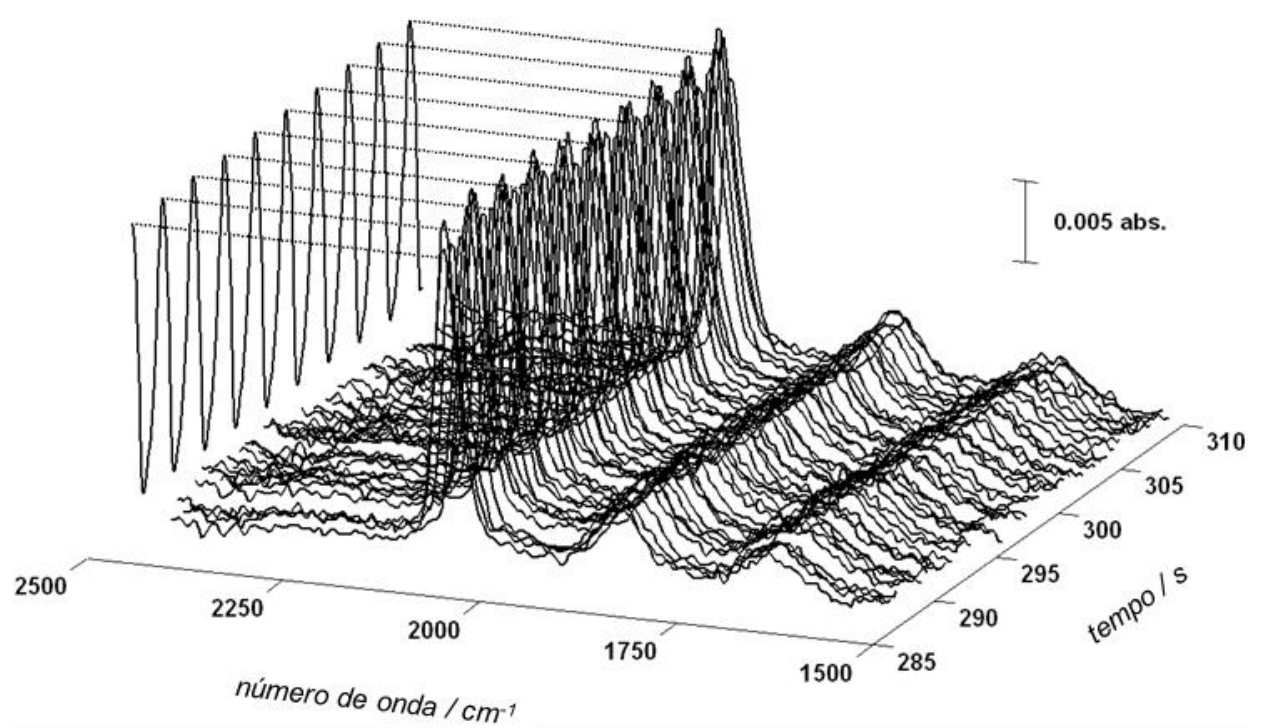

Figura 14 - Série de espectros, em unidades de absorvância, registrados simultaneamente às oscilações de potencial. Linhas tracejadas conectam máximos de ciclos de potencial com seus respectivos espectros. As resoluções espaciais e temporais foram $8 \mathrm{~cm}^{-1}$ e $500 \mathrm{~ms}$, respectivamente. Eletrólito: $\mathrm{H}_{2} \mathrm{SO}_{4}$ $0,5 \mathrm{M}+\mathrm{CH}_{3} \mathrm{OH} 0,1 \mathrm{M}$. Corrente aplicada: $0,18 \mathrm{~mA} \mathrm{~cm}^{-2}$.

A intensificada absorvância praticada pelos adsorbatos proporcionada pelo efeito AIVIS, ver Cap.1, viabilizou a coleta de interferogramas em modo de alta velocidade de varredura dos espelhos, gerando espectros com resolução temporal de $0,5 \mathrm{~s}$, como aqueles exibidos na Fig. 14 os quais, adquiridos concomitantemente com oscilações de potencial, permitem discernir oscilações também na intensidade das bandas de $\mathrm{CO}_{\mathrm{L}}$. A representação da área da banda de $\mathrm{CO}_{\mathrm{L}}$ (na forma de recobrimento superficial relativo, ver Seção 2.4) destes espectros em função do tempo, Fig. 15c, torna mais clara a visualização das esperadas oscilações no perfil temporal do recobrimento de monóxido de carbono simultâneas às oscilações de potencial. Estes dados têm potencial para permitir inferências sobre o funcionamento do mecanismo oscilatório; contudo, antes disso é preciso certificarse de que eles estejam bem sincronizados. Para tanto, representou-se na Fig. 15b a posição da banda de $\mathrm{CO}_{\mathrm{L}}, v_{\mathrm{CO}_{L}}$, em função do tempo. Sabe-se que, pelo efeito Stark [88], a frequência de vibração de $\mathrm{CO}_{\mathrm{L}}$ varia linearmente com o potencial a uma taxa de $29 \mathrm{~cm}^{-1} \mathrm{~V}^{-1}$, assim, o fato das oscilações de $v_{C O_{L}}$ na Fig. $15 \mathrm{~b}$ acompanhar exatamente em fase as ondas de potencial observadas na Fig. 15a, atestam sincronia entre os dados eletroquímicos e os espectroscópicos. 


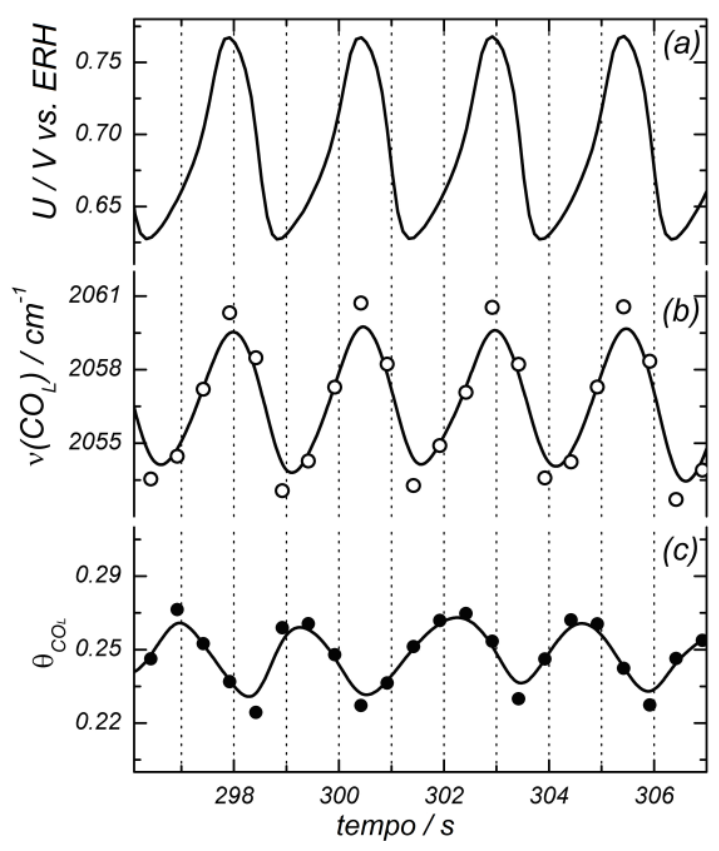

Figura 15 - Oscilações (a) de potencial durante eletro-oxidação galvanostática de metanol; (b) da posição da banda; e (c) do recobrimento de $\mathrm{CO}_{\mathrm{L}}$, registrados simultaneamente com o experimento eletroquímico. Dados extraídos da Fig. 14.

Durante experimentos galvanostáticos um determinado fluxo de carga, $l_{a p}$, é imposto ao sistema controlando-se externamente a diferença de potencial, $U$, entre os eletrodos de trabalho e de referência; contudo, com o tempo, o desenvolvimento de um bloqueio superficial causado pela adsorção de venenos catalíticos dificulta a oxidação eletroquímica das espécies eletroativas e, por conseguinte, a manutenção de $I_{a p}$ através da interface eletrodo/solução, ao que o controle galvanostático externo responde com um aumento em U. Este raciocínio pode induzir à idéia de que a diminuição na área superficial disponível para reação é diretamente proporcional a $U$ e, assim, criar a expectativa de que $\theta_{C O_{L}}$,rel. devesse oscilar exatamente em fase com o potencial. Entretanto, não é o que se observa quando se

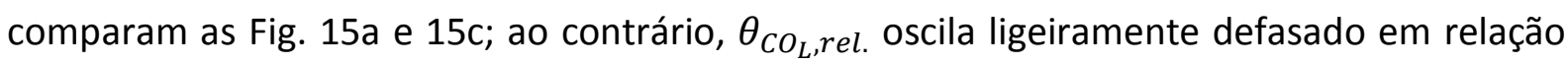
ao potencial. Isto acontece por que, na verdade, quem está diretamente relacionado à obstrução do processo de eletro-oxidação é a velocidade de aumento, ou seja, a derivada, do potencial. Este ponto voltará a ser discutido na Subseção 3.1.2, juntamente com as implicações mecanísticas envolvidas. 
Analisando-se a Fig. $15 \mathrm{c}$ percebe-se que as oscilações de $\theta_{C O_{L}}$ rel. desenvolvem-se numa faixa entre 0,22 e 0,27 monocamadas, aproximadamente. Este intervalo é

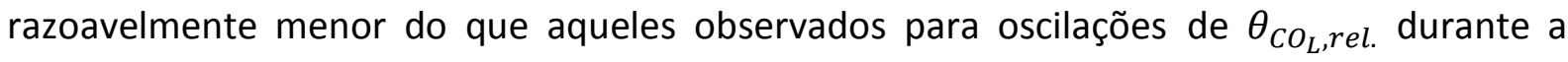
eletro-oxidação oscilatória de ácido fórmico [89], onde também foram registradas oscilações na intensidade da banda de formato adsorvido, sugerindo a participação desta espécie no mecanismo oscilatório. Estudos teóricos sobre sistemas dinâmicos [90] mostram que a ocorrência de oscilações mistas e/ou caos requer ao menos três variáveis independentes participantes no mecanismo responsável pelas instabilidades. Nos resultados aqui mostrados para a eletro-oxidação oscilatória de metanol reconhecem-se duas, recobrimento de monóxido carbono, Fig. 15b, e de espécies oxigenadas, estas dedutíveis da análise conjunta entre a Fig. 15b e a reação (21), já que o potencial da dupla camada ficaria determinado, majoritariamente, pelos inibidores superficiais. A ausência de uma terceira espécie adsorvida que participe ativamente das oscilações bem como o pequeno intervalo de fração de monocamada em que o monóxido de carbono oscila seriam causas prováveis da difícil observação de comportamentos mais complexos do que o harmônico durante a eletro-oxidação oscilatória de metanol, apesar do complexo mecanismo como discutido anteriormente e esquematizado na Fig. 11.

\subsubsection{Estudo da eletro-oxidação oscilatória de metanol por espectroscopia de infravermelho in situ utilizando eletrólito em fluxo}

Experimentalmente, tem-se registrado casos [91, 92] em que o comportamento oscilatório apresentado durante a eletro-oxidação de moléculas orgânicas pequenas sobre platina consegue permanecer estável sob condições de transporte de massa aumentado de espécies em solução para a superfície e vice-versa, sugerindo não essencialidade de intermediários solúveis para a observação dos processos oscilatórios. Para ácido fórmico, contudo, foi mostrado que a velocidade de rotação do eletrodo pode ser identificada como parâmetro de bifurcação entre diferentes padrões de oscilação [92]. Nesta subseção, 
apresentam-se resultados de eletro-oxidação de metanol sobre platina em meio de ácido perclórico obtidos usando-se uma célula de fluxo, com velocidade de, aproximadamente, 50 $\mu \mathrm{L} \mathrm{s}{ }^{-1}$, rápida o bastante para trocar todo o volume de solução da célula, $10 \mu \mathrm{L}$, em cerca de $4 \mathrm{~s}$, acoplada a um espectrômetro de radiação infravermelha (ver Cap.2 para detalhes) com o objetivo de monitorar a dinâmica de adsorbatos. ${ }^{10}$

Assim como para o ácido sulfúrico também em meio de ácido perclórico, $\mathrm{HClO}_{4}$ 0,5 M, se observam, durante varredura de potencial, os picos de corrente associados à adsorção/dessorção de hidrogênio sobre eletrodos de platina como se pode visualizar na Fig. 16a, onde a região hachurada, correspondente à dessorção de hidrogênio, foi utilizada para calcular a área real do eletrodo, $4 \mathrm{~cm}^{2}$, a partir da densidade de carga associada a uma monocamada de hidrogênio, $210 \mu \mathrm{C} \mathrm{cm}^{-2}$ [93]. A região de formação de óxido inicia-se em potenciais ligeiramente mais baixos do que no caso de ácido sulfúrico, uma consequência da menor força de adsorção do ânion perclorato, e consequente menor inibição, quando comparada àquela do ânion sulfato [94].

Na Fig. 16b exibe-se o espectro da interface eletrodo/solução obtido na condição de superfície saturada com $\mathrm{CO}_{\text {ads. }}$ Para tanto, o eletrodo foi polarizado a $50 \mathrm{mV}$ e o fluxo de eletrólito em curso pela célula foi trocado de $\mathrm{HClO}_{4}$ 0,5 $\mathrm{M}$ puro para outro contendo eletrólito saturado com $\mathrm{CO}_{(\mathrm{g})}$ por dez minutos, então, o fluxo foi trocado novamente para aquele contendo apenas eletrólito puro e, após trinta minutos, a coleta do espectro foi realizada. Desta forma, a máxima intensidade integrada das bandas referentes às espécies $\mathrm{CO}_{\mathrm{ads}}$, nesta superfície, foi encontrada pela eq. (11) ser de $4,44 \mathrm{~cm}^{-1}$. Este valor pode ser utilizado na eq. (12) para estimar o grau de recobrimento de $\mathrm{CO}_{\mathrm{L}}$ durante o experimento oscilatório a ser apresentado nesta subseção, Figs.17 a 19.

\footnotetext{
${ }^{10}$ Os experimentos desta subseção foram realizados no laboratório do Professor R. J. Behm, durante estágio na Universidade de Ulm, em Ulm - Alemanha, entre fevereiro e junho de 2012.
} 

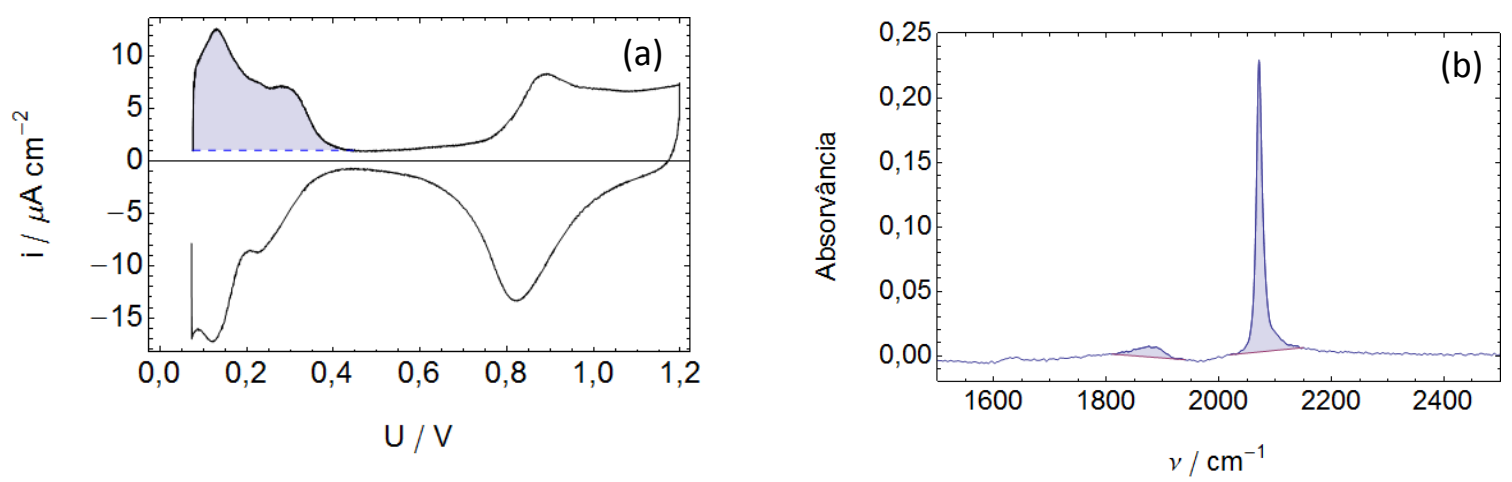

Figura 16 - (a) Voltamograma base do filme de platina, depositado sobre o prisma de $\mathrm{Si}$, em contato com $\mathrm{HClO}_{4}$ 0,5 M. Velocidade de varredura $=10 \mathrm{mV} \mathrm{s}^{-1}$. Corrente normalizada pela área real de $4 \mathrm{~cm}^{2}$. Velocidade de fluxo de eletrólito $\approx$ $50 \mu \mathrm{L} \mathrm{s}^{-1}$; (b) Espectro obtido com o eletrodo saturado com $\mathrm{CO}_{\text {ads }}$ e polarizado a $50 \mathrm{mV}$ em contato apenas com eletrólito, $\mathrm{HClO}_{4}$ 0,5 M. A soma entre a área da banda de $\mathrm{CO}_{\mathrm{L}}$ com duas vezes a de $\mathrm{CO}_{\mathrm{B}}$ resultou ser $4,44 \mathrm{~cm}^{-1}$. O espectro de referência foi coletado com o eletrodo polarizado a $60 \mathrm{mV}$ na presença apenas de eletrólito de suporte.

Células de fluxo permitem trocar a solução sem que o potencial do eletrodo deixe de ser controlado, isto possibilita o desenvolvimento de procedimentos rápidos e práticos para pré-tratamento da superfície que visem assegurá-la livre de adsorbatos estáveis previamente às medidas de interesse, favorecendo a reprodutibilidade dos experimentos e dissipando eventuais efeitos de "história do eletrodo" ao se partir sempre de condições iniciais próximas. Para o pré-tratamento dos resultados apresentados nesta subseção, o procedimento adotado consistiu em: realizar a limpeza da superfície, com o eletrodo em contato apenas com o eletrólito suporte a circular pelo sistema, via cerca de cinquenta ciclagens de potencial entre $50 \mathrm{mV}$ e $1200 \mathrm{mV}$ vs. ERH a uma taxa de $300 \mathrm{mV} \mathrm{s}^{-1}$; fixar o potencial em $0 \mathrm{~V}$, uma restrição do equipamento para se passar do controle de potencial para o de corrente; trocar o fluxo de eletrólito de suporte para aquele contendo também a molécula de estudo; aplicar 0 A para se passar para o controle de corrente; e, finalmente, aplicar a corrente de interesse.

Desta forma, valendo-se da vantagem proporcionada pela célula de fluxo, conduziuse experimento galvanostático precedido pelo pré-tratamento descrito acima. Iniciando-se com o eletrodo (também, como na Subseção 3.1.1, um filme de platina depositado sobre um prisma de silício, mas desta vez hemicilíndrico) em contato apenas com o eletrólito suporte $\mathrm{HClO}_{4}$ 0,5 M, procedeu-se a limpeza eletroquímica da superfície, trocou-se a solução para a 
de interesse, contendo metanol a uma concentração de $\mathrm{CH}_{3} \mathrm{OH} \mathrm{0,1} \mathrm{M}$, e aplicou-se uma densidade de corrente de $0,62 \mathrm{~mA} \mathrm{~cm}^{-2}$, Fig. 17. Após um aumento abrupto, devido ao envenenamento superficial causado pela formação de $\mathrm{CO}_{\mathrm{ads}}$, o potencial entra em estado quase-estacionário que, após cerca de $75 \mathrm{~s}$, desestabiliza-se para dar origem a oscilações sustentadas. Visando obter informações sobre a dinâmica dos adsorbatos, simultaneamente ao experimento eletroquímico foram coletados espectros in situ da interface eletrodo/solução, com resolução temporal de 0,24 s. Da mesma forma como no caso da Subseção 3.1.1 foi possível observar bandas relativas a monóxido de carbono adsorvido linearmente e a mais de um sítio, bem como formato adsorvido em ponte, $\mathrm{HCOO}_{a d s}$. Para comparação com o perfil de potencial também são representadas na Fig. 17 o comportamento temporal das intensidades integradas das bandas de $\mathrm{CO}_{\mathrm{L}}$ (vermelho), $\mathrm{CO}_{\mathrm{B}}$ (verde), $\mathrm{HCOO}_{\mathrm{ads}}$ (laranja), além da variação da posição da banda de $\mathrm{CO}_{\mathrm{L}}$ (azul).

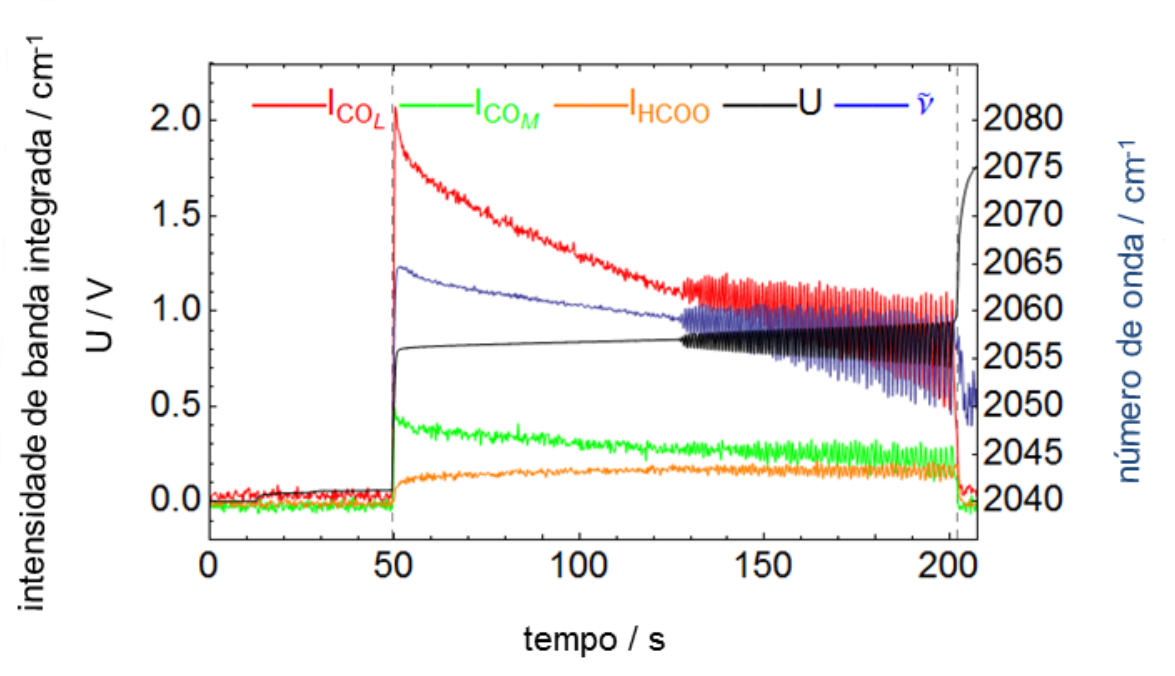

Figura 17: Evolução temporal do potencial (preto), posição da banda de $\mathrm{CO}_{\mathrm{L}}$ (azul) e intensidades integradas de $\mathrm{CO}_{\mathrm{L}}$ (vermelho), $\mathrm{CO}_{\mathrm{B}}$ (verde) e formato (laranja) adsorvidos durante eletro-oxidação galvanostática de $\mathrm{CH}_{3} \mathrm{OH} 0,1 \mathrm{M}+$ $\mathrm{HClO}_{4} 0,5 \mathrm{M}$ a 0,62 mA cm${ }^{-2}$ (aplicada em $\mathrm{t}=50 \mathrm{~s}$ ). 
Em concordância com o que foi observado no caso de ácido sulfúrico e eletrólito estagnado, Subseção 3.1.1, durante o experimento galvanostático a intensidade integrada da banda de $\mathrm{CO}_{\mathrm{L}}$ decresce, de forma contínua no período de indução e em média dentro do regime oscilatório. Já as intensidades integradas de $\mathrm{CO}_{\mathrm{B}}$ e formato não apresentam variação apreciável; contudo, como se pode observar de forma mais clara na Fig. 19, elas também oscilam. As Figs. 18 e 19 apresentam regiões ampliadas do eixo temporal, em intervalos de dez segundos, no início e no fim do regime oscilatório apresentado na Fig. 17, mostrando também os respectivos espectros na região das bandas de $\mathrm{CO}_{\mathrm{L}}$ e formato adsorvido. $\mathrm{O}$ comportamento da intensidade integrada da banda de $\mathrm{CO}_{\mathrm{L}}$ é muito próximo daquele exibido no caso de ácido sulfúrico, com seus mínimos precedendo os de potencial durante as oscilações. Com relação à espécie formato os mínimos de sua intensidade integrada acontecem após os mínimos de potencial. Percebe-se, nestas visões ampliadas, que também neste caso a posição da banda de $\mathrm{CO}_{\llcorner}$oscila em fase com as ondas de potencial, sugerindo boa sincronização entre os dados eletroquímicos e espectroscópicos. 


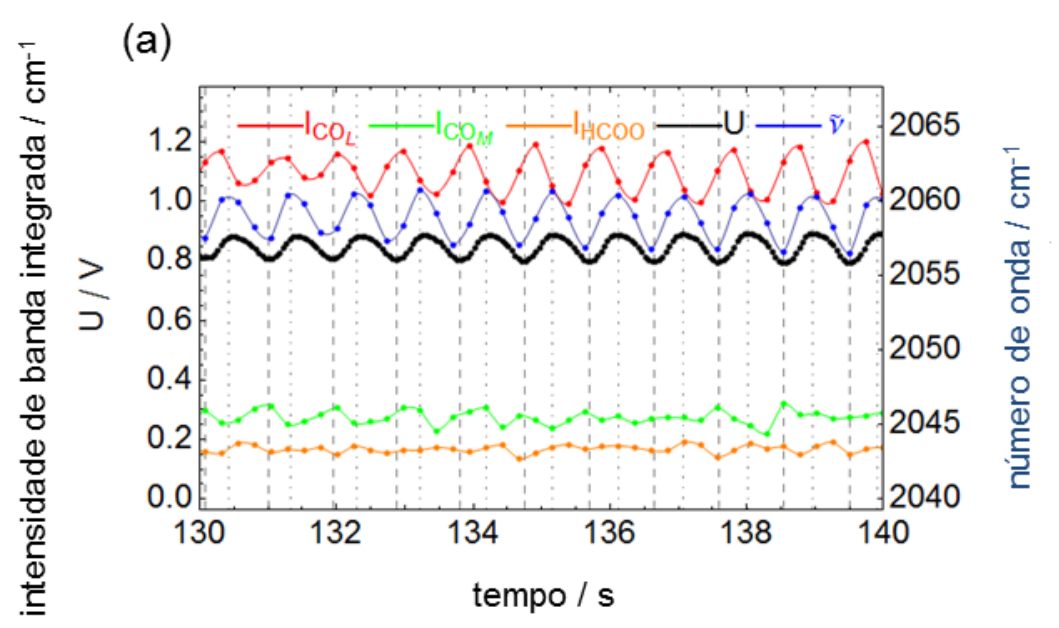

(b)

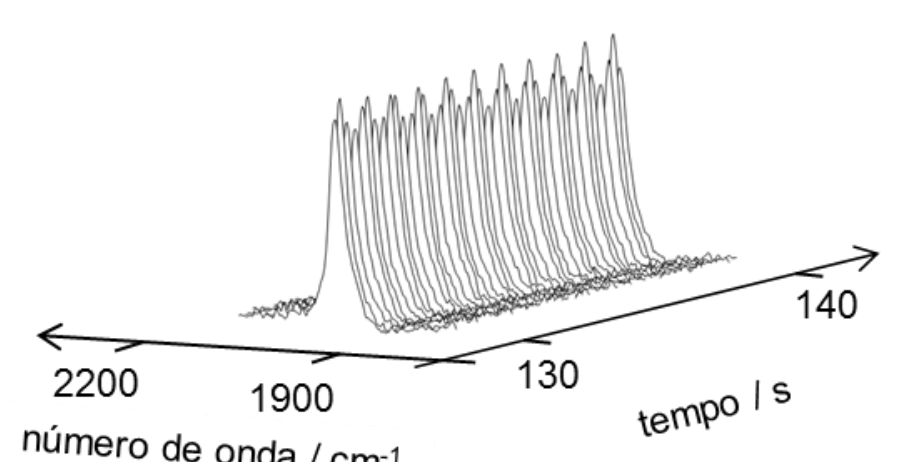

(c)

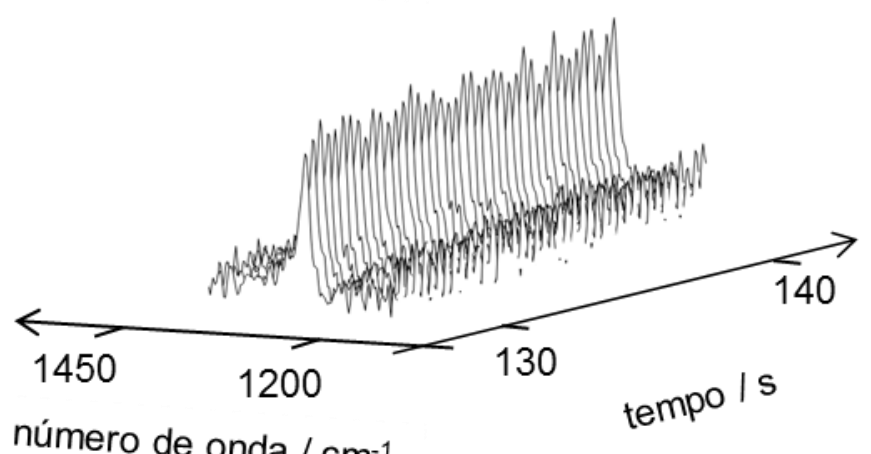

número de onda $/ \mathrm{cm}^{-1}$

Figura 18 - (a) Visão ampliada da Fig. 17 e respectivos espectros na região de número de onda de (b) $\mathrm{CO}_{\mathrm{L}}$ e (c) formato entre 130 e $140 \mathrm{~s}$.

Como exposto na Subseção 3.1.1 o papel de veneno catalítico do monóxido de carbono adsorvido é amplamente aceito, já o papel do formato adsorvido como intermediário reativo ainda motiva debates $[63,68,70,72,73]$. Diante disso, quando se compara o perfil das intensidades integradas de $\mathrm{CO}$ e $\mathrm{HCOO}$ adsorvidos durante as 
oscilações, Fig. 19, percebe-se que suas ondas estão em anti-fase, o que sugeriria que eles desempenham papéis opostos no mecanismo de eletro-oxidação de metanol.

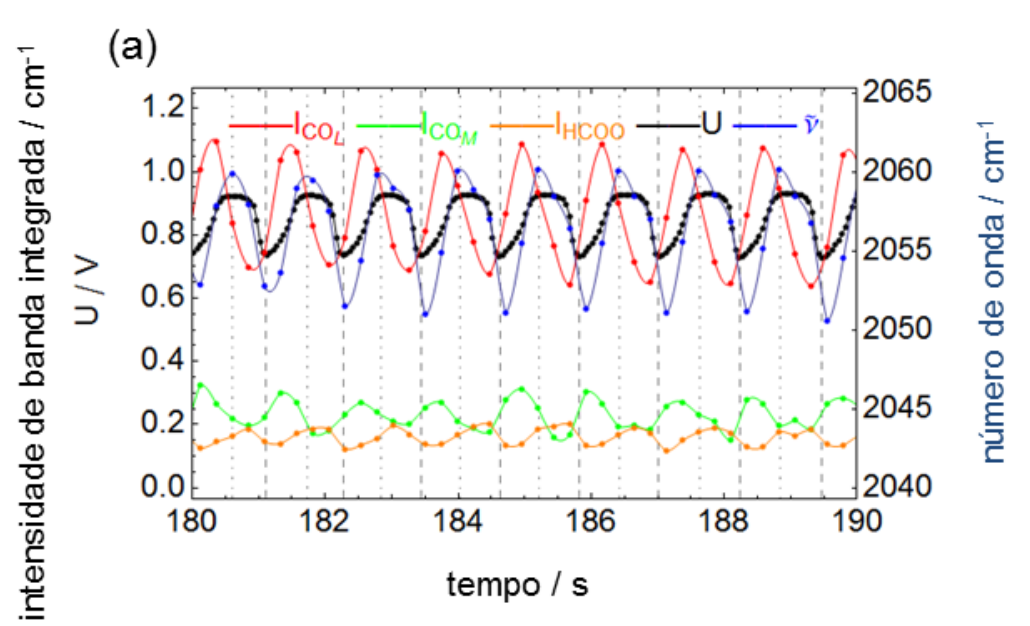

(b)

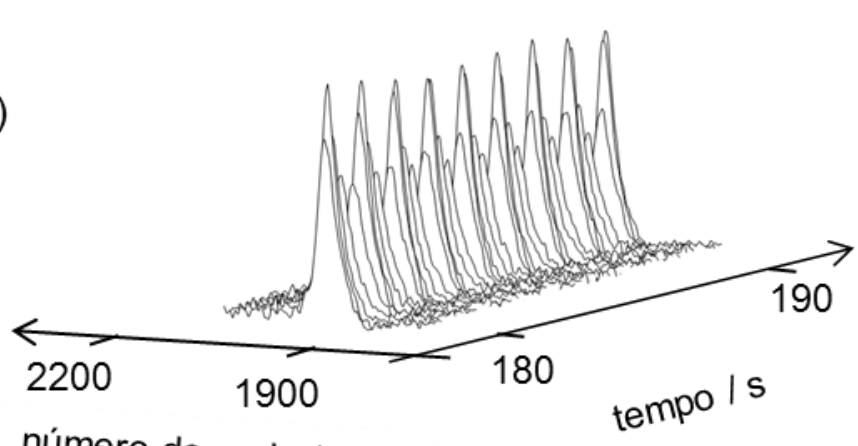

número de onda $/ \mathrm{cm}^{-1}$

(c)

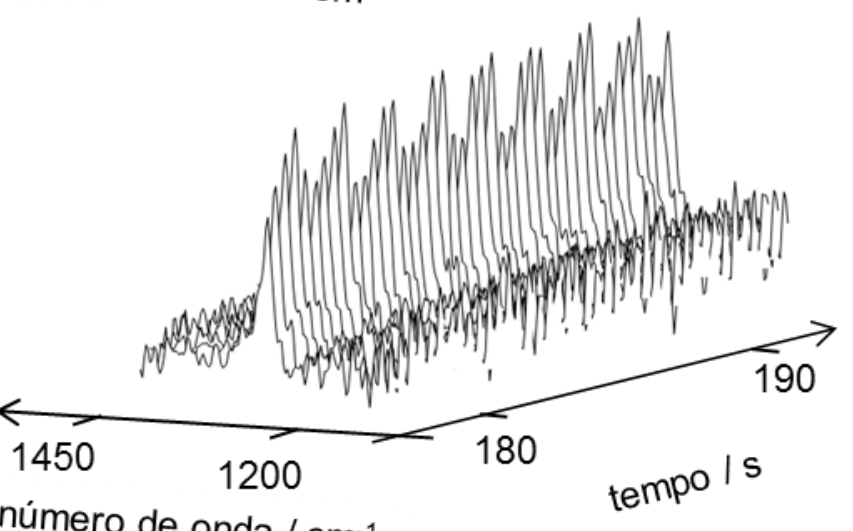

número de onda $/ \mathrm{cm}^{-1}$

Figura 19 - (a) Visão ampliada da Fig. 17 e respectivos espectros na região de número de onda de (b) $\mathrm{CO}_{\mathrm{L}}$ e (c) formato entre 180 e $190 \mathrm{~s}$. 
Uma possibilidade de aprofundar esta discussão consiste em selecionar algumas das etapas reacionais propostas na Fig. 11 e usá-las para compor um modelo cinético que, sujeito a integração numérica, forneceria os comportamentos teoricamente esperados para os recobrimentos de $\mathrm{CO}_{\mathrm{L}}, \mathrm{CO}_{\mathrm{B}}$ e $\mathrm{HCOO}$ permitindo comparação com os resultados experimentais e, então, chegar a conclusões sobre o mecanismo oscilatório [54]. Um caminho alternativo consiste em pensar no comportamento qualitativo das derivadas positiva e negativa do potencial, uma vez que elas podem, em um experimento galvanostático, ser associadas a diferentes formas de circulação de carga pela interface eletrodo/solução. A corrente total é a soma das correntes faradaica, decorrente da transferência de elétrons entre espécies químicas em solução e o eletrodo, e capacitiva, consequência da acomodação de cargas opostas na interface eletrodo/solução. Esta última ocorre, geralmente, quando a cinética das reações é insuficiente para manter a corrente exigida pelo controle externo, assim, poder-se-ia estimar que, na ausência de limitação por transporte de massa, a corrente capacitiva é proporcional à extensão do bloqueio superficial por venenos catalíticos. Ademais, assumindo uma forma aproximada para a corrente faradaica em que esta dependa do produto entre uma constante genérica $k$, que represente a quantidade de material reativo na interface bem como a eficiência de suas colisões reacionais com o eletrodo, e o termo $\left(1-\theta_{C O_{L}, r e l .}\right)$ representando a área do eletrodo disponível para reação, ter-se-ia:

$$
I_{C} \propto \frac{d \phi}{d t}=\frac{d U}{d t} \approx I_{T}-k\left(1-\theta_{C O_{L}, r e l .}\right)
$$

ou seja,

$$
\frac{d U}{d t} \propto \theta_{C O_{L}}
$$

em que a derivada do potencial medido foi igualada à derivada do potencial interno porque $\phi$ difere de $\mathrm{U}$ por $I_{T} R_{\Omega}$, um valor constante em medidas galvanostáticas e, por conseguinte, com derivada nula. Desta forma, ao se representar a derivada do potencial deveria obter-se, então, o perfil qualitativo do recobrimento de $\mathrm{CO}_{\mathrm{L}}$. De posse dos valores de potencial 
apresentados na Fig. 17 não é difícil obter uma função de interpolação que possa ser derivada, resultando na curva vermelha da Fig. 20a que, ao ser comparada com a Fig. 19 revela uma similaridade com o comportamento de $\theta_{C O_{L}}$ aquém da esperada se as suposições feitas acima fossem válidas. Contudo, há que se considerar que os dados espectroscópicos da Fig. 17 foram coletados com resolução temporal de $240 \mathrm{~ms}$, ou seja, os pontos representam a média das intensidades em intervalos igualmente espaçados com esta resolução. Assim, a fim de simular a obtenção dos resultados teóricos com a mesma resolução experimental pode-se dividir a curva da derivada do potencial da Fig. 20a em intervalos de 240 ms e ao se calcular a média dos valores neles compreendidos, obter uma nova curva, Fig. 20b, que se aproxima daquela apresentada na Fig. 19 para $\theta_{C O_{L}, r e l .}$. A concordância entre estes resultados tem duas implicações: primeiro, a resolução temporal de 240 ms seria insuficiente para determinar com fidelidade a amplitude e a forma das ondas de recobrimento de monóxido de carbono durante oscilações de potencial com período comparável aos da Fig. 19 (para conhecimento, uma resolução temporal de 60 ms bastaria para definir o perfil contínuo da derivada do potencial para este caso); segundo, fortaleceria a hipótese de que $\mathrm{CO}_{\mathrm{ads}}$ é o principal inibidor da oxidação das espécies eletroativas durante o desenvolvimento das oscilações.
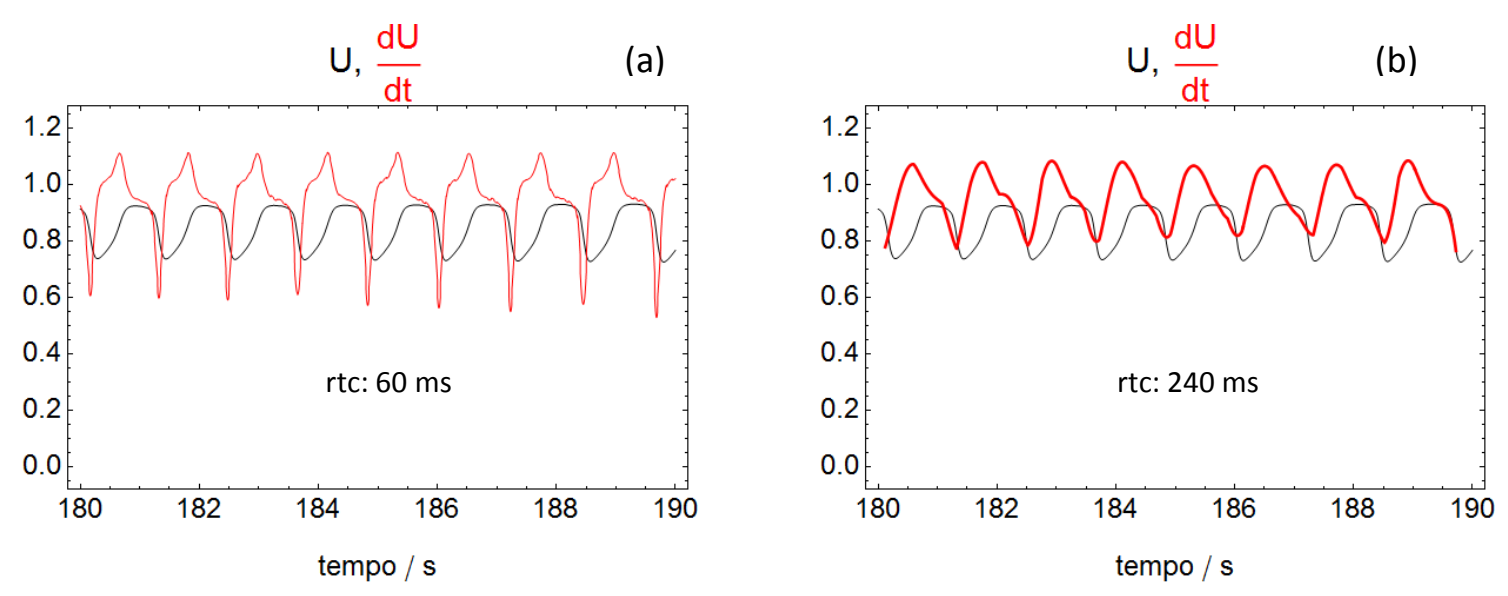

Figura 20 - Perfis temporais das oscilações de potencial (preto) observadas na Fig. 17 e suas derivadas (vermelho) com resolução temporal considerada ( $\mathrm{rtc}$ ) de (a) 60 e (b) $240 \mathrm{~ms}$. 
Uma análise similar pode ser feita com relação à derivada negativa do potencial. Da equação de continuidade de corrente tem-se

$$
I_{f}=I_{t}-C \frac{d U}{d t}
$$

de modo que, à parte do valor da corrente aplicada, uma constante que não interfere na posição de máximos e mínimos, a corrente faradaica é proporcional ao negativo da corrente capacitiva ou, de modo equivalente, ao negativo da derivada do potencial. Assim, pode-se representar $-\frac{d U}{d t}$ vs. $\mathrm{t}$ e comparar qualitativamente seu perfil com o da intensidade integrada de formato adsorvido, que é candidato a intermediário reativo. A Fig. 21 exibe a representação de potencial com sua derivada negativa e, novamente, se fez um tratamento para simular uma coleta de dados com a resolução temporal empregada experimentalmente. A comparação entre as Fig. 19 e 21b, sugere que corrente faradaica e $I_{\text {HCoO }}$ têm o mesmo comportamento temporal, com seus mínimos acontecendo após aqueles do potencial.
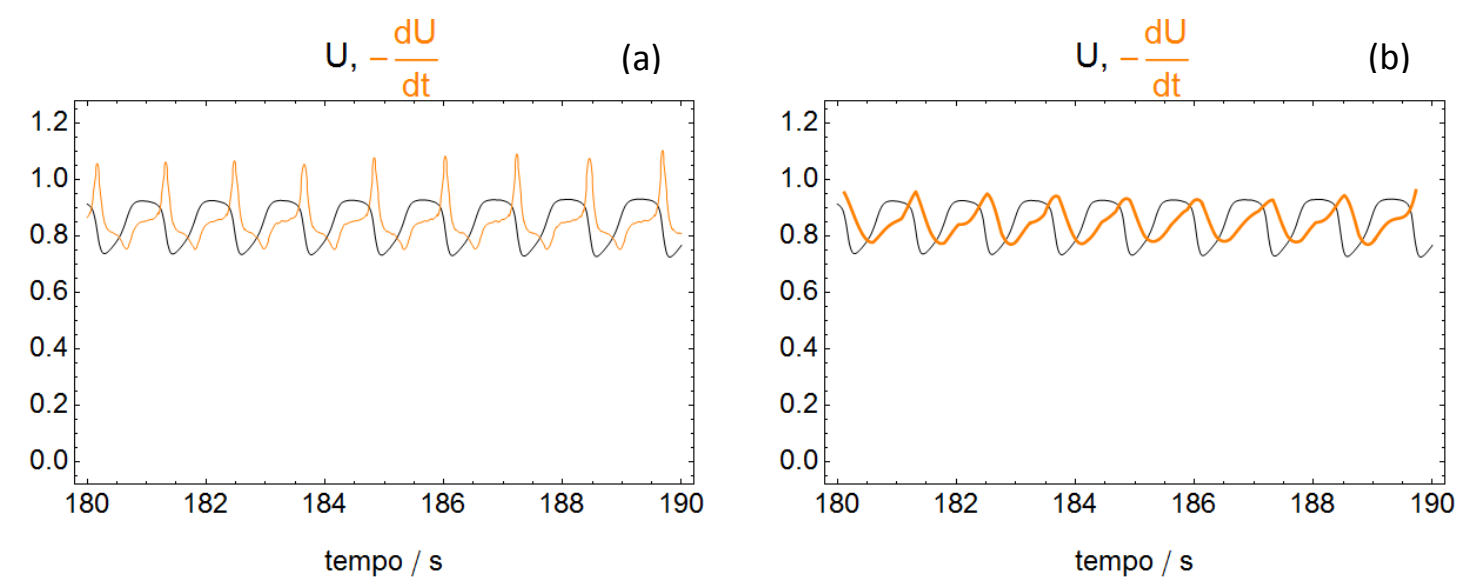

Figura 21 - Perfis temporais das oscilações de potencial (preto) observadas na Fig. 17 e do negativo de suas derivadas (laranja) com resolução temporal considerada de (a) 60 e (b) 240 ms. 
Contudo, isto não é suficiente para identificar a espécie formato adsorvido em ponte como intermediário reativo; pode ser que, tal como acontece com o acetato durante a eletro-oxidação de etanol [95], ele aja apenas como um expectador cuja adsorção é modulada pela disponibilidade de sítios e pelo potencial. Também, se as oscilações no recobrimento de formato refletissem uma participação ativa no mecanismo oscilatório, seria esperada, mais facilmente, a observação de oscilações mistas durante a eletro-oxidação de metanol. A frustração desta expectativa sugere que a dinâmica do recobrimento de formato não é uma variável essencial do mecanismo oscilatório.

Portanto, em termos de processos superficiais, as oscilações podem ser entendidas da seguinte forma: quando o potencial começa a cair, indício de liberação de sítios superficiais, $\mathrm{CO}_{\mathrm{ads}}$ começa a se formar e acumular até que o potencial cresça o bastante ao ponto de produzir espécies oxigenadas adsorvidas em quantidade suficiente para consumirem $\mathrm{CO}_{\mathrm{ads}}$ numa velocidade maior que a formação deste último. $\mathrm{O}$ fato que o potencial se mantenha mais tempo em altos valores do que em baixos pode significar que a fração da superfície disponível para novas adsorções está reduzida ou que vias pouco eficientes na produção de elétrons estão sendo favorecidas, como a formação de formaldeído.

Algo a se notar é o decréscimo na posição da banda de $\mathrm{CO}_{\mathrm{L}}$ com o aumento do potencial durante o período de indução. É bem conhecido que a posição de bandas de espécies adsorvidas desloca-se em $29 \mathrm{~cm}^{-1}$ para cada aumento de $1 \mathrm{~V}$ no potencial do eletrodo [88]. Assim, a taxa de queda de $-111.4 \mathrm{~cm}^{-1} \mathrm{~V}^{-1}$ observada no período de indução, Fig. 22, só pode ser explicada por um relaxamento na interação dipolo-dipolo, o que equivale a dizer que as moléculas de $\mathrm{CO}_{\text {ads }}$ ficam mais distantes com o passar do tempo e que não há tendência para formação de ilhas de monóxido de carbono [96]. Isto exclui o condicionamento à formação de padrões espaciais de $\mathrm{CO}_{\llcorner}$para a observação das oscilações temporais desenvolvidas durante a eletro-oxidação de metanol. Dentro do regime oscilatório, como pode ser visto também na Fig. 17, a taxa de variação volta a se aproximar de $29 \mathrm{~cm}^{-1} \mathrm{~V}^{-1}$ uma vez que a variação no potencial é bem mais significativa do que aquela observada no período de indução e predomina sobre o efeito da interação dipolo-dipolo. 


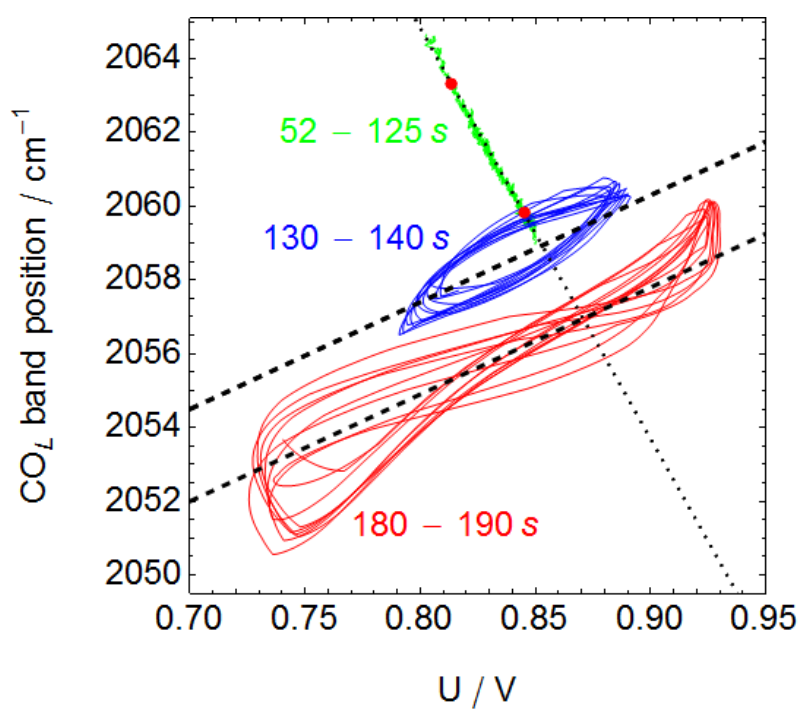

Figura 22 - Representação da posição da banda de $\mathrm{CO}_{\mathrm{L}}$ em função do potencial em três diferentes intervalos de tempo, no período de indução (verde), após o início (azul) e próximo do fim (vermelho) das oscilações. O coeficiente angular da reta pontilhada é de $-111.4 \mathrm{~cm}^{-1} \mathrm{~V}^{-1}$ e o coeficiente angular das linhas tracejadas é de $29 \mathrm{~cm}^{-1} \mathrm{~V}^{-1}$.

A posição da banda é diretamente proporcional à energia de vibração da molécula adsorvida, que, por sua vez, depende da interação com seu ambiente imediato. Assim, quando uma molécula de CO é cercada por outras iguais a ela, com quem não compartilha densidade eletrônica, ela reserva mais energia para vibrar do que uma molécula de CO que realiza interações com seu meio, Fig. 23. A mesma conclusão pode ser atingida analisando a derivada total da posição da banda ao se considerar que ela é função apenas do potencial do eletrodo e do recobrimento de CO:

$$
d \vartheta=\left(\frac{\partial \vartheta}{\partial U}\right)_{\theta_{C O}} d U+\left(\frac{\partial \vartheta}{\partial \theta_{C O}}\right)_{U} d \theta_{C O}
$$

tomando-se a derivada em $U$, obtém-se: 


$$
\begin{array}{|c|c|c|}
\hline \frac{d \vartheta}{d U} & =\left(\begin{array}{c|c|}
\left(\frac{\partial \vartheta}{\partial U}\right) \\
-111
\end{array}\right. \\
29
\end{array} \quad \begin{array}{cc}
\left(\frac{\partial \vartheta}{\partial \theta_{C O}}\right) & \frac{d \theta_{C O}}{d U} \\
>0 & <0 \\
\hline
\end{array}
$$

Sabendo-se, a partir dos resultados apresentados na Fig. 17 e 22, que, na região do período de indução, o termo do lado esquerdo da igualdade é negativo e, da literatura [88], que o primeiro termo do lado direito é positivo, só resta ao segundo termo da direita ser negativo e superior em módulo a $\frac{\partial \vartheta}{\partial U}$. Como, também pela Fig. 17, sabe-se que o recobrimento de monóxido de carbono está diminuindo durante o período de indução, conclui-se que o coeficiente $\left(\frac{\partial \vartheta}{\partial \theta_{C O}}\right)$ deve ser positivo, ou seja, um aumento no recobrimento de CO reflete-se em aumento na posição da banda da molécula adsorvida.

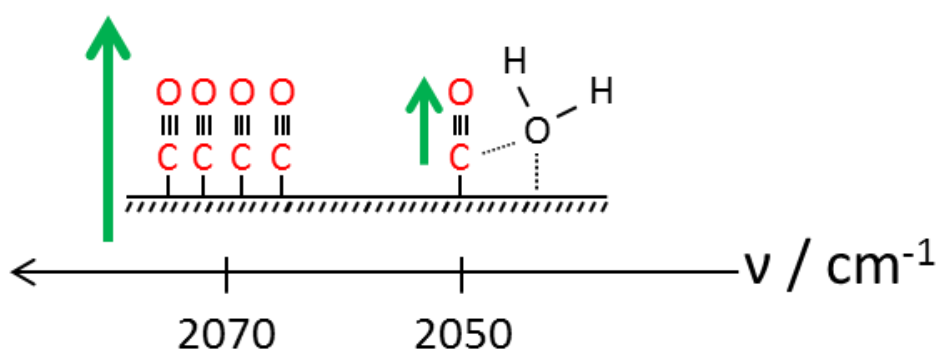

Figura 23 - Esquema ilustrando efeito da repulsão lateral na força de vibração de moléculas de $\mathrm{CO}$ adsorvidas. O tamanho das setas em verde indica a magnitude relativa da energia de vibração. 


\subsubsection{Influência da presença extra de espécies oxigenadas sobre a eletro-oxidação oscilatória de metanol sobre platina}

Diante dos indícios de que o acúmulo de espécies oxigenadas, na forma de ilhas de $\mathrm{Pt}_{-} \mathrm{OH}_{\mathrm{x}}$ ou na forma de $\mathrm{O}_{\text {sub }}-\mathrm{Pt}$, é o responsável por desestabilizar as oscilações observadas durante a eletro-oxidação de metanol e limitar sua duração, projetou-se um experimento para testar esta hipótese, o qual consiste em perturbar a presença de espécies oxigenadas no sistema. A investigação teve início com a escolha da maneira pela qual realizar a perturbação. Entre as possíveis incluem-se aumento do $\mathrm{pH}$, fluxo controlado de oxigênio através da solução e adição de peróxido de hidrogênio. A primeira possibilidade pode afetar consideravelmente o mecanismo da eletro-oxidação de metanol, o que invalidaria o estudo. A segunda possibilidade além de requerer certo aparato experimental também tem o limitante da concentração máxima atingível de oxigênio dissolvido ser da ordem de $1 \mathrm{mM}$, por exemplo, exatamente este valor é obtido a $42{ }^{\circ} \mathrm{C}$ e $1 \mathrm{~atm}$ [97]. Baixar a temperatura poderia aumentar a concentração de saturação do oxigênio dissolvido mas também traz a inconveniência de alterar o mecanismo e/ou a cinética de reação. Isto posto, optou-se pela terceira alternativa visto que, como será mostrado adiante, com a adição de peróxido de hidrogênio tais problemas são minimizados.

O primeiro fato a considerar é o da presença de peróxido de hidrogênio não desencadear processos limitados ou promovidos por potencial na faixa em que as oscilações normalmente se desenvolvem, isto é, entre 0,6 e 0,8 V. Isto pode ser visualizado na Fig. 24 que apresenta curvas de varreduras positivas, com potencial de reversão em 0,8 V, do potencial do eletrodo de platina em contato com soluções crescentemente concentradas em peróxido de hidrogênio, $\mathrm{H}_{2} \mathrm{SO}_{4} 0,5 \mathrm{M}+\mathrm{H}_{2} \mathrm{O}_{2} \times \mathrm{mM}$, com x $=0,1,2,3,4,5$. O que se nota é que a forma do voltamograma base de $\mathrm{H}_{2} \mathrm{SO}_{4}$ 0,5 $\mathrm{M}$ é pouco afetada pela crescente adição de $\mathrm{H}_{2} \mathrm{O}_{2}$, embora ele seja deslocado para valores mais catódicos de corrente. Isto ocorre porque a etapa determinante da redução do peróxido de hidrogênio entre 0,05 e 0,8 V seria sua adsorção dissociativa [98]: 
uma etapa química e, logo, independente do potencial, ainda mais porque $\mathrm{H}_{2} \mathrm{O}_{2}$ é uma molécula neutra. Uma vez formado, o Pt-OH seria reduzido a água [98]:

$$
\mathrm{Pt}-\mathrm{OH}+\mathrm{H}^{+}+\mathrm{e}^{-} \rightarrow \mathrm{Pt}+\mathrm{H}_{2} \mathrm{O}
$$

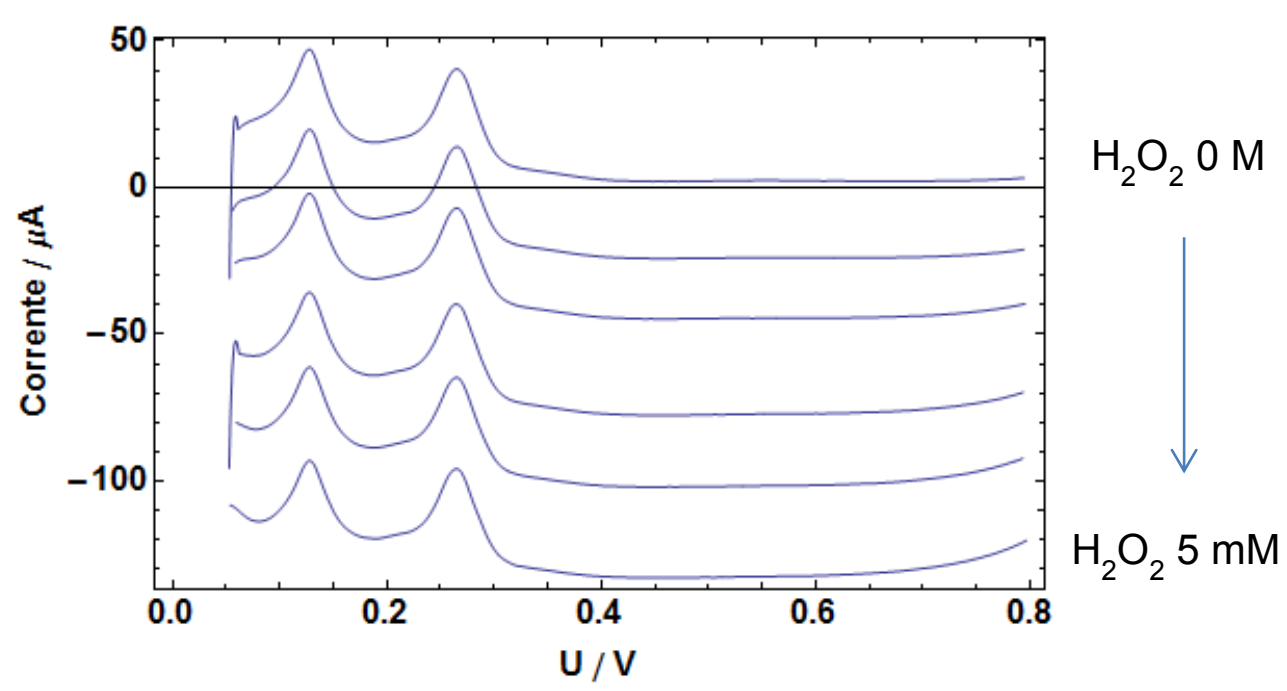

Figura 24 - Varreduras positivas a $50 \mathrm{mV} / \mathrm{s}$ do potencial do eletrodo de Pt em contato com $\mathrm{H}_{2} \mathrm{SO}_{4} 0,5 \mathrm{M}+\mathrm{H}_{2} \mathrm{O}_{2} \times \mathrm{mM}, \mathrm{x}=0,1,2,3,4,5$. Potencial limite superior ou de reversão da voltametria $\left(U_{\text {rev }}\right)=0,8 \mathrm{~V}$.

Desta forma, a adição de peróxido de hidrogênio ao sistema Pt $/ \mathrm{H}_{2} \mathrm{SO}_{4} 0,5 \mathrm{M}$ não ocasiona processos limitados ou promovidos por potencial na faixa de $U$ relevante para este estudo, servindo-o oportunamente ao desempenhar apenas um papel de provedor de espécies oxigenadas na superfície do catalisador.

Por outro lado, quando o potencial de reversão é aumentado para 1,4 V, Fig. 25, a varredura positiva exibe uma grande corrente anódica, cerca do triplo daquela observada no voltamograma base. Ela vem da produção de oxigênio catalisada pelas espécies oxigenadas superficiais [99]: 


$$
\begin{aligned}
& \text { Pt- } \mathrm{OH}+\mathrm{H}_{2} \mathrm{O}_{2} \rightarrow\left[\mathrm{Pt}-\mathrm{OH}\left(\mathrm{H}_{2} \mathrm{O}_{2}\right)_{\text {ads }}\right] \\
& {\left[\mathrm{Pt}-\mathrm{OH}\left(\mathrm{H}_{2} \mathrm{O}_{2}\right)_{\text {ads }}\right] \rightarrow \mathrm{Pt}+3 / 2 \mathrm{O}_{2}+3 \mathrm{H}^{+}+3 \mathrm{e}^{-}}
\end{aligned}
$$

Na varredura negativa, Fig. 25b, observa-se uma grande corrente catódica correspondente à redução de óxido e oxigênio formados na varredura positiva:

$$
\mathrm{O}_{2}+2 \mathrm{Pt} \rightarrow 2 \mathrm{Pt}-\mathrm{O}
$$

$$
\mathrm{Pt}-\mathrm{O}+2 \mathrm{H}^{+}+2 \mathrm{e}^{-} \rightarrow \mathrm{Pt}+\mathrm{H}_{2} \mathrm{O}
$$
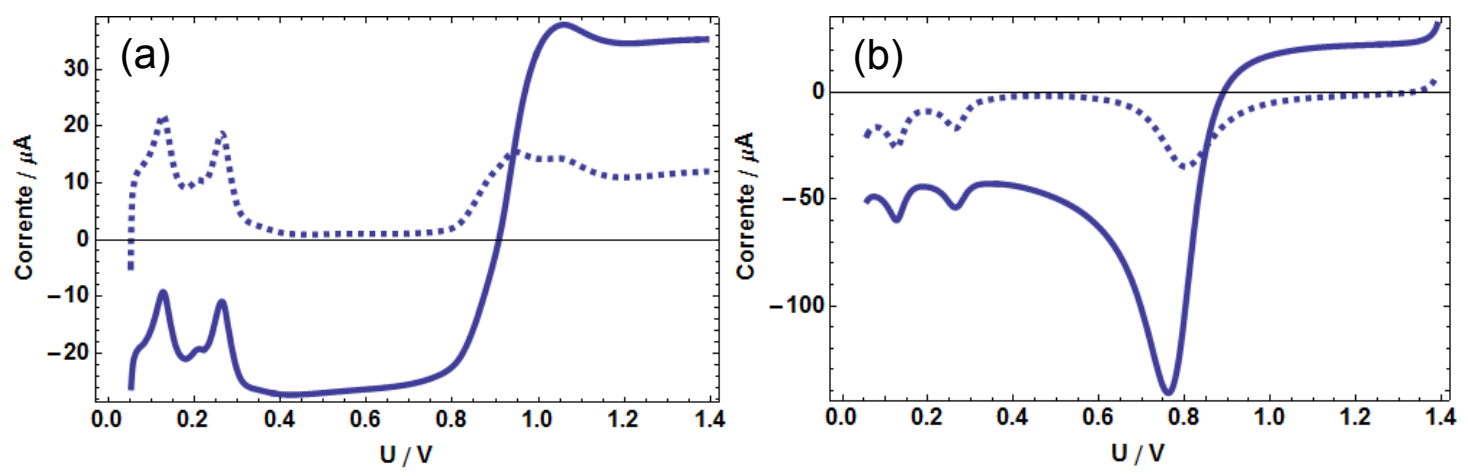

Figura 25 - Varreduras, a $25 \mathrm{mV} / \mathrm{s}$, de ida (a) e volta (b) do potencial do eletrodo de Pt na presença de $\mathrm{H}_{2} \mathrm{SO}_{4} 0,5 \mathrm{M}$ (linha tracejada) e de $\mathrm{H}_{2} \mathrm{SO}_{4} 0,5 \mathrm{M}+\mathrm{H}_{2} \mathrm{O}_{2} 1$ $\mathrm{mM}$ (linha contínua).

Um modo de avaliar o quanto a presença de peróxido de hidrogênio afeta a eletrooxidação de metanol é comparar um voltamograma hipotético, obtido pela soma aritmética das correntes obtidas em voltamogramas apenas com metanol, Fig. 26a, e apenas com peróxido de hidrogênio, Fig. 26b, com o voltamograma experimental onde as duas espécies estão presentes ao mesmo tempo na solução. Haveria perfeita sobreposição das curvas se peróxido de hidrogênio, metanol e seus intermediários de reação não influenciassem uns nas reações dos outros, ou seja, se os processos fossem independentes. Isto não é esperado e não acontece, como se pode ver na Fig. 26c, onde se compara o voltamograma 
experimental com o hipotético. Nota-se que a oxidação de metanol é antecipada por cerca de $65 \mathrm{mV}$ pela presença de $\mathrm{H}_{2} \mathrm{O}_{2}$ 0,001 M, possivelmente consequência da (eletro-) oxidação de monóxido de carbono antecipada por espécies oxigenadas fornecidas pela adsorção dissociativa do peróxido de hidrogênio, reação (40).
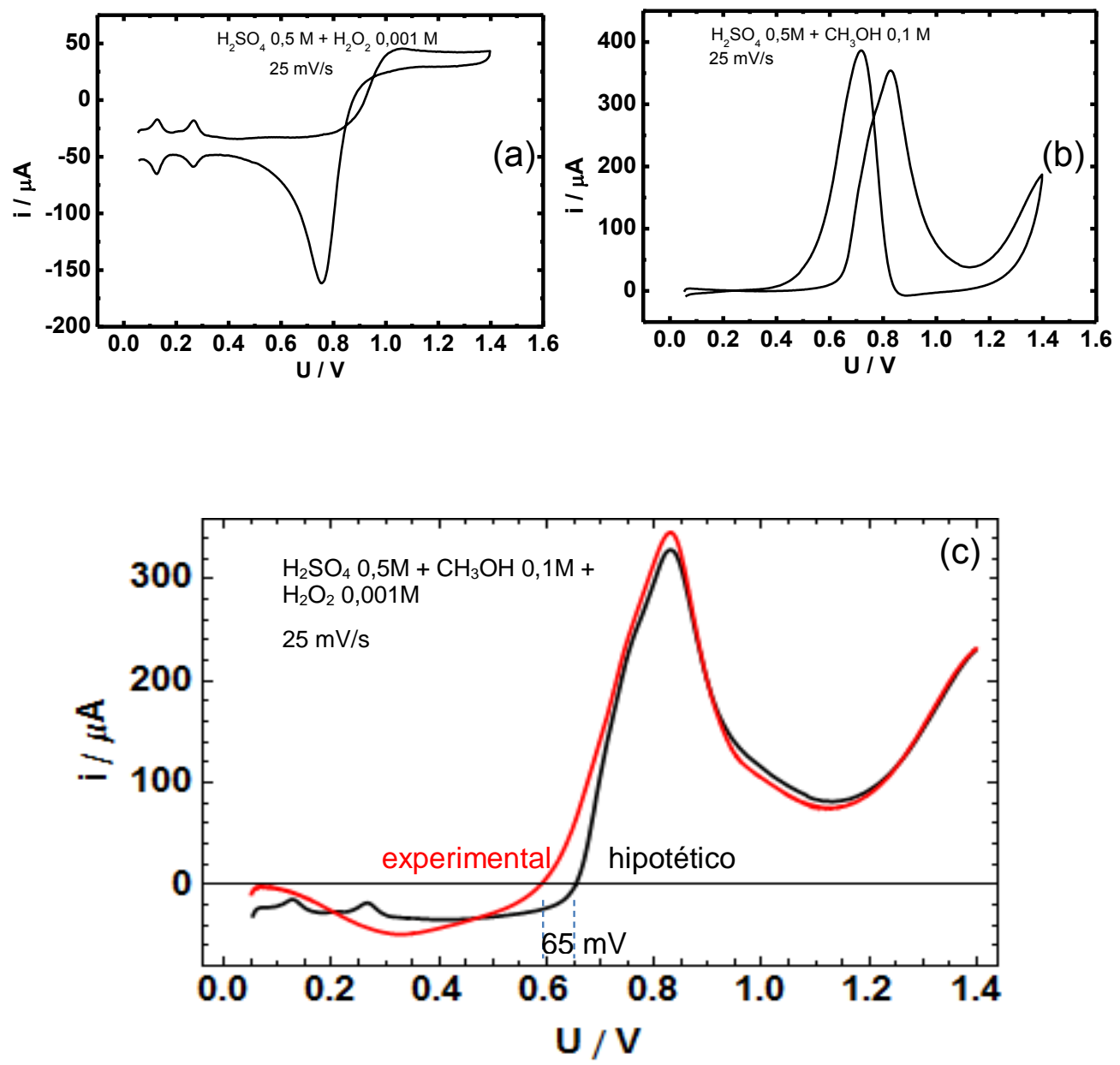

Figura 26 - Voltamogramas a $25 \mathrm{mV} / \mathrm{s}$ do eletrodo de platina em contato com (a) $\mathrm{H}_{2} \mathrm{SO}_{4} 0,5 \mathrm{M}+\mathrm{H}_{2} \mathrm{O}_{2} \quad 0,001 \mathrm{M}$, (b) $\mathrm{H}_{2} \mathrm{SO}_{4} 0,5 \mathrm{M}+\mathrm{CH}_{3} \mathrm{OH} \mathrm{0,1} \mathrm{M}$ e varredura positiva, a $25 \mathrm{mV} / \mathrm{s}$, prevista e experimental (ver texto) do sistema misto $\mathrm{H}_{2} \mathrm{SO}_{4}$ $0,5 \mathrm{M}+\mathrm{H}_{2} \mathrm{O}_{2} 0,001 \mathrm{M}+\mathrm{CH}_{3} \mathrm{OH} 0,1 \mathrm{M}$.

Esta presença adicional de espécies oxigenadas na superfície propiciada pelo peróxido de hidrogênio tem fortes conseqüências sobre a dinâmica oscilatória. Como exemplo, na presença de $\mathrm{H}_{2} \mathrm{O}_{2}$ 0,005 M para uma corrente aplicada de $140 \mu \mathrm{A}$ existe uma redução de mais de $90 \%$ (Fig. $27 \mathrm{~b}$ ) no número de ciclos apresentados quando se compara com o resultado em que o eletrodo está em contato apenas com $\mathrm{CH}_{3} \mathrm{OH} 0,1 \mathrm{M}$ dissolvido no 
eletrólito de suporte, Fig. 27a. Isto sugere fortemente que o recobrimento de espécies oxigenadas possui papel central na desestabilização das séries oscilatórias observadas durante a eletro-oxidação de metanol. Mais dados sobre a redução do número de ciclos são apresentados na Fig. 28b.
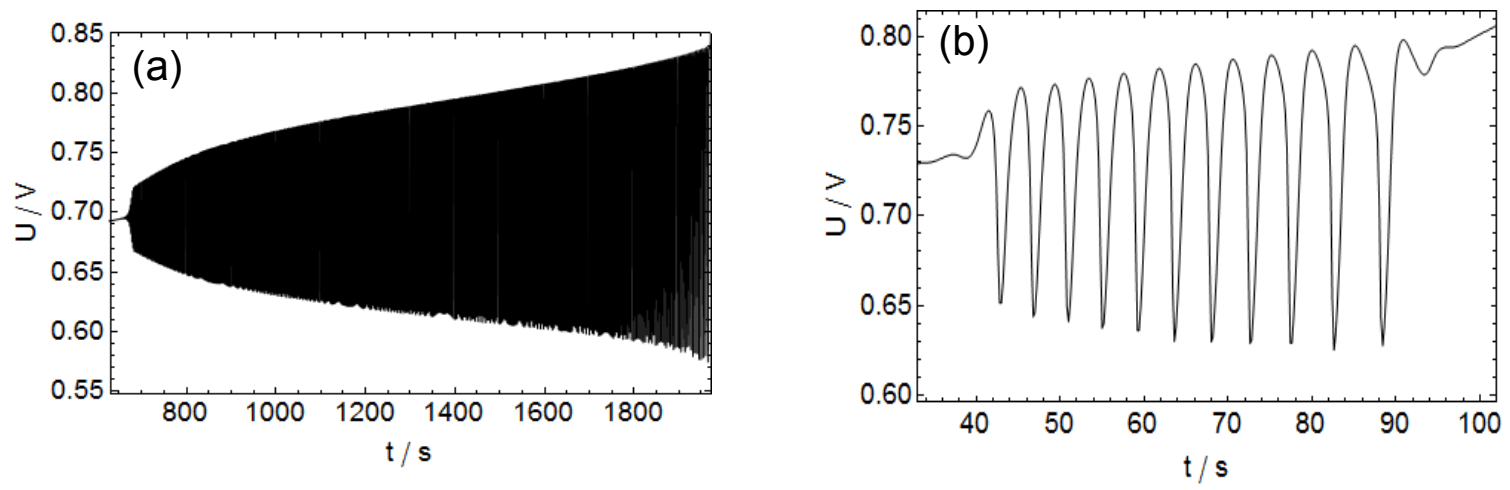

Figura 27 - Oscilações de potencial sob corrente aplicada de $140 \mu \mathrm{A}$ para (a) $\mathrm{H}_{2} \mathrm{SO}_{4} 0,5 \mathrm{M}+\mathrm{CH}_{3} \mathrm{OH} \mathrm{0,1} \mathrm{M} \mathrm{e} \mathrm{(b)} \mathrm{H}_{2} \mathrm{SO}_{4} 0,5 \mathrm{M}+\mathrm{CH}_{3} \mathrm{OH} 0,1 \mathrm{M}+\mathrm{H}_{2} \mathrm{O}_{2} 5 \mathrm{mM}$.

Uma consequência esperada e confirmada da influência do peróxido de hidrogênio é a redução na amplitude (diferença de potencial entre o potencial máximo de um ciclo e o mínimo do seguinte) máxima das oscilações, a qual pode ser percebida pelos dados apresentados na Fig. 28a.
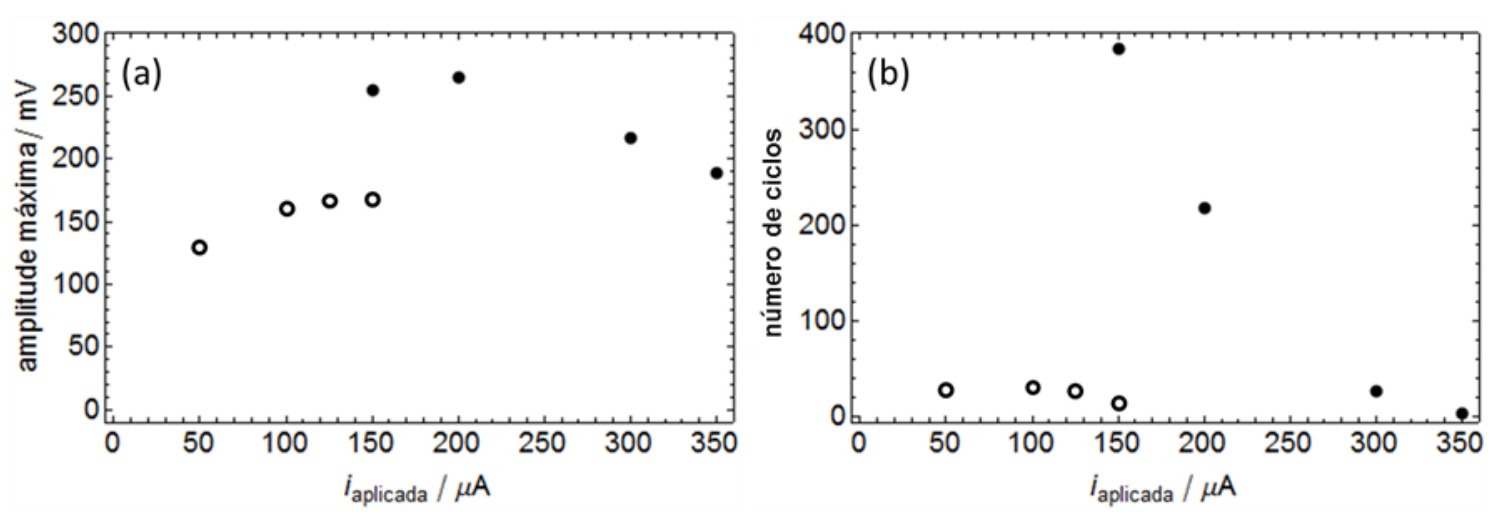

Figura 28 - Amplitude máxima e número de ciclos para oscilações obtidas com os sistemas $\mathrm{H}_{2} \mathrm{SO}_{4} 0,5 \mathrm{M}+\mathrm{CH}_{3} \mathrm{OH} 0,1 \mathrm{M}$ (círculos cheios) e $\mathrm{H}_{2} \mathrm{SO}_{4} 0,5 \mathrm{M}+\mathrm{CH}_{3} \mathrm{OH}$ $0,1 \mathrm{M}+\mathrm{H}_{2} \mathrm{O}_{2}$ 0,005 $\mathrm{M}$ (círculos vazios) em função de corrente aplicada. 
Isto ocorre, provavelmente, devido à maior intersecção entre as isotermas de adsorção de $\mathrm{CO}$ e $\mathrm{OH}$, onde as oscilações desenvolvem-se, causada pela formação de espécies oxigenadas em potenciais menores na presença de peróxido de hidrogênio, como ilustrado pela linha pontilhada na Fig. 29b.
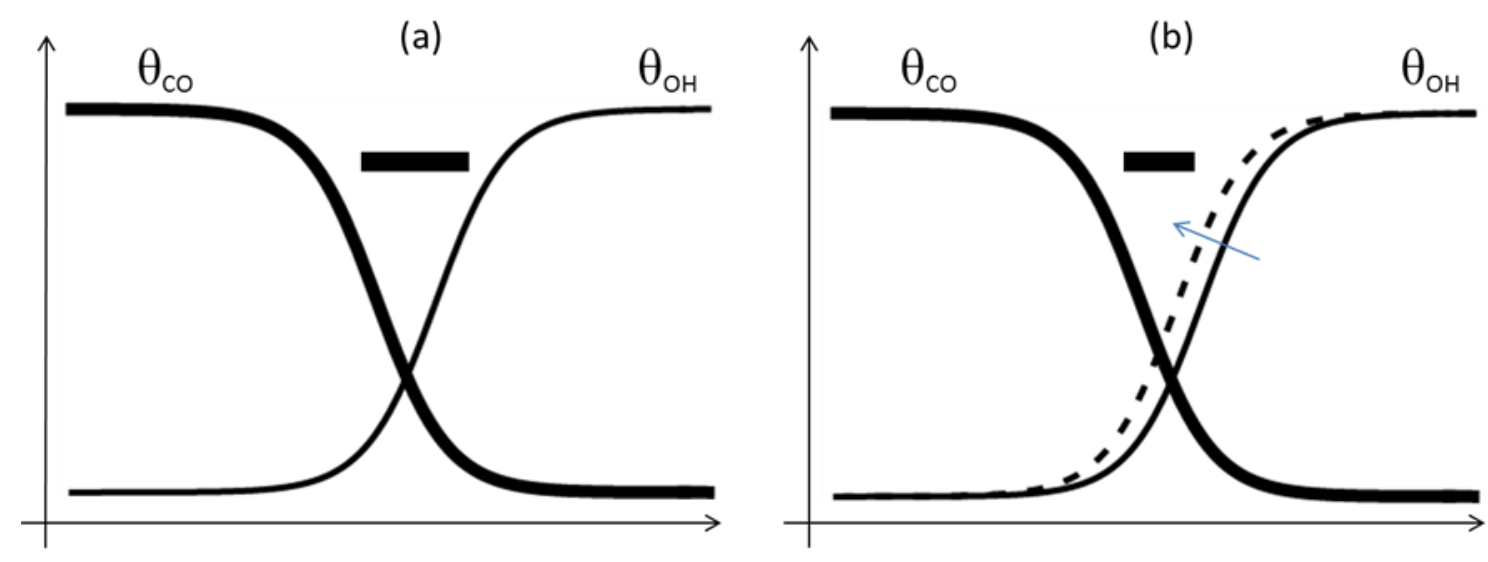

$\mathrm{U} / \mathrm{V}$

$\mathrm{U} / \mathrm{V}$

Figura 29 - llustração de isotermas de adsorção de espécies oxigenadas sem (a) e com (b) a presença de peróxido de hidrogênio (linha tracejada) durante a eletrooxidação de metanol. Isotermas do recobrimento de CO (linha mais grossa) também foram incluídas. 


\subsection{Eletro-oxidação oscilatória de etanol estudada por espectroscopia de infravermelho in situ e espectrometria de massas on line $e^{11}$}

Instabilidades cinéticas podem se desenvolver também durante a eletro-oxidação de etanol sobre platina $[100,101]$, porém, o baixo número de trabalhos dedicado ao seu estudo, somado ao fato deles não terem sido beneficiados pelo uso de técnicas in situ e/ou on line auxiliares, deixa a atual compreensão do mecanismo oscilatório observado nestes casos em um nível insatisfatório. Assim, visando obter um melhor entendimento da dinâmica das espécies envolvidas no conjunto de processos que dão origem às oscilações, nesta seção a eletro-oxidação oscilatória de etanol foi estudada acoplando-se as técnicas de espectroscopia de infravermelho in situ e de espectrometria de massas on line à técnica eletroquímica de salto galvanostático em uma célula de fluxo. Antes da apresentação dos resultados oscilatórios, entretanto, serão introduzidas a seguir algumas características da eletro-oxidação de etanol sobre platina e apresentados os voltamogramas do eletrodo utilizado em contato apenas com o eletrólito de suporte bem como na presença também de etanol.

A molécula de etanol possui dois átomos de carbono ligados entre si, sendo o rompimento desta ligação um fator limitante para a observação, a temperatura ambiente, de sua oxidação eletroquímica completa sobre eletrodos de platina, a qual produziria duas moléculas de $\mathrm{CO}_{2}$ mais 12 elétrons [102]:

$$
\mathrm{CH}_{3} \mathrm{CH}_{2} \mathrm{OH}+3 \mathrm{H}_{2} \mathrm{O} \rightarrow 2 \mathrm{CO}_{2}+12 \mathrm{H}^{+}+12 \mathrm{e}^{-}
$$

$$
E^{\circ}=0,085 \vee(v s . E P H)
$$

\footnotetext{
11 Os experimentos cujos resultados são apresentados nesta seção foram realizados no laboratório do Professor R. J. Behm, durante estágio na Universidade de Ulm, em Ulm - Alemanha, entre fevereiro e junho de 2012.
} 
A exemplo do que acontece com outros compostos alifáticos oxigenados de cadeia curta, como metanol e ácido fórmico [57,60], a eletro-oxidação de etanol sobre platina também é aceita proceder via caminhos paralelos [95, 103-106], um deles passando pelo rompimento da ligação $\mathrm{C}-\mathrm{C}$, formando $\mathrm{CO}_{\text {ads }}$ e $\mathrm{CH}_{\mathrm{x}}$ (a partir dos quais $\mathrm{CO}_{2}$ pode ser produzido via reação com espécies oxigenadas), e outros envolvendo a formação de produtos com dois carbonos, como acetaldeído e ácido acético. Este último é bastante estável à temperatura ambiente e não é oxidado na faixa de potenciais entre 0,06 e 1,3 $\vee$ [95], o que limita consideravelmente a eficiência da eletro-oxidação de etanol, uma vez que apenas quatro elétrons são produzidos nesta via. Resultados de espectroscopia de infravermelho in situ obtidos em célula de fluxo durante eletro-oxidação de etanol isotopicamente marcado sugerem que uma banda observada em $1635 \mathrm{~cm}^{-1}$ se deve à espécie acetil adsorvida [95], uma espécie adsorvida pelo carbono alfa sem hidrogênios ligados a ele. Realizando saltos potenciostáticos desde $0,06 \mathrm{~V}$ até $0,4 \mathrm{~V}$ os autores observaram o aparecimento desta banda em tempos menores do que os necessários para a observação da banda correspondente a $\mathrm{CO}_{\mathrm{ads}}$; ademais, a intensidade integrada da banda de acetil adsorvido rapidamente atinge um máximo enquanto a de $\mathrm{CO}_{\text {ads }}$ tem um comportamento logaritmicamente crescente. Diante disto, os autores sugerem que a espécie acetil é precursora da formação de $\mathrm{CO}_{\mathrm{ads}}$ e que a baixos potenciais o principal fator limitante da velocidade de eletro-oxidação do etanol seria a oxidação dos intermediários contendo apenas um carbono (C1) em vez da quebra da ligação C-C. Como a formação de ácido acético depende da incorporação de um oxigênio e, consequentemente, de uma fonte de oxigênio, ela não é favorecida até que o potencial do eletrodo atinja valores que promovam a adsorção de espécies oxigenadas, reação (16). Em geral, a eficiência das diferentes vias depende de fatores como concentração do composto orgânico [107, 108], potencial aplicado [109] e estrutura e natureza do catalisador [105, 106, 110]. Um esquema simplificado para a eletro-oxidação de etanol, em meio ácido, é apresentado na Fig. 29 levando em conta a formação dos principais produtos observados, os quais incluem além de dióxido de carbono, as espécies parcialmente oxidadas acetaldeído e ácido acético [95, 107, 109, 111, 112]. Entretanto, o mecanismo real completo envolve provavelmente outras etapas reacionais e espécies intermediárias [113]. 


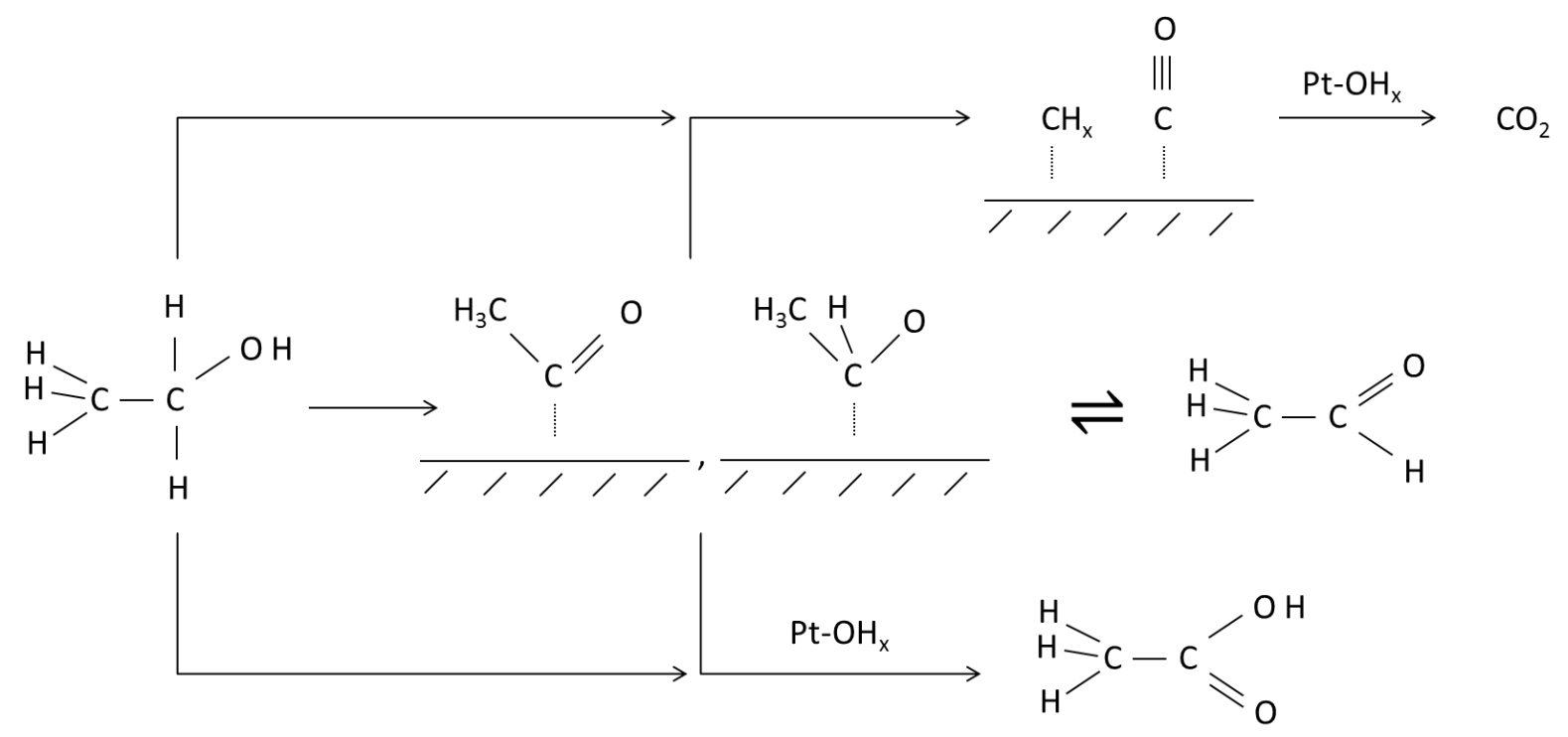

Figura 30 - Esquema simplificado das vias paralelas presentes na eletrooxidação de etanol sobre eletrodos de platina [95, 103-106].

Como usual, foram realizadas várias varreduras do potencial do eletrodo de trabalho utilizado (um filme de platina depositado sobre um prisma de silício, ver Cap.2 para detalhes) em contato apenas com o eletrólito de suporte, $\mathrm{H}_{2} \mathrm{SO}_{4}$ 0,5 $\mathrm{M}$, obtido com uma velocidade de varredura de $10 \mathrm{mV} \mathrm{s}^{-1}$, até que um perfil estável se definisse, mostrado na Fig. 31a. A área real do eletrodo foi encontrada por integração da região (hachurada na Fig. 31a) correspondente à dessorção de hidrogênio. Supondo uma densidade de carga para este processo de $210 \mu \mathrm{C} \mathrm{cm}^{-2}$ [93], a área real foi estimada em $4,36 \mathrm{~cm}^{2}$, o que resultou num fator de rugosidade de 4,36 uma vez que a área geométrica do eletrodo utilizado foi de $1 \mathrm{~cm}^{2}$. Também são apresentadas, na Fig. 31b, as duas primeiras varreduras, a $10 \mathrm{mV} \mathrm{s}^{-1}$, do potencial do eletrodo na presença de $\mathrm{C}_{2} \mathrm{H}_{5} \mathrm{OH} 0,05 \mathrm{M}$. No primeiro ciclo, linha contínua, é possível observar um pequeno pico de corrente em torno de $0,26 \mathrm{~V}$ correspondente à desidrogenação que acompanha a adsorção de etanol, o qual não é observado no segundo ciclo, linha tracejada, e nos seguintes não mostrados, devido ao bloqueio da superfície resultante da formação de $\mathrm{CO}_{\mathrm{ads}}$ em baixos potenciais. O perfil de corrente nestes voltamogramas é relativamente similar àquele observado quando metanol está em contato com eletrodos de platina, ver Fig. 10b, Subseção 3.1.1. Baixas densidades de corrente resultam da presença de espécies bloqueantes adsorvidas: espécies carbonáceas a baixos potenciais e óxidos de platina a altos. A densidade de corrente apresenta máximos na região 
intermediária, entre 0,4 e $1 \mathrm{~V}$, nas varreduras positiva e negativa. $\mathrm{O}$ fato da oxidação de etanol ser desacelerada para baixos potenciais no segundo ciclo comparado ao primeiro sugere o esperado maior envenenamento superficial em comparação a quando a superfície está inicialmente limpa.
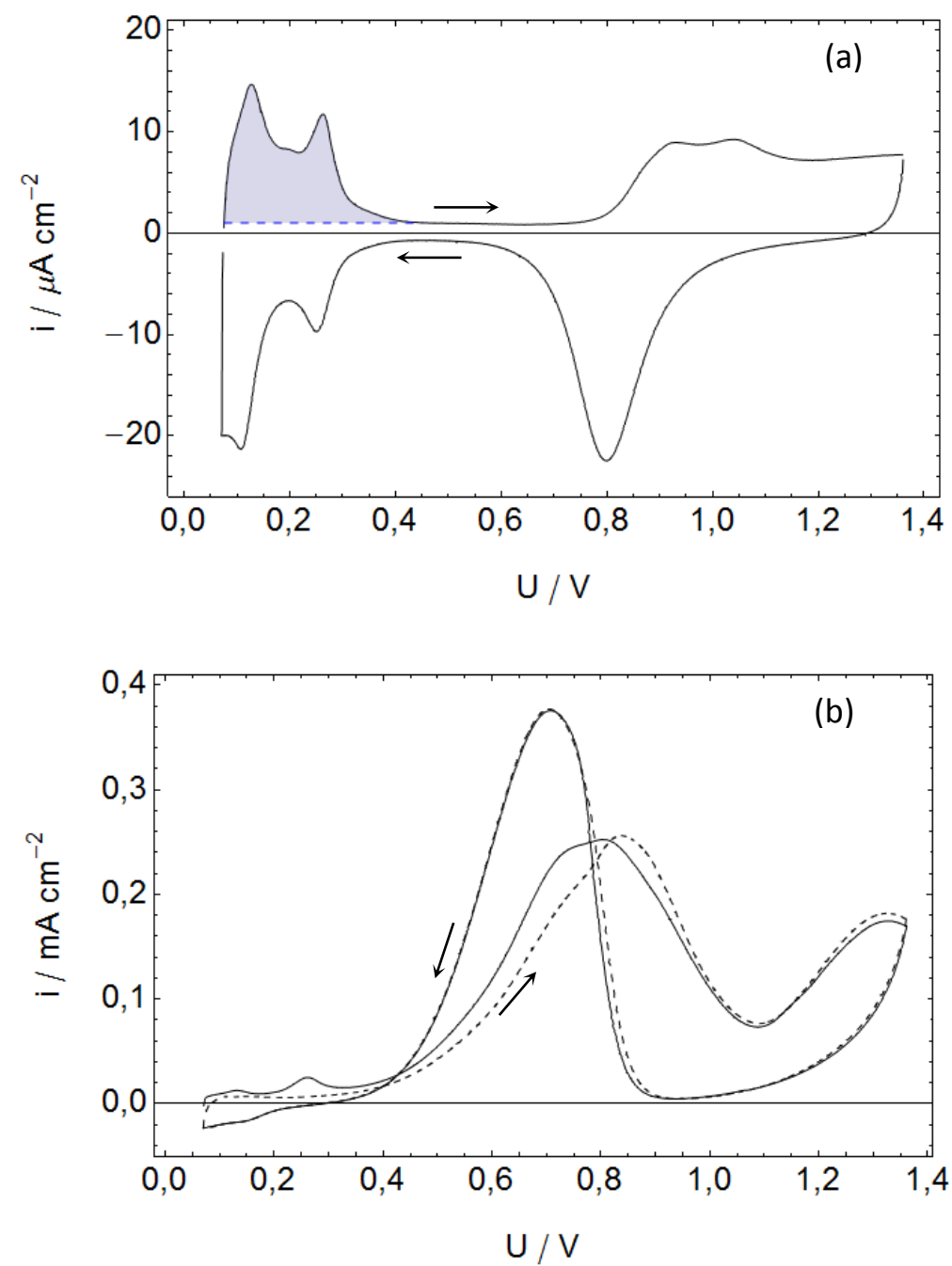

Figura 31 - Voltamograma cíclico do eletrodo de platina em contato com (a) $\mathrm{H}_{2} \mathrm{SO}_{4} 0,5 \mathrm{M}$ e (b) $\mathrm{H}_{2} \mathrm{SO}_{4} 0,5 \mathrm{M}+\mathrm{CH}_{3} \mathrm{CH}_{2} \mathrm{OH} 0,05 \mathrm{M}$. A corrente foi normalizada pela área real, $4,36 \mathrm{~cm}^{2}$, encontrada pela região de dessorção de hidrogênio, região hachurada em (a). Velocidade de varredura de potencial: $10 \mathrm{mV} \mathrm{s}^{-1}$.

Um exemplo representativo de oscilações de potencial observáveis durante a eletrooxidação de etanol é apresentado na Fig. 32 para uma densidade de corrente aplicada de $0,183 \mathrm{~mA} \mathrm{~cm}^{-2}$. Neste caso, as condições são tais que, imediatamente após o salto 
galvanostático, o sistema já se encontra dentro do regime oscilatório, sem passar por um período de indução. As oscilações são inicialmente simples, período-1, mas cerca de $40 \mathrm{~s}$ após a aplicação da corrente a deriva do sistema o desloca para um regime de período-2 em que, em cada ciclo $^{12}$, além do mínimo ínfimo presente abaixo de $0,55 \mathrm{~V}$, outro mínimo é observado acima de 0,7 V. Após completar três dezenas de ciclos o potencial de máximo atinge valores tão altos quanto $0,85 \mathrm{~V}$, em que as oscilações deixam de ser estáveis e, não fosse a interrupção em cerca de $t=370 \mathrm{~s}$ da corrente aplicada, o sistema deslocar-se-ia para um (quase) estado estacionário acima de $1 \mathrm{~V}$.

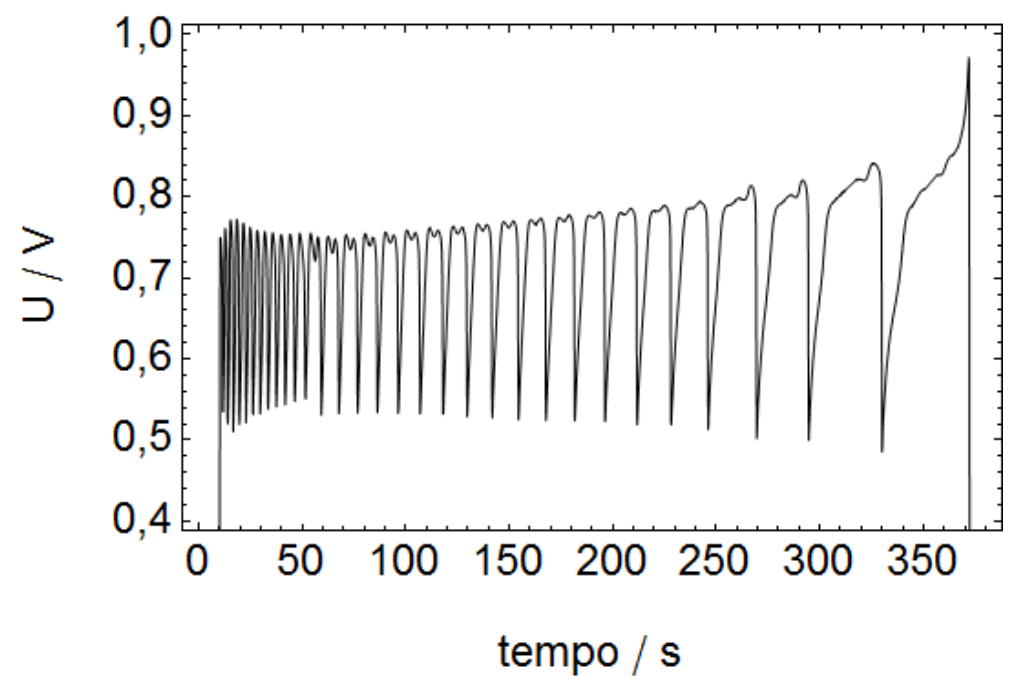

Figura 32 - Perfil do potencial em função do tempo registrado durante eletro-oxidação de $\mathrm{H}_{2} \mathrm{SO}_{4} 0,5 \mathrm{M}+\mathrm{CH}_{3} \mathrm{CH}_{2} \mathrm{OH} 0,05 \mathrm{M}$ sobre platina. Densidade de corrente aplicada: $0,183 \mathrm{~mA} \mathrm{~cm}^{-2}$.

Quando se avalia a variação da amplitude e a frequência dos ciclos destas oscilações ao longo do tempo, Fig. 33, se percebe a permanente ação da deriva sobre o sistema, manifestada nas contínuas mudanças pelas quais ele passa. As oscilações nascem com uma amplitude em torno de $230 \mathrm{mV}$ que ainda aumenta nos dois ciclos seguintes, atingindo um valor máximo em $260 \mathrm{mV}$, antes de decrescer até o ponto em que ocorre a bifurcação espontânea do período-1 para o período-2, momento em que sofre uma descontinuidade, inverte a tendência de queda para a de aumento com o tempo, a qual persiste durante o

\footnotetext{
${ }^{12}$ Tomados como a curva entre dois mínimos extremos adjacentes, não são ciclos exatos desde que um potencial de mínimo não é igual ao outro por causa da deriva presente no sistema.
} 
restante da série temporal. De acordo com a equação de continuidade do fluxo de cargas através da interface eletrodo/solução, eq. (37) (Subseção 3.1.2), nos pontos que definem a magnitude da amplitude, ou seja, aqueles de máximo e de mínimo de potencial, a corrente capacitiva é nula e a corrente faradaica se iguala à corrente total aplicada. Desta forma, processos que corroboram ou obstruem o pleno desenvolvimento de $l_{f}$ devem ter papel central na determinação da amplitude. Fatores que influenciam as velocidades das reações eletroquímicas incluem consumo de material eletro-reativo além da capacidade de sua reposição pela difusão, baixo sobrepotencial de reação ou acesso dificultado ao catalisador. Assumindo que, na faixa em que as oscilações se manifestam, o elemento mais impactante sobre a corrente faradaica seja a limitação de área ativa acarretada pela adsorção de espécies relativamente estáveis, poder-se-ia dizer que, quanto menor o potencial de mínimo, mais sítios livres estariam sendo formados durante o processo de limpeza e, por outro lado, quanto maior o potencial de máximo, menor a fração da superfície com sítios reacionais desocupados no momento que antecede o desencadeamento do processo de limpeza. Analisando-se, então, a Fig. 33 poder-se-ia afirmar que, para a metade final da série temporal, quanto maior o número de sítios liberados sobre a superfície ao término de cada ciclo, mais difícil se torna desencadear o processo para voltar a desenvenena-la no ciclo seguinte, uma vez que o potencial de máximo cresce continuamente.

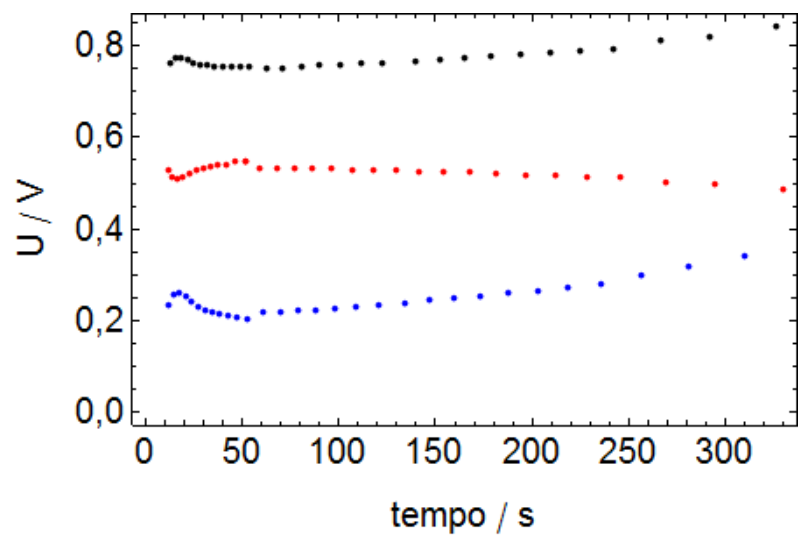

Figura 33 - Amplitude (azul) e potenciais de máximo (preto) e de mínimo (vermelho) das oscilações exibidas na Fig. 32 em função do tempo.

O perfil temporal da frequência, Fig. 34, é sempre decrescente, com os ciclos repetindo-se em intervalos que vão de 3 a 5 segundos na região de período- 1 e de 8 a $35 \mathrm{~s}$ 
na região de período morfológico mais complexo. A frequência está relacionada com os tempos gastos no processo de envenenamento do eletrodo, naquele(s) que mantém o sistema em valores de potencial próximos do máximo e no processo de limpeza, o qual, como será mostrado adiante, é o fator que exerce menor influência sobre a variação na duração dos ciclos.

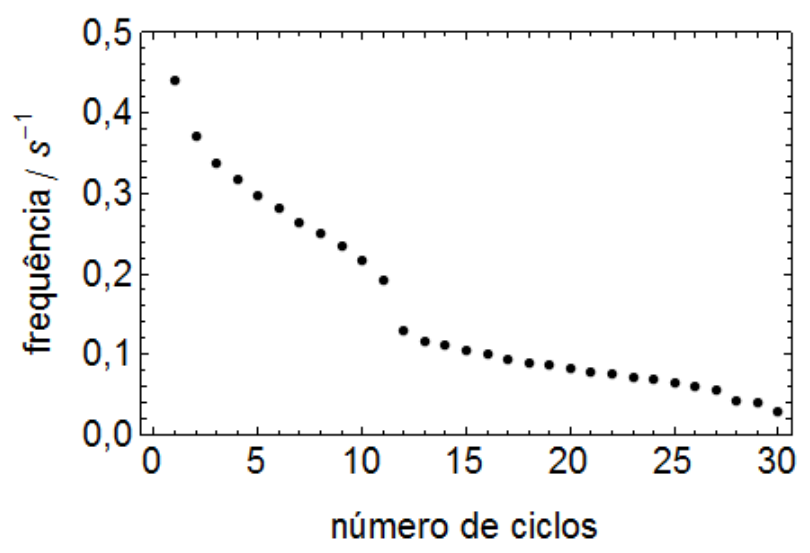

Figura 34 - Frequência das oscilações exibidas na Fig. 32 em função do número de ciclos.

Uma das características das oscilações observadas durante a eletro-oxidação de etanol é a alta velocidade de queda do potencial no final dos ciclos, se aproximando a $1 \mathrm{~V} \mathrm{~s}^{-1}$ como ilustrado na Fig. 35 para ciclos entre, aproximadamente, $14-16,5$ s e $246-270 \mathrm{~s}$, onde a diminuição do potencial com o tempo, na região compreendida entre os dois pontos vermelhos, acontece, respectivamente, a taxas de $(-0,16 \mathrm{~V} / 0,15 \mathrm{~s}=)-1,07 \mathrm{~V} \mathrm{~s}^{-1}$ e $(-0,26 \mathrm{~V} /$ $0,3 \mathrm{~s}=)-0,86 \mathrm{~V} \mathrm{~s}^{-1}$. Isto sugere que a limpeza superficial acontece de maneira auto-catalítica. Analisando-se a velocidade com que o potencial cresce na parte inicial dos ciclos, nota-se que ela diminui com o avançar ao longo da série temporal, passando de 130 a $460 \mathrm{mV} \mathrm{s}^{-1}$ no segundo ciclo para menos de $40 \mathrm{mV} \mathrm{s}^{-1}$ em média no vigésimo oitavo ciclo. Isto sugere desaceleração na taxa de envenenamento da superfície, contudo, o sistema permanece mais tempo na região de altos potenciais, indicando a dificuldade para desencadear o processo de limpeza superficial. 

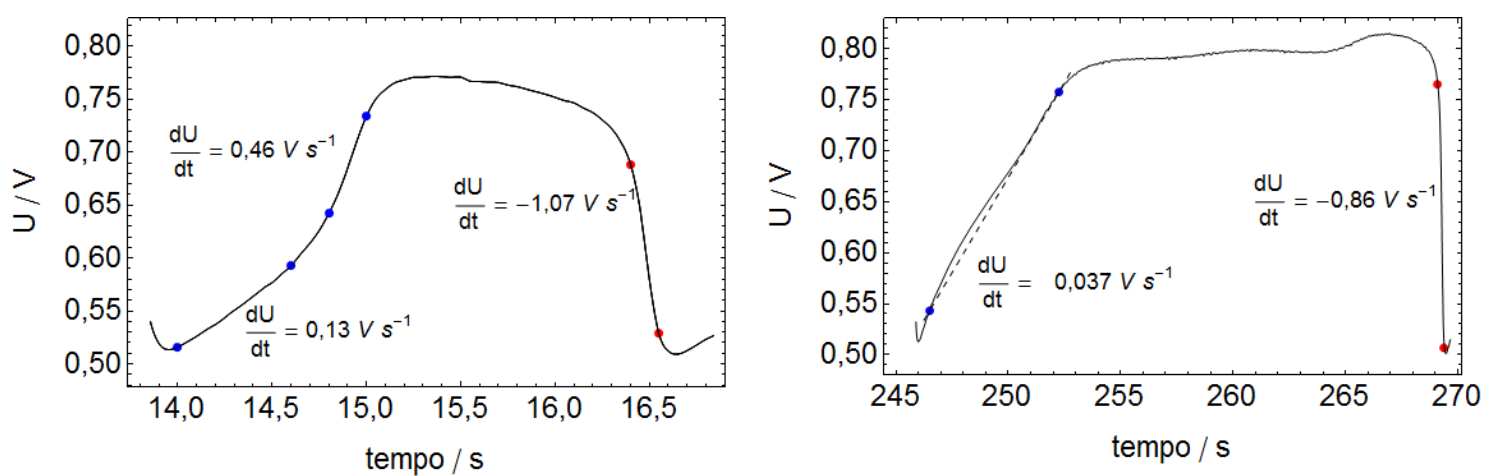

Figura 35 - Representação de ciclos de potencial no início (a) e próximo do fim (b) da série temporal mostrada na Fig. 32. Os pontos vermelhos delimitam a região em que foram calculadas as taxas de variação do potencial, cujos valores estão indicados na figura.

Usando a eq. 33, introduzida na Subseção 3.1.1, é possível calcular o potencial médio em cada um dos ciclos que compõem as oscilações exibidas na Fig. 32 e, a partir de sua taxa de variação, avaliar a velocidade de envenenamento superficial ao longo da série temporal. A representação de $\bar{U}$ em função do tempo é mostrada na Fig. 36, onde duas regiões podem ser distinguidas, uma referente à de período-1 e outra referente à de período morfológico mais complexo. É possível observar que em grande parte delas a variação temporal de $\bar{U}$ pode ser bem ajustada por linhas retas, sendo que o coeficiente angular daquela correspondente à região de período-1, 0,765 $\mathrm{mV} \mathrm{s}^{-1}$, é cerca de quatro vezes maior do que o observado na região de período morfológico maior, $0,187 \mathrm{mV} \mathrm{s}^{-1}$, como indicado na Fig. 27. Isto sugere que regimes de estabilidade que apresentam instabilidades com formas complexas poderiam atuar diminuindo a velocidade do envenenamento superficial causado por venenos catalíticos, algo que, como já mencionado anteriormente, Subseção 3.1.1, seria de interesse para aplicação em células a combustível. 


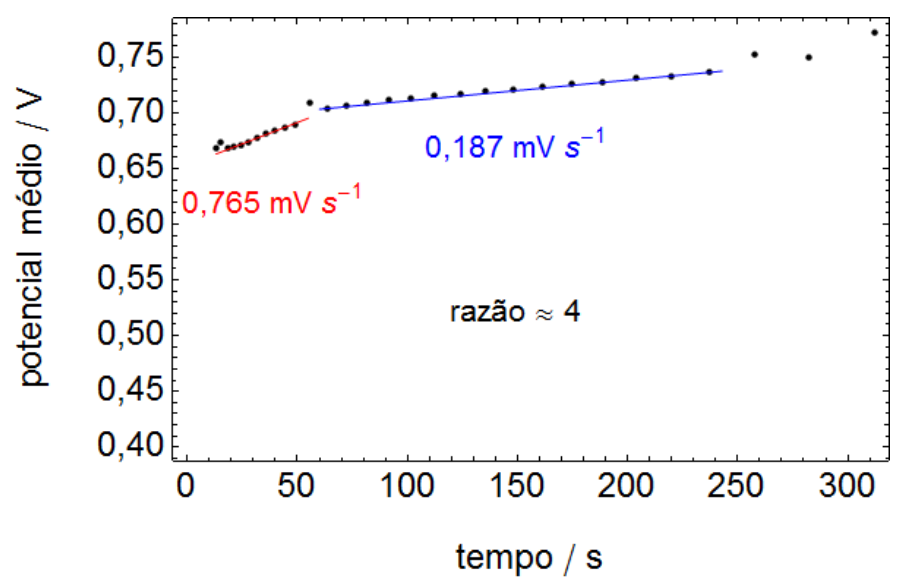

Figura 36 - Representação do potencial médio em função do tempo com os coeficientes angulares aproximados para as regiões de período-1 e período-2. A razão entre elas é de 4,1.

Visando aprofundar o entendimento da dinâmica de adsorbatos presente durante o desenvolvimento do fenômeno oscilatório foram adquiridos, simultaneamente ao experimento eletroquímico da Fig. 32, espectros da superfície reacional na região do infravermelho. Um exemplo representativo, coletado aos $20 \mathrm{~s}$, quando $\mathrm{U}$ era de $0,56 \mathrm{~V}$ e o sistema estava dentro da região oscilatória, é mostrado na Fig. 37, onde é possível distinguir bandas em $2046 \mathrm{~cm}^{-1}, 1829 \mathrm{~cm}^{-1}, 1407 \mathrm{~cm}^{-1}, 1207 \mathrm{~cm}^{-1}$ e $1113 \mathrm{~cm}^{-1}$, que, segundo a literatura [95] podem ser atribuídas, respectivamente, a $\mathrm{CO}_{\mathrm{L}}, \mathrm{CO}_{\mathrm{M}}$, acetato adsorvido coordenado a dois sítios superficiais e a espécies sulfato e bi-sulfato. É interessante notar que como o espectro de referência foi coletado com o eletrodo polarizado a $70 \mathrm{mV}$, dentro da região de adsorção de hidrogênio, e a técnica de espectroscópica utilizada (EAIVIS-RTA) detecta majoritariamente espécies adsorvidas, as duas bandas referentes às espécies sulfato são direcionadas para cima, indicando formação em relação ao estado tomado como referência. Em experimentos realizados em configuração de camada ultrafina, as bandas destas espécies aparecem em forma bipolar, uma vez que espécies em solução também são detectadas e como o pH local diminui com o aumento do potencial e consequente dissociação da água, a concentração de sulfato diminui em detrimento ao aumento daquela de (bi)-sulfato [33]. 


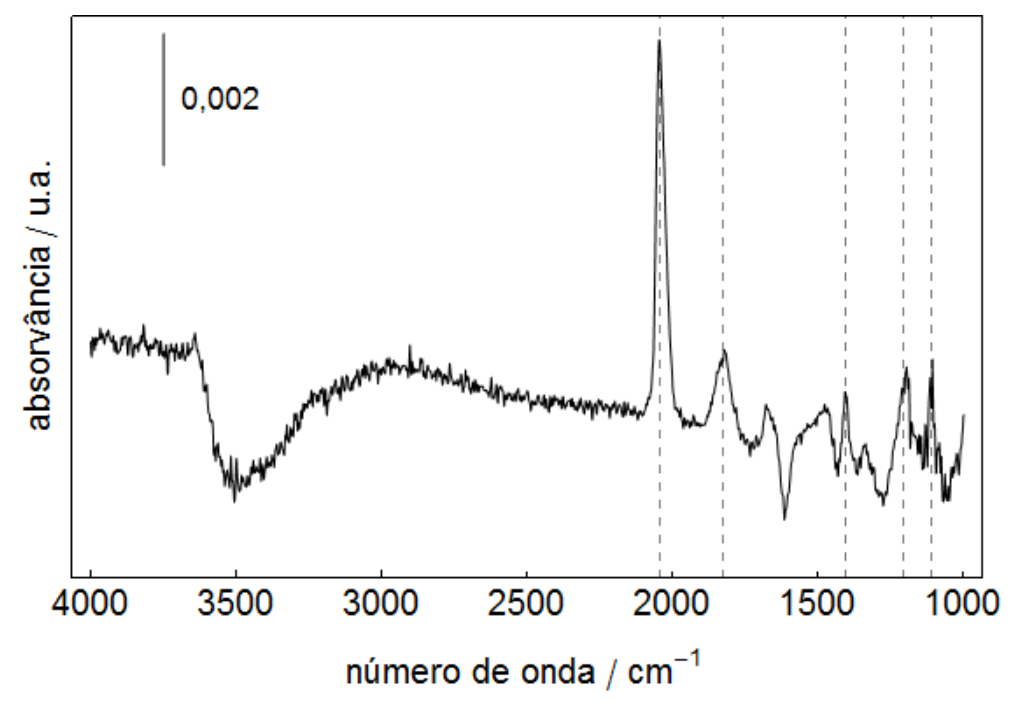

Figura 37 - Espectro de radiação infravermelha da interface eletrodo/solução coletado aos $20 \mathrm{~s}(\mathrm{U}=0,56 \mathrm{~V})$ do experimento da Fig. 32. As linhas tracejadas marcam o centro, em média, das bandas referentes aos adsorbatos $\mathrm{CO}_{L}, 2046$ $\mathrm{cm}^{-1}, \mathrm{CO}_{\mathrm{M}}, 1829 \mathrm{~cm}^{-1}$, acetato, $1407 \mathrm{~cm}^{-1}$, e espécies sulfato, 1207 e $1113 \mathrm{~cm}^{-1}$. A resolução espectral utilizada foi de $0,5 \mathrm{~cm}^{-1}$ e o espectro de referência foi coletado com o eletrodo polarizado a $70 \mathrm{mV}$ e em contato apenas com eletrólito suporte. Resolução temporal: 0,302 s.

Enquanto para o caso da eletro-oxidação de metanol ainda está sob debate o papel desempenhado pela espécie formato adsorvido, se é um intermediário reativo ou um expectador [63], para o caso da oxidação eletroquímica de etanol se aceita que acetato adsorvido é um bloqueador de sítios reacionais $[95,114]$. Assim, sem mencionar o possível efeito inibitório das espécies $\mathrm{C}_{\beta} \mathrm{H}_{\mathrm{x}}$, cuja oxidação para $\mathrm{CO}_{2}$ poderia se dar lentamente [104, 106], para a eletro-oxidação de etanol existem dois inibidores superficiais, $\mathrm{CO}_{\mathrm{ads}} \mathrm{e}$ $\mathrm{CH}_{3} \mathrm{COO}_{\text {ads, }}$, sendo que o primeiro predomina em potenciais mais baixos do que o segundo, já que o consumo de um e a produção do outro é favorecida por espécies oxigenadas, embora acetato adsorvido não se adsorva fortemente e esteja em rápido equilíbrio com sua forma protonada em solução, $\mathrm{CH}_{3} \mathrm{COOH}_{\text {sol }}$ [95]. Isto cria a expectativa, confirmada pelos perfis temporais de intensidade de banda integrada apresentados na Fig. 38, de que durante as oscilações de potencial os recobrimentos superficiais de $\mathrm{CO}_{\mathrm{L}}$ e de acetato oscilam em antifase. 


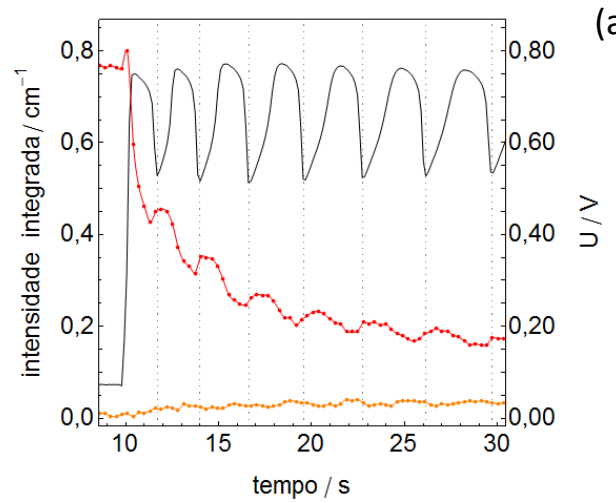

(a1)
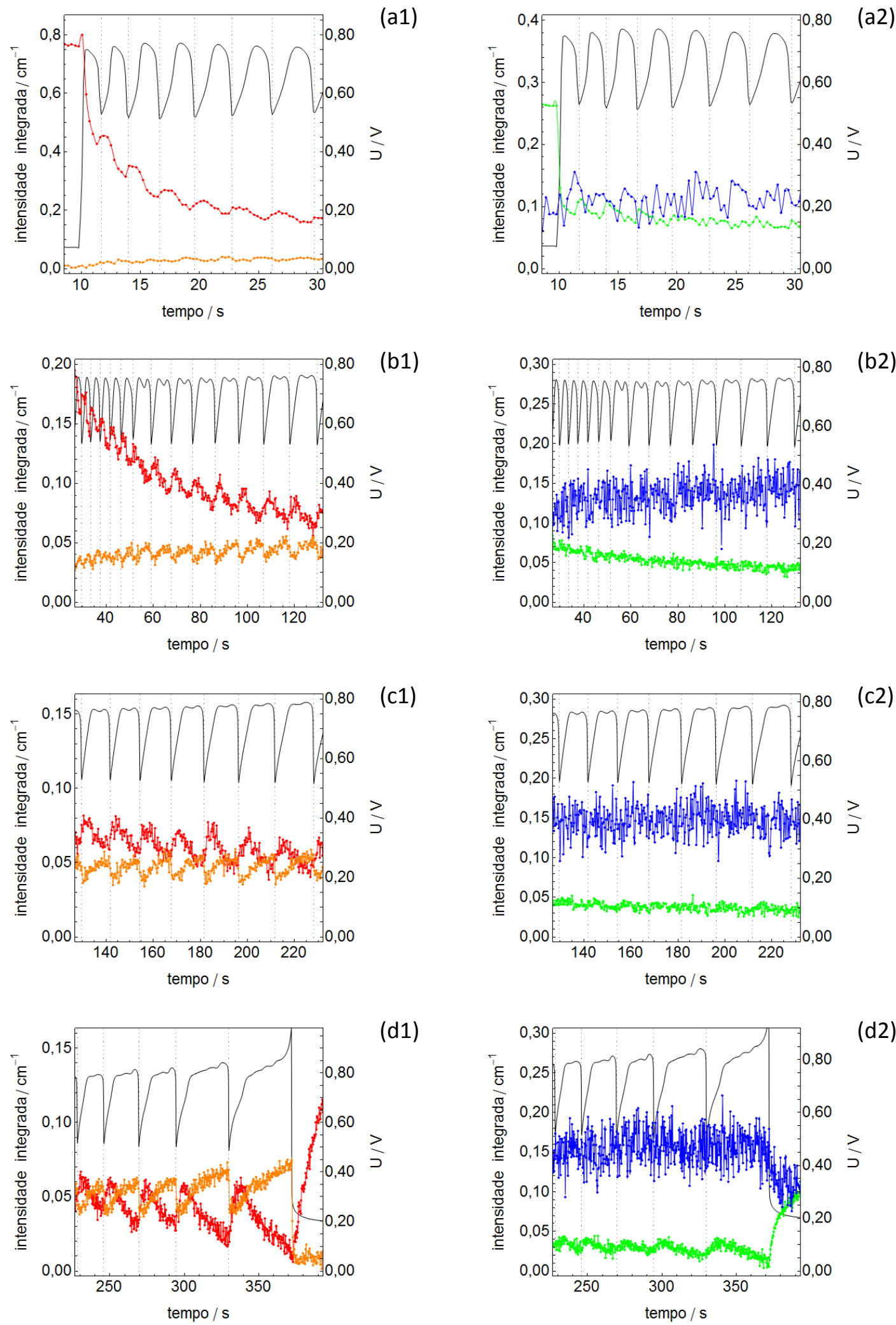

Figura 38 - Intensidades integradas das bandas de $\mathrm{CO}_{\mathrm{L}}$ (vermelho), $\mathrm{CO}_{\mathrm{B}}$ (verde), acetato adsorvido (laranja) e sulfato adsorvido (azul) ao longo dos ciclos de potencial (preto) em diferentes intervalos de tempo, $9-30 \mathrm{~s}$ (a1) e (a2), $29-130$ s (b1) e (b2), $129-230 \mathrm{~s}$ (c1) e (c2) e $230-390 \mathrm{~s}$ (d1) e (d2) do experimento da Fig. 32. 
$\mathrm{Na}$ região em que a intensidade integrada de $\mathrm{CO}_{\mathrm{L}}$ varia decrescentemente, sítios superficiais são liberados e moléculas de acetato, geradas no caminho paralelo que não passa pela quebra da ligação $\mathrm{C}-\mathrm{C}$, se adsorvem. Olhando a série temporal em toda sua extensão, se pode notar que as intensidades de $\mathrm{CO}_{\mathrm{L}}$ e $\mathrm{CO}_{\mathrm{B}}$ diminuem, em média, ao longo do experimento enquanto que as de acetato e sulfato aumentam, embora a intensidade integrada desta última espécie esteja bastante ruidosa, em parte devido à presença, a menores números de onda, da banda de (bi)-sulfato, a qual também apresenta algum comportamento dinâmico durante as oscilações. O perfil temporal da intensidade integrada da banda de acetato adsorvido acompanha aproximadamente aquele do potencial, como seria esperado para ânions. As oscilações na população superficial de $\mathrm{CO}_{\mathrm{B}}$ se tornam visíveis apenas nos últimos ciclos, possivelmente porque o recobrimento total de CO está num nível já bastante baixo, condição em que a adsorção linear do monóxido de carbono é desfavorecida.

A prevalência da detecção de espécies adsorvidas pela técnica de RTA-AIVIS dificulta o acompanhamento dos produtos solúveis formados, por isso, também foi acoplada neste experimento a técnica de espectrometria de massas eletroquímica diferencial (EMED), em que espécies voláteis como acetaldeído e gasosas como $\mathrm{CO}_{2}$ podem ser detectadas.

Os principais fragmentos observados durante a eletro-oxidação de etanol acompanhada com a técnica EMED são $\mathrm{CHO}^{+}$, proveniente de moléculas de acetaldeído, com razão massa/carga $\left(\mathrm{m} / \mathrm{c}\right.$ ) igual a 29 , além de $\mathrm{CH}_{3} \mathrm{CHO}^{+}$e $\mathrm{CO}_{2}{ }^{+}$ambos com razão $\mathrm{m} / \mathrm{c}$ igual a 44 e provenientes, respectivamente, de acetaldeído e de dióxido de carbono. Desta forma, alguma estratégia deve ser adotada para separar a contribuição da produção de $\mathrm{CO}_{2}$ ao sinal $\mathrm{m} / \mathrm{c} 44$ daquela devido a $\mathrm{CH}_{3} \mathrm{CHO}$. Uma possível alternativa consiste em alternar saltos de potencial entre valores de $U$ em que apenas acetaldeído seja formado, como $U=0,46 \mathrm{~V}$, e outros em que não há oxidação apreciável de etanol, como $U=0,2 \mathrm{~V}$. Nestas condições, o sinal m/c 44 para além da linha de base decorreria inteiramente da produção de acetaldeído, o que possibilita encontrar a razão entre as correntes iônicas provenientes desta espécie associadas aos sinais m/c 44 e m/c 29, a qual dependeria apenas das características do espectrômetro. O valor encontrado, para as mesmas condições experimentais em que os resultados deste capítulo foram obtidos, foi: 


$$
\frac{I_{\mathrm{CH}_{3} \mathrm{CHO}^{+}}}{I_{\mathrm{CHO}^{+}}} \approx 0,43
$$

Assim, se torna possível discernir a corrente iônica devida à produção de $\mathrm{CO}_{2}$ daquela associada à produção de acetaldeído durante as oscilações de potencial, as quais são apresentadas na Fig. 39. Devido ao alto conteúdo de CO adsorvido inicialmente, a quantidade de $\mathrm{CO}_{2}$ produzida é alta no começo do experimento e depois decresce. A corrente devida a acetaldeído, por outro lado, é inicialmente baixa mas cresce até atingir um estado estacionário, não sendo possível, na presente resolução experimental, observar oscilações em $\mathrm{I}_{\mathrm{CH}_{3} \mathrm{CHO}}$.
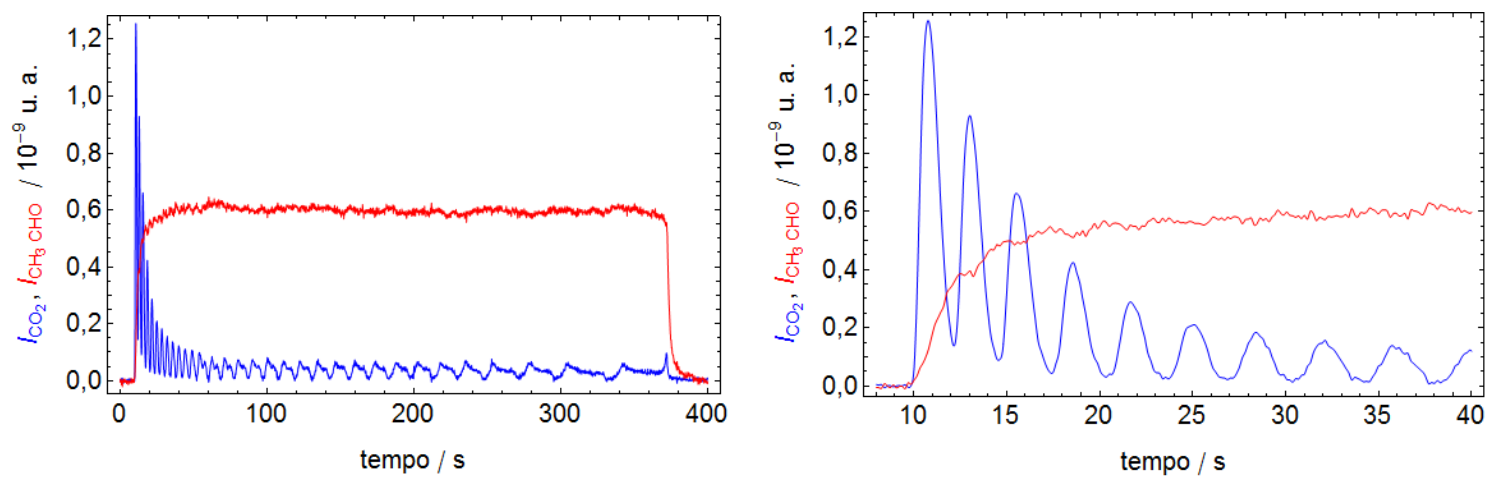

Figura 39 - Perfil temporal das correntes iônicas associadas à produção de $\mathrm{CO}_{2}$ (azul) e acetaldeído (vermelho) ao longo das oscilações da Fig. 32 (a); região ampliada no começo da série temporal (b).

A corrente iônica de $\mathrm{CO}_{2}$ pode agora ser representada conjuntamente com a curva de potencial e a intensidade integrada da banda de $\mathrm{CO}_{\mathrm{L}}$, que pode ser tomada como proporcional ao recobrimento de $\mathrm{CO}$, o que é feito na Fig. 40. Também é representado o negativo da derivada do potencial, que é qualitativamente proporcional à corrente faradaica. Sua forma difere bastante da curva de $\mathrm{I}_{\mathrm{CO}_{2}}$, resultado da baixa eficiência da oxidação completa de etanol para $\mathrm{CO}_{2}$. 

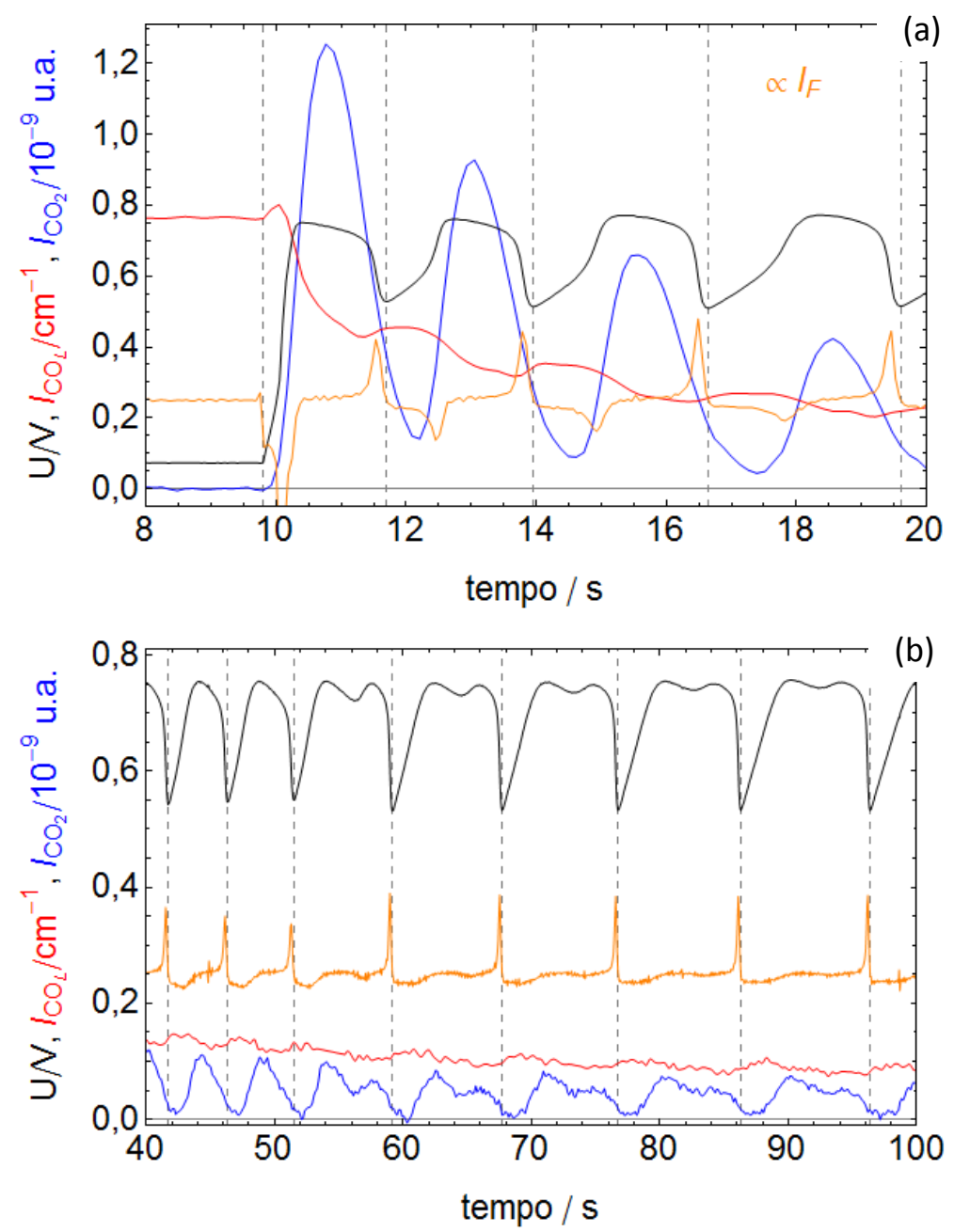

Figura 40 - Representação de oscilações de potencial (preto) da Fig. 32 juntamente com as variações temporais na corrente iônica de $\mathrm{CO}_{2}$ (azul), na intensidade integrada da banda de $\mathrm{CO}_{\mathrm{L}}$ (vermelho) e do negativo da derivada do potencial (laranja) no início das oscilações (a) e no intervalo de tempo compreendendo a bifurcação espontânea de período-1 para período-2 (b).

$\mathrm{Na}$ Fig. $40 \mathrm{~b}$ pode-se perceber que o perfil temporal de corrente de $\mathrm{CO}_{2}$ duplica seu período morfológico ao mesmo tempo em que as oscilações de potencial o fazem. Por outro lado, o perfil temporal da intensidade integrada da banda de $\mathrm{CO}_{\mathrm{L}}$, Fig. 38b1, aparentemente permanece com período morfológico simples mesmo o ponto de bifurcação. Isto indicaria que o segundo pico observado na corrente de $\mathrm{CO}_{2}$ poderia ser proveniente da oxidação de outra espécie que não $\mathrm{CO}_{\mathrm{ads}}$. Contudo, os dados da Fig. 38b1 são um tanto ruidosos e mais experimentos precisam ser realizados para confirmar ou refutar esta hipótese. 
Sob influência do efeito Stark [88], a energia de vibração de algumas espécies adsorvidas tende a responder de forma linear a mudanças no potencial do eletrodo e, ademais, segundo Osawa et al. [89], a coincidência dos tempos de máximo e mínimo da variação temporal da posição da banda de $\mathrm{CO}_{\mathrm{L}}$ com os tempos de máximo e mínimo das oscilações de potencial garante a sincronização entre os dados eletroquímicos e espectroscópicos. De fato, como pode-se notar nas Fig. 41 e 42, onde se representa a posição das cinco bandas indicadas na Fig. 37 em função do tempo, que, à exceção da banda de acetato, todas as bandas apresentam dependência de sua posição com o potencial, sendo mais claramente observada para $\mathrm{CO}_{\mathrm{L}}, \mathrm{CO}_{\mathrm{M}}$ e sulfato. Com o intuito de acompanhar a dinâmica das oscilações, uma resolução temporal de 0,302 s foi empregada na coleta dos espectros; contudo, os espectros resultantes muitas vezes possuem uma baixa razão sinal/ruído, o que dificulta a determinação da posição da banda. Assim, um procedimento para amenizar o efeito do ruído, que consiste basicamente em fazer médias do sinal, ver detalhes no Apêndice A, foi adotado para encontrar a posição das bandas. Linhas tracejadas verticais são representadas nos tempos correspondentes aos de mínimo de potencial e o que se observa é uma muito boa coincidência com os tempos correspondentes aos tempos de mínimo na posição das bandas. 


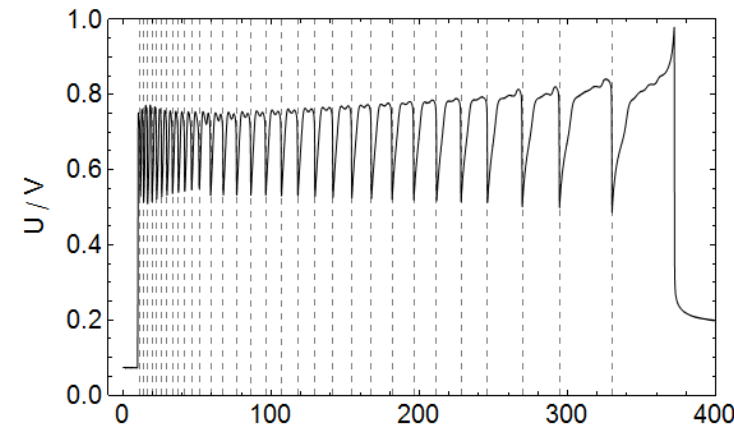

(a)
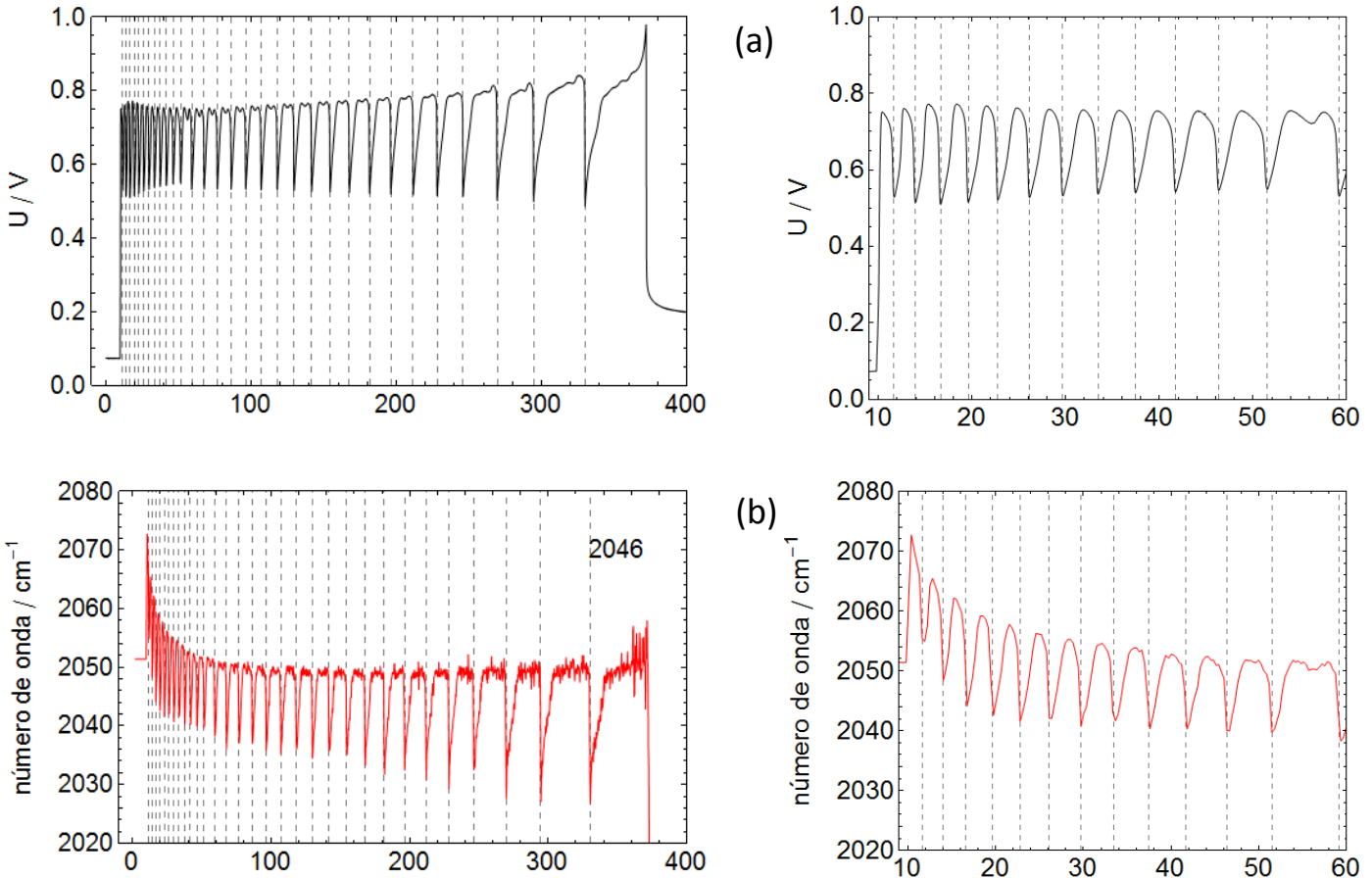

(b)
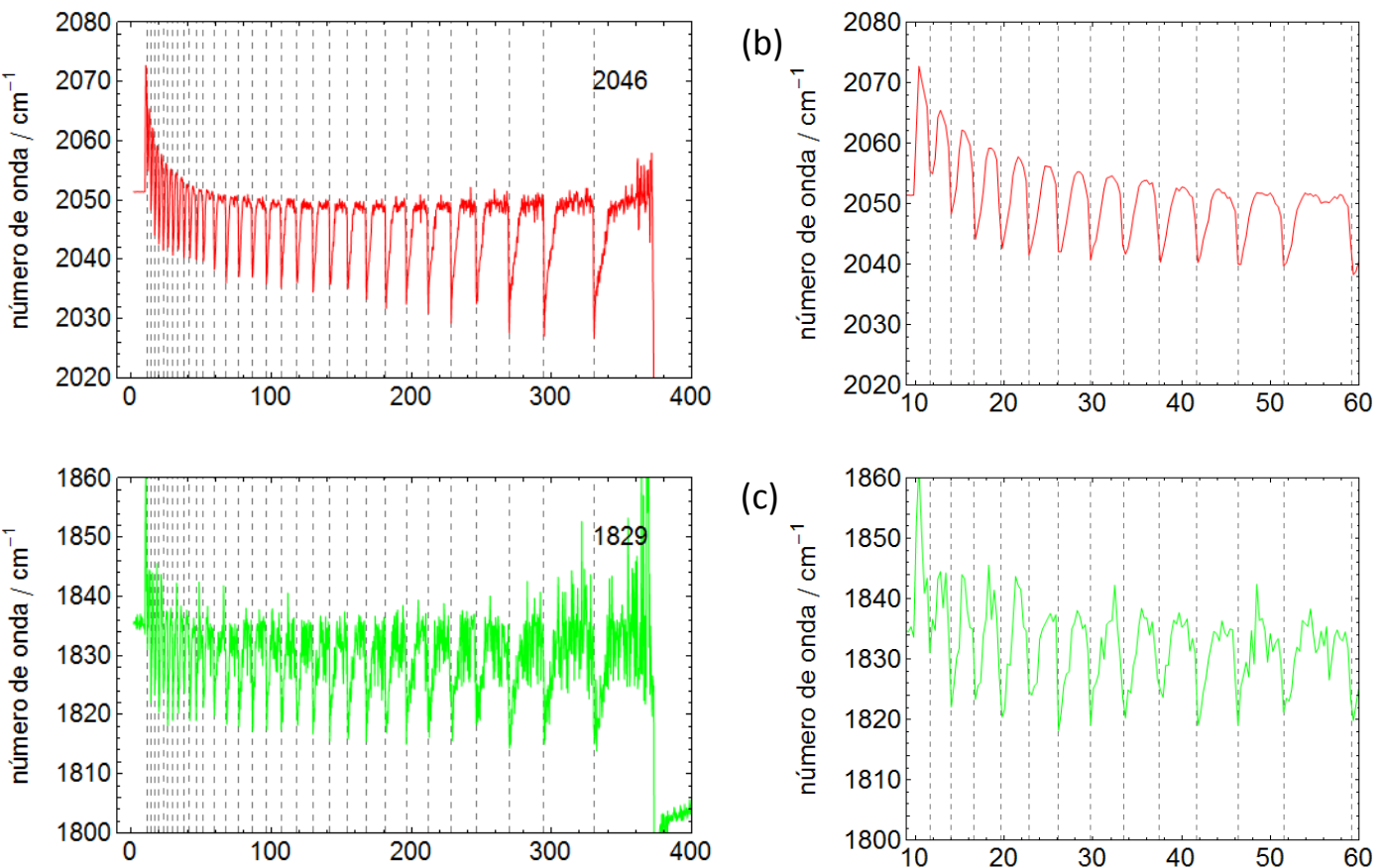

(c)
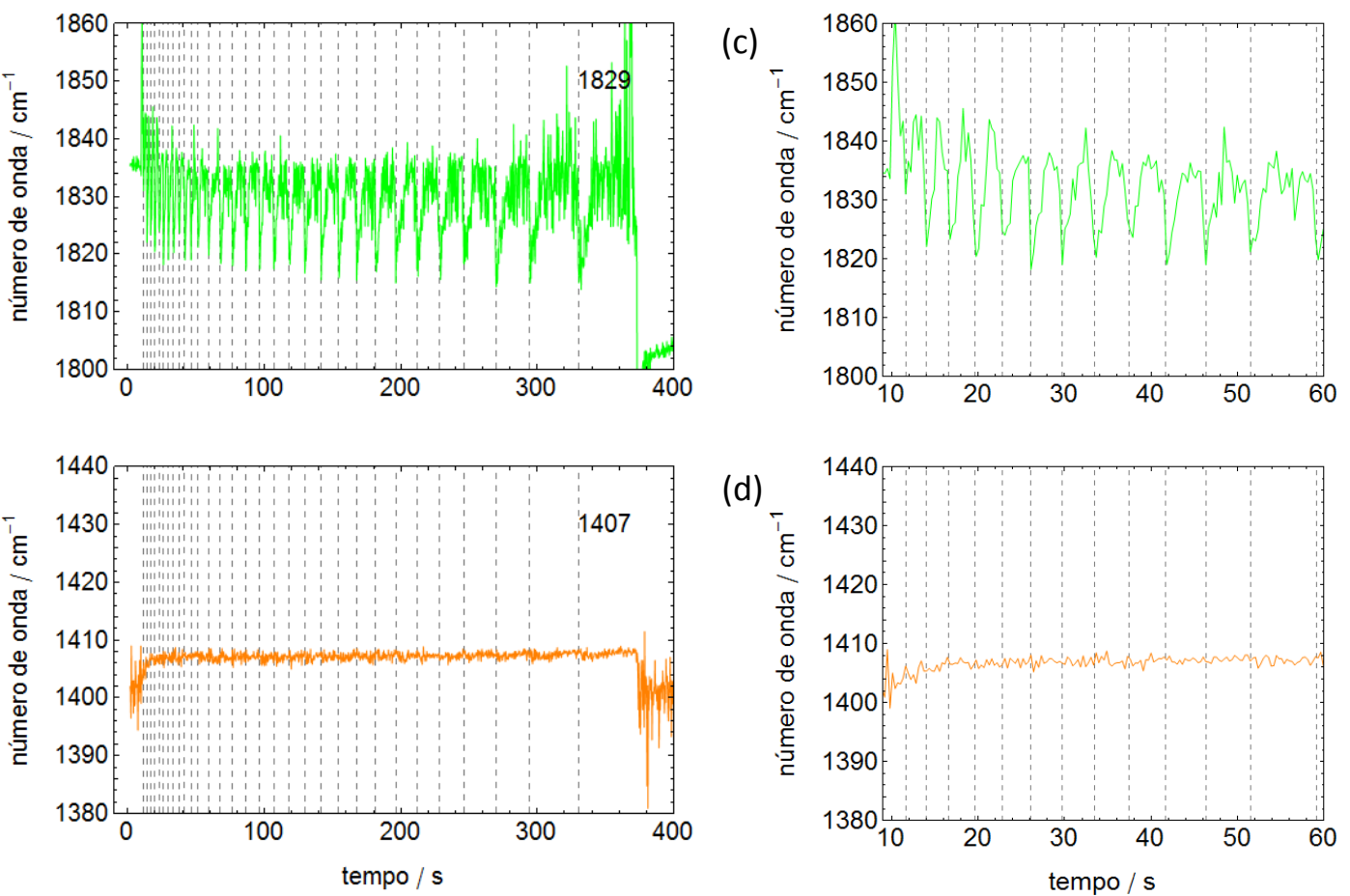

(d)

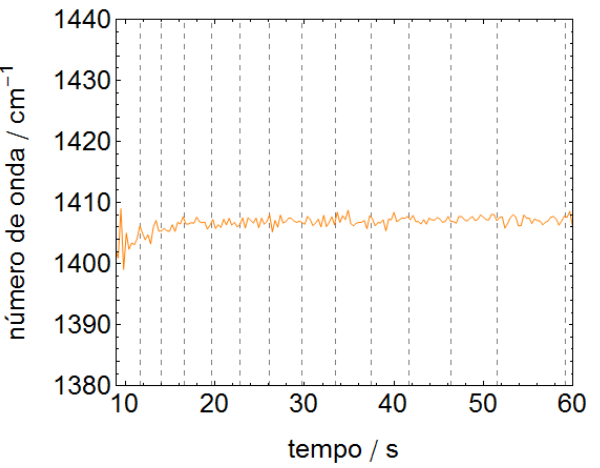

Figura 41 - Variação temporal de U (a) e das posições das bandas de $\mathrm{CO}_{\mathrm{L}}$ (b), $\mathrm{CO}_{\mathrm{B}}$ (c) e acetato adsorvido (d), cujas posições médias tomadas entre 100 e $300 \mathrm{~s}$ são, respectivamente, $2046 \mathrm{~cm}^{-1}, 1829 \mathrm{~cm}^{-1}$ e $1407 \mathrm{~cm}^{-1}$ durante o experimento apresentado na Fig. 32. 

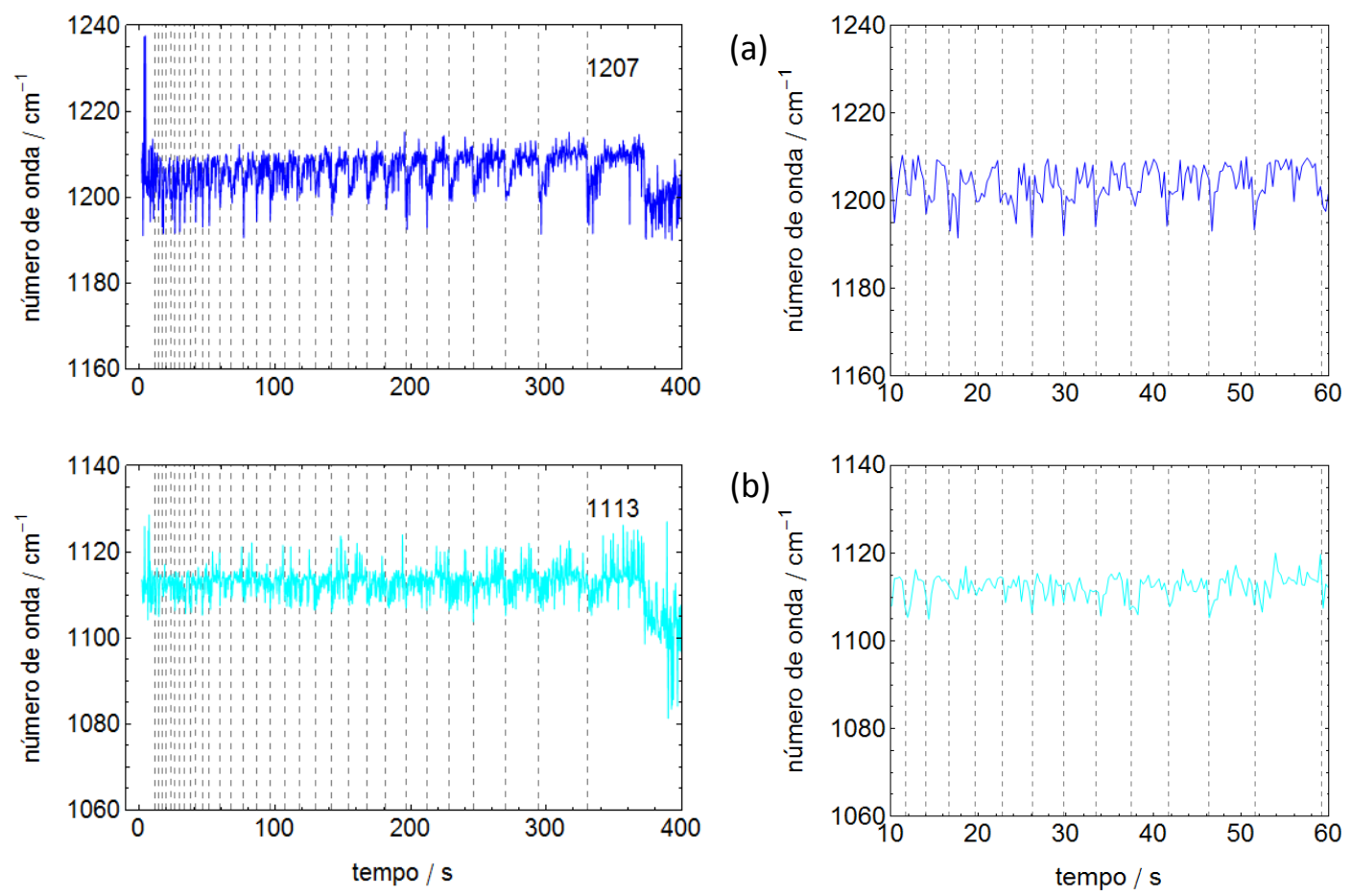

Figura 42 - Variação temporal das posições das bandas das espécies sulfato (a) e bi-sulfato (b) cujas posições médias tomadas entre 100 e $300 \mathrm{~s}$ são, respectivamente, $1207 \mathrm{~cm}^{-1}$ e $1113 \mathrm{~cm}^{-1}$ durante o experimento apresentado na Fig. 32. 


\section{Conclusões}

Com base nos resultados apresentados e discutidos ao longo da Seção 3.1 pode-se dar alguns passos para a compreensão do fenômeno oscilatório observado durante a eletrooxidação de metanol e concluir que:

- a técnica RTA-EAIVIS mostrou-se adequada para acompanhar, efetivamente in situ, a dinâmica de adsorbatos que se desenvolve durante a eletro-oxidação de metanol sobre platina. Já o mesmo não pode ser dito a respeito da técnica de reflexão externa, a qual além de possuir baixa resolução temporal pode conduzir a enganos, sendo inclusive desaconselhado seu uso para acompanhar o recobrimento de CO ainda que em média;

- ao contrário do que era aceito até então, o monóxido de carbono adsorvido não se acumula na superfície durante a oxidação eletroquímica oscilatória de metanol a corrente constante; em vez disso decai, continuamente, em média;

- a representação do recobrimento relativo de CO em função do tempo concomitantemente às oscilações de potencial observadas durante a eletro-oxidação de metanol sugere que, em condições oscilatórias, a espécie $\mathrm{CO}_{a d s}$ é o principal veneno que bloqueia a superfície;

- a conjunção entre o conhecimento de que espécies oxigenadas são consumidoras de monóxido de carbono adsorvido, com o fato experimental de que $\theta_{C O_{L}, r e l}$. decai continuamente, enquanto o potencial médio cresce durante a evolução da série temporal, sugere que o acúmulo de espécies oxigenadas está relacionado ao parâmetro intrínseco do sistema que o põe à deriva rumo a outro regime de estabilidade;

- a variação negativa da posição da banda de $\mathrm{CO}_{\mathrm{L}}$ enquanto o potencial aumenta ligeiramente durante o período de indução sugere que há diminuição na interação dipolodipolo entre moléculas de $\mathrm{CO}_{\mathrm{ads}}$, ou seja, que não há tendência para formação de ilhas de $\mathrm{CO}$ e que esta não é requisito para a observação de oscilações temporais de potencial durante a eletro-oxidação de metanol; 
- experimentos de eletro-oxidação oscilatória de metanol perturbados por presença extra de espécies oxigenadas, proporcionada pela adição de peróxido de hidrogênio, exibiram encurtamento do tempo de estabilidade das oscilações, corroborando a hipótese de que o acúmulo de espécies oxigenadas é o responsável pela deriva do sistema;

- Embora os ânions de sulfato possuam maior caráter inibidor de sítios reacionais do que ânions perclorato nenhuma influência do ânion do eletrólito de suporte foi identificada nos casos estudados.

Com base nos resultados apresentados e discutidos na Seção 3.2, referente à eletrooxidação oscilatória de etanol sobre platina pode-se concluir que:

- Um aumento na complexidade do perfil morfológico pode levar à diminuição na velocidade de aumento do potencial médio durante as oscilações e retardar o envenenamento da superfície;

- O período das oscilações observadas durante a eletro-oxidação de etanol sobre platina é determinado principalmente pelos processos que mantém o potencial na região de altos valores, o qual pode estar associado à produção de ácido acético, já que há um aumento na população de espécies acetato adsorvidas nesta região;

- A técnica RTA-AIVIS in situ possibilitou seguir as bandas relativas a $\mathrm{CO}_{\mathrm{L}}$ e acetato adsorvido e concluir que a população de ambas as espécies oscilam em anti-fase uma em relação à outra;

- A técnica EMED on line permitiu acompanhar as correntes iônicas relativas à produção de $\mathrm{CO}_{2}$ e acetaldeído; enquanto a primeira segue a dinâmica da curva temporal de potencial a segunda apresentou um comportamento estacionário dentro do regime oscilatório. Ainda, na condição oscilatória estudada, a formação de $\mathrm{CO}_{2}$ não é a principal via contribuindo para a corrente total. 


\section{Referências Bibliográficas}

1 NOVAK, B.; TYSON, J.J. Design principles of biochemical oscillators. Nature Reviews Molecular Cell Biology, v. 9, n. 12, p. 981-991, 2008.

2 HESS, B.; BOITEUX, A. Oscillatory phenomena in biochemistry. Annual Review of Biochemistry, v. 40, n. 1, p. 237-258, 1971.

3 EIGEN, M. Selforganization of matter and the evolution of biological macromolecules. Naturwissenschaften, v. 58, n. 10, p. 465-523, 1971.

4 SADEGHI, S.; THOMPSON, M. Towards information processing from nonlinear physical chemistry: A synthetic electrochemical cognitive system. BioSystems, v. 102, n. 2-3, p. 99111, 2010.

5 DE WIT, A. Spatial patterns and spatiotemporal dynamics in chemical systems. In: Advances in Chemical Physics. John Wiley \& Sons, 1999. p. 435-513.

6 SAGUES, F.; EPSTEIN, I.R. Nonlinear chemical dynamics. Dalton Transactions, n. 7, p. 12011217, 2003.

7 EPSTEIN, I.R.; SHOWALTER, K. Nonlinear chemical dynamics: oscillations, patterns, and chaos. Journal of Physical Chemistry, v. 100, n. 31, p. 13132-13147, 1996.

8 HUDSON, J.L.; TSOTSIS, T.T. Electrochemical reaction dynamics: a review. Chemical Engineering Science, v. 49, n. 10, p. 1493-1572, 1994.

9 EPSTEIN, I.R. Oscillations and chaos in chemical systems. Physica D: Nonlinear Phenomena, v. 7, n. 1-3, p. 47-56, 1983.

10 ERTL, G. Reactions at surfaces: from atoms to complexity (Nobel Lecture). Angewandte Chemie International Edition, v. 47, n. 19, p. 3524-3535, 2008.

11 ORLIK, M. Self-organization in nonlinear dynamical systems and its relation to the materials science. Journal of Solid State Electrochemistry, v. 13, n. 2, p. 245-261, 2009. 
12 FINKENSTÄDT, B.; KUHBIER, P. Chaotic dynamics in agricultural markets. Annals of Operations Research, v. 37, n. 1, p. 73-96, 1992.

13 BUZSÁKI, G. Rhythms of the brain. Oxford, Reino Unido: Oxford University Press, 2011. $464 \mathrm{p}$.

14 GOLDBETER, A. Biochemical oscillations and cellular rhythms - the molecular bases of periodic and chaotic behaviour. Cambridge, Reino Unido: Cambridge University Press, 1997. $632 \mathrm{p}$.

15 GOLDBETER, A.; CAPLAN, S.R. Oscillatory enzymes. Annual Review of Biophysics and Bioengineering, v. 5, n. 1, p. 449-476, 1976.

16 KRISCHER, K.; VARELA, H. Oscillations and other dynamic instabilities. In: VIELSTICH, W.; GASTEIGER, H.; LAMM, A.; YOKOKAWA, H., (Eds.). Handbook of Fuel Cells. John Wiley \& Sons, 2010. 23 p.

17 STRASSER, P.; EISWIRTH, M.; KOPER, M.T.M. Mechanistic classification of electrochemical oscillators - an operational experimental strategy. Journal of Electroanalytical Chemistry, v. 478, n. 1-2, p. 50-66, 1999.

18 T. M. KOPER, M. Non-linear phenomena in electrochemical systems. Journal of the Chemical Society, Faraday Transactions, v. 94, n. 10, p. 1369-1378, 1998.

19 KRISCHER, K. Principles of temporal and spatial pattern formation in electrochemical systems. In: CONWAY, B.E.; BOCKRIS, J.O.M; WHITE, R. (Eds.). Modern Aspects of Electrochemistry. Estados Unidos da América: Springer US, 1998. p. 1-142.

20 KOPER, M.T.M. Oscillations and complex dynamical bifurcations in electrochemical systems. In: Advances in Chemical Physics. John Wiley \& Sons, 1996. p. 161-298.

21 WOJTOWICZ, J. Oscillatory behavior in electrochemical systems. In: Modern Aspects of Electrochemistry, BOCKRIS, J.O.M.; CONWAY, B.E., (Eds.). 1972, Springer US. p. 47-120.

22 NAGAO, R. Efeito da temperatura na eletro-oxidação oscilatória de ácido fórmico sobre platina: experimentos e simulações. 2009. 79 f. Dissertação (Mestrado em Físico-Química) Instituto de Química de São Carlos, Universidade de São Paulo, São Carlos, 2009. 
23 NASCIMENTO, M.A.; GALLAS, J.A.C.; VARELA, H. Self-organized distribution of periodicity and chaos in an electrochemical oscillator. Physical Chemistry Chemical Physics, v. 13, n. 2, p. 441-446, 2011.

24 OKAMOTO, H.; TANAKA, N.; NAITO, M. Chaotic and periodic potential oscillations in formaldehyde oxidation. Journal of Physical Chemistry A, v. 102, n. 38, p. 7343-7352, 1998.

25 NAGAO, R.; SITTA, E.; VARELA, H. Stabilizing nonstationary electrochemical time series. Journal of Physical Chemistry C, v. 114, p. 22262-22268, 2010.

26 ATKINS, P.; PAULA, J.D. Physical Chemistry. $8^{\mathrm{a}}$ ed. Reino Unido: Oxford University Press, 2006. $1053 \mathrm{p}$.

27 HARRIS, D.C.; BERTOLUCCI, M.D. Symmetry and spectroscopy - an introduction to vibrational and electronic spectroscopy. Estados Unidos: Dover, 1989. $550 \mathrm{p}$.

28 BEDEN, B.; BEWICK, A.; LAMY, C. A study by electrochemically modulated infrared reflectance spectroscopy of the electrosorption of formic acid at a platinum electrode. Journal of Electroanalytical Chemistry and Interfacial Electrochemistry, v. 148, n. 1, p. 147160, 1983.

29 BEDEN, B.; BEWICK, A.; LAMY, C. A comparative study of formic acid adsorption on a platinum electrode by both electrochemical and EMIRS techniques. Journal of Electroanalytical Chemistry and Interfacial Electrochemistry, v. 150, n. 1-2, p. 505-511, 1983.

30 BEDEN, B.; LAMY, C.; BEWICK, A.; KUNIMATSU, K. Electrosorption of methanol on a platinum electrode. IR spectroscopic evidence for adsorbed $\mathrm{CO}$ species. Journal of Electroanalytical Chemistry and Interfacial Electrochemistry, v. 121, p. 343-347, 1981.

31 BEWICK, A.; KUNIMATSU, K.; STANLEY PONS, B. Infrared spectroscopy of the electrodeelectrolyte interphase. Electrochimica Acta, v. 25, n. 4, p. 465-468, 1980.

32 OSAWA, M. Surface-enhanced infrared absorption spectroscopy. In: Handbook of Vibrational Spectroscopy. John Wiley \& Sons, 2006. p. 785 - 799.

33 IWASITA, T.; NART, F.C. In situ infrared spectroscopy at electrochemical interfaces. Progress in Surface Science, v. 55, n. 4, p. 271-340, 1997. 
34 IWASITA, T.; NART, F.C.; RODES, A.; PASTOR, E.; WEBER, M. Vibrational spectroscopy at the electrochemical interface. Electrochimica Acta, v. 40, n. 1, p. 53-59, 1995.

35 OSAWA, M. Surface-enhanced infrared absorption. In: KAWATA, S., (Ed.). Near-Field Optics and Surface Plasmon Polaritons. Springer Berlin Heidelberg, 2001. p. 163-187.

36 OSAWA, M.; ATAKA, K.-I.; YOSHII, K.; YOTSUYANAGI, T. Surface-enhanced infrared ATR spectroscopy for in situ studies of electrode/electrolyte interfaces. Journal of Electron Spectroscopy and Related Phenomena, v. 64-65, p. 371-379, 1993.

37 OSAWA, M. Dynamic processes in electrochemical reactions studied by surface-enhanced infrared absorption spectroscopy (SEIRAS). Bulletin of the Chemical Society of Japan, v. 70, n. 12, p. 2861-2880, 1997.

38 SILVERSTEIN, R.M.; WEBSTER, F.X.; KIEMLE, D.J. Spectrometric identification of organic compounds. Estados Unidos da América: John Wiley and Sons, 2005. 502 p.

39 ASHTON, S.J. Differential electrochemical mass spectrometry. In: Design, construction and research application of a differential electrochemical mass spectrometer (DEMS). Springer Berlin Heidelberg, 2012. p. 9-27.

40 BALTRUSCHAT, H. Differential electrochemical mass spectrometry. Journal of the American Society for Mass Spectrometry, v. 15, n. 12, p. 1693-1706, 2004.

41 SOUZA, J.P.I.D.; QUEIROZ, S.L.; NART, F.C. Uso de espectrometria de massas em medidas eletroquímicas - a técnica de DEMS. Química Nova, v. 23, p. 384-391, 2000.

42 BRUCKENSTEIN, S.; GADDE, R.R. Use of a porous electrode for in situ mass spectrometric determination of volatile electrode reaction products. Journal of the American Chemical Society, v. 93, n. 3, p. 793-794, 1971.

43 WOLTER, O.; HEITBAUM, J. The adsorption of CO on a porous Pt-electrode in sulfuric acid studied by DEMS. Berichte der Bunsengesellschaft für physikalische Chemie, v. 88, n. 1, p. 6-10, 1984.

44 WOLTER, O.; HEITBAUM, J. Differential electrochemical mass spectroscopy (DEMS) - a new method for the study of electrode processes. Berichte der Bunsengesellschaft für physikalische Chemie, v. 88, n. 1, p. 2-6, 1984. 
45 LEUNG, L.W.H.; WEAVER, M.J. Real-time FTIR spectroscopy as a quantitative kinetic probe of competing electrooxidation pathways of small organic molecules. The Journal of Physical Chemistry, v. 92, n. 14, p. 4019-4022, 1988.

46 VILLEGAS, I.; WEAVER, M.J. Carbon monoxide adlayer structures on platinum (111) electrodes: A synergy between in-situ scanning tunneling microscopy and infrared spectroscopy. The Journal of Chemical Physics, v. 101, n. 2, p. 1648-1660, 1994.

47 HEINEN, M. Electrooxidation of small organic molecules studied by simultaneous in situ ATR-FTIRS and on-line differential electrochemical mass spectrometry. 2010. $381 \mathrm{f}$. Tese Instituto de Superfície Química e Catálise, Universidade de Ulm, Ulm, Alemanha, 2010.

48 MIYAKE, H.; YE, S.; OSAWA, M. Electroless deposition of gold thin films on silicon for surface-enhanced infrared spectroelectrochemistry. Electrochemistry Communications, v. 4, n. 12, p. 973-977, 2002.

49 HEINEN, M.; CHEN, Y.X.; JUSYS, Z.; BEHM, R.J. In situ ATR-FTIRS coupled with on-line DEMS under controlled mass transport conditions-A novel tool for electrocatalytic reaction studies. Electrochimica Acta, v. 52, n. 18, p. 5634-5643, 2007.

50 LI, L.; WEI, Z.; QI, X.; SUN, C.; YIN, G. Chemical oscillation in electrochemical oxidation of methanol on Pt surface. Science in China Series B: Chemistry, v. 51, n. 4, p. 322-332, 2008.

51 LEE, J.; EICKES, C.; EISWIRTH, M.; ERTL, G. Electrochemical oscillations in the methanol oxidation on Pt. Electrochimica Acta, v. 47, p. 2297-2301, 2002.

52 KRAUSA, M.; VIELSTICH, W. Potential oscillations during methanol oxidation at Ptelectrodes Part 1: experimental conditions. Journal of Electroanalytical Chemistry, v. 399, n. 1-2, p. 7-12, 1995.

53 MARTINS, A.L.; BATISTA, B.C.; SITTA, E.; VARELA, H. Oscillatory instabilities during the electrocatalytic oxidation of methanol on platinum. Journal of Brazilian Chemical Society, $v$. 19, n. 4, p. 679-687, 2008.

54 NAGAO, R.; CANTANE, D.A.; LIMA, F.H.B.; VARELA, H. The dual pathway in action: decoupling parallel routes for $\mathrm{CO}_{2}$ production during the oscillatory electro-oxidation of methanol. Physical Chemistry Chemical Physics, v. 14, p. 8294-8298, 2012.

55 FELIU, J.; CLIMENT, V. Thirty years of platinum single crystal electrochemistry. Journal of Solid State Electrochemistry, v. 15, p. 1297-1315, 2011. 
56 ANGERSTEIN-KOZLOWSKA, H.; CONWAY, B.E.; SHARP, W.B.A. The real condition of electrochemically oxidized platinum surfaces: Part I. Resolution of component processes. Journal of Electroanalytical Chemistry and Interfacial Electrochemistry, v. 43, n. 1, p. 9-36, 1973.

57 IWASITA, T. Electrocatalysis of methanol oxidation. Electrochimica Acta, v. 47, p. 36633674, 2002.

58 KUNIMATSU, K.; HANAWA, H.; UCHIDA, H.; WATANABE, M. Role of adsorbed species in methanol oxidation on Pt studied by ATR-FTIRAS combined with linear potential sweep voltammetry. Journal of Electroanalytical Chemistry, v. 632, p. 109-119, 2009.

59 BAGOTZKY, V.S.; VASSILYEV, Y.B. Mechanism of electro-oxidation of methanol on the platinum electrode. Electrochimica Acta, v. 12, p. 1323-1343, 1967.

60 PARSONS, R.; VANDERNOOT, T. The oxidation of small organic molecules - a survey of recent fuel cell related research. Journal of Electroanalytical Chemistry, v. 257, p. 9-45, 1988.

61 BAGOTZKY, V.S.; VASSILIEV, Y.B.; KHAZOVA, O.A. Generalized scheme of chemisorption, electrooxidation and electroreduction of simple organic compounds on platinum group metals. Journal of Electroanalytical Chemistry and Interfacial Electrochemistry, v. 81, n. 2, p. 229-238, 1977.

62 SITTA, E.; VARELA, H. On the open-circuit interaction between methanol and oxidized platinum electrodes. Journal of Solid State Electrochemistry, v. 12, p. 559-567, 2008.

63 CHEN, Y.-X.; HEINEN, M.; JUSYS, Z.; BEHM, R.J. Bridge-bonded formate: active intermediate or spectator species in formic acid oxidation on a Pt film electrode? Langmuir, v. 22, p. 10399-10408, 2006.

64 HEINEN, M.; JUSYS, Z.; BEHM, R.J. Reaction pathway analysis and reaction intermediate detection via simultaneous differential electrochemical mass spectrometry (DEMS) and attenuated total reflection Fourier transform infrared spectroscopy (ATR-FTIRS). In: VIELSTICH, W.; GASTEIGER, H.A.; LAMM, A.; YOKOKAWA, H., (Eds.). Handbook of Fuel Cells Fundamentals, Technology and Applications. John Wiley \& Sons, 2010. 32 p.

65 HOUSMANS, T.H.M.; WONDERS, A.H.; KOPER, M.T.M. Structure sensitivity of methanol electrooxidation pathways on platinum: an on-line electrochemical mass spectrometry study. Journal of Physical Chemistry B, v. 110, p. 10021-10031, 2006. 
66 JUSYS, Z.; BEHM, R.J. Methanol, formaldehyde, and formic acid adsorption/oxidation on a carbon-supported Pt nanoparticle fuel cell catalyst: a comparative quantitative DEMS study. In: KOPER, M.T.M. (Ed.). Fuel Cell Catalysis. John Wiley \& Sons, 2009. p. 410 - 464.

67 CUESTA, A.; CABELLO, G.; HARTL, F.W.; ESCUDERO-ESCRIBANO, M.; VAZ-DOMÍNGUEZ, C.; KIBLER, L.A.; OSAWA, M.; GUTIÉRREZ, C. Electrooxidation of formic acid on gold: An ATRSEIRAS study of the role of adsorbed formate. Catalysis Today, v. 202, p. 79-86, 2013.

68 CUESTA, A.; CABELLO, G.; GUTIÉRREZ, C.; OSAWA, M. Adsorbed formate: the key intermediate in the oxidation of formic acid on platinum electrodes. Physical Chemistry Chemical Physics, v. 13, p. 20091-20095, 2011.

69 ABD-EL-LATIF, A.A.; BALTRUSCHAT, H. Formation of methylformate during methanol oxidation revisited: The mechanism. Journal of Electroanalytical Chemistry, v. 662, p. 204212, 2011.

$70 \mathrm{XU}$, J.; YUAN, D.; YANG, F.; MEI, D.; ZHANG, Z.; CHEN, Y.-X. On the mechanism of the direct pathway for formic acid oxidation at a Pt(111) electrode. Physical Chemistry Chemical Physics, v. 15, n. 12, p. 4367-4376, 2013.

71 CUESTA, A.; CABELLO, G.; OSAWA, M.; GUTIÉRREZ, C. Mechanism of the electrocatalytic oxidation of formic acid on metals. ACS Catalysis, v. 2, p. 728-738, 2012.

72 GROZOVSKI, V.; VIDAL-IGLESIAS, F.J.; HERRERO, E.; FELIU, J.M. Adsorption of formate and its role as intermediate in formic acid oxidation on platinum electrodes. ChemPhysChem, $v$. 12, n. 9, p. 1641-1644, 2011.

73 SAMJESKÉ, G.; MIKI, A.; YE, S.; OSAWA, M. Mechanistic study of electrocatalytic oxidation of formic acid at platinum in acidic solution by time-resolved surface-enhanced infrared absorption spectroscopy. Journal of Physical Chemistry B, v. 110, n. 33, p. 16559-16566, 2006.

74 BATISTA, E.A. As reações de eletroxidação de metanol e monóxido de carbono: novos aspectos e novas interpretações 2005. 136 f. Tese (Doutorado em Físico-Química) - Instituto de Química de São Carlos, Universidade de São Paulo, São Carlos, 2005.

75 CUESTA, A. At least three contiguous atoms are necessary for $\mathrm{CO}$ formation during methanol electrooxidation on platinum. Journal of the American Chemical Society, v. 128, n. 41, p. 13332-13333, 2006. 
76 SITTA, E.; NASCIMENTO, M.A.; VARELA, H. Complex kinetics, high frequency oscillations and temperature compensation in the electro-oxidation of ethylene glycol on platinum. Physical Chemistry Chemical Physics, v. 12, n. 46, p. 15195-15206, 2010.

77 OKAMOTO, H.; TANAKA, N.; NAITO, M. Chaos in the oxidation of formaldehyde and/or methanol. Journal of Physical Chemistry A, v. 101, n. 45, p. 8480-8488, 1997.

78 OLIVEIRA, C.P.; LUSSARI, N.V.; SITTA, E.; VARELA, H. Oscillatory electro-oxidation of glycerol on platinum. Electrochimica Acta, v. 85, p. 674-679, 2012.

79 ZHANG, J.; FEHRIBACH, J.D.; DATTA, R. Mechanistic and bifurcation analysis of anode potential oscillations in PEMFCs with $\mathrm{CO}$ in anode feed. Journal of Electrochemical Society, v. 151, n. 5, p. A689-A697, 2004.

80 ZHANG, J.; DATTA, R. Sustained potential oscillations in proton exchange membrane fuel cells with PtRu as anode catalyst. Journal of Electrochemical Society, v. 149, n. 11, p. A1423A1431, 2002.

81 ZHANG, J.; DATTA, R. Higher power output in a PEMFC operating under autonomous oscillatory conditions in the presence of CO. Electrochemical and Solid-State Letters, v. 7, n. 3, p. A37-A40, 2004.

82 CABRAL, M.F.; NAGAO, R.; SITTA, E.; EISWIRTH, M.; VARELA, H. Mechanistic aspects of the linear stabilization of non-stationary electrochemical oscillations. Physical Chemistry Chemical Physics, v. 15, p. 1437-1442, 2013.

83 FERREIRA, G.C.A.; BATISTA, B.C.; VARELA, H. Experimental assessment of the sensitiveness of an electrochemical oscillator towards chemical perturbations. PLoS ONE, v. 7, n. 11, p. e50145, 2012.

84 KREBS, H.J.; LÜTH, H. Evidence for two different adsorption sites of CO on Pt(111) from infrared reflection spectroscopy. Applied physics, v. 14, n. 4, p. 337-342, 1977.

85 CHEN, Y.X.; MIKI, A.; YE, S.; SAKAI, H.; OSAWA, M. Formate, an active intermediate for direct oxidation of methanol on Pt Electrode. Journal of the American Chemical Society, $v$. 125, n. 13, p. 3680-3681, 2003. 
86 ENDO, M.; MATSUMOTO, T.; KUBOTA, J.; DOMEN, K.; HIROSE, C. Formation of formate in the deep oxidation of methanol on Pt(111) under UHV condition studied by IRAS. Journal of Physical Chemistry B, v. 104, n. 20, p. 4916-4922, 2000.

87 COLUMBIA, M.R.; THIEL, P.A. The stabilization of formate on Pt(111) by coadsorbed atomic oxygen. Chemical Physics Letters, v. 220, n. 3-5, p. 167-171, 1994.

88 LAMBERT, D.K. Vibrational Stark effect of adsorbates at electrochemical interfaces. Electrochimica Acta, v. 41, n. 5, p. 623-630, 1996.

89 SAMJESKE, G.; MIKI, A.; YE, S.; YAMAKATA, A.; MUKOUYAMA, Y.; OKAMOTO, H.; OSAWA, $M$. Potential oscillations in galvanostatic electrooxidation of formic acid on platinum: a timeresolved surface-enhanced infrared study. Journal of Physical Chemistry B, v. 109, p. 2350923516, 2005.

90 HILBORN, R. Chaos and Nonlinear Dynamics - An Introduction for Scientists and Engineers. $2^{a}$ ed. Reino Unido: Oxford University Press, 2004. 672 p.

91 SEIDEL, Y.E.; JUSYS, Z.; LINDSTRÖM, R.W.; STENFELDT, M.; KASEMO, B.; KRISCHER, K. Oscillatory behaviour in galvanostatic formaldehyde oxidation on nanostructured Pt/glassy carbon model electrodes. ChemPhysChem, v. 11, n. 7, p. 1405-1415, 2010.

92 SCHMIDT, T.J.; GRGUR, B.N.; MARKOVIC, N.M.; ROSS JR, P.N. Oscillatory behavior in the electrochemical oxidation of formic acid on $\mathrm{Pt}(100)$ : rotation and temperature effects. Journal of Electroanalytical Chemistry, v. 500, n. 1-2, p. 36-43, 2001.

93 BIEGLER, T.; RAND, D.A.J.; WOODS, R. Limiting oxygen coverage on platinized platinum; Relevance to determination of real platinum area by hydrogen adsorption. Journal of Electroanalytical Chemistry and Interfacial Electrochemistry, v. 29, n. 2, p. 269-277, 1971.

94 BATISTA, E.A.; MALPASS, G.R.P.; MOTHEO, A.J.; IWASITA, T. New mechanistic aspects of methanol oxidation. Journal of Electroanalytical Chemistry, v. 571, n. 2, p. 273-282, 2004.

95 HEINEN, M.; JUSYS, Z.; BEHM, R.J. Ethanol, acetaldehyde and acetic acid adsorption/electrooxidation on a Pt thin film electrode under continuous electrolyte flow: an in situ ATR-FTIRS flow cell study. Journal of Physical Chemistry C, v. 114, n. 21, p. 9850-9864, 2010. 
96 CHEN, Y.X.; HEINEN, M.; JUSYS, Z.; BEHM, R.J. Potential-induced $\mathrm{CO}_{a d}$ island formation on a platinum thin-film electrode in the $\mathrm{H}$-upd potential region. Journal of Physical Chemistry C, v. 111, n. 1, p. 435-438, 2007.

97 KIKUCHI, M.; MIYAHARA, S.; MUKOUYAMA, Y.; OKAMOTO, H. Potential oscillation generated by formic acid in the presence of dissolved oxygen. Journal of Physical Chemistry C, v. 112, p. 7186-7192, 2008.

98 MUKOUYAMA, Y.; NAKANISHI, S.; CHIBA, T.; MURAKOSHI, K.; NAKATO, Y. Mechanisms of two electrochemical oscillations of different types, observed for $\mathrm{H}_{2} \mathrm{O}_{2}$ reduction on a $\mathrm{Pt}$ electrode in the presence of a small amount of halide ions. Journal of Physical Chemistry B, v. 105, n. 30, p. 7246-7253, 2001.

99 RODRIGUEZ, J.L.; PASTOR, E.; ZINOLA, C.F.; SCHMIDT, V.M. Heterogeneously assisted oxidation of adsorbates from carbonmonoxide, methanol and ethanol by hydrogen peroxide solutions on platinum electrodes in sulphuric acid. Journal of Applied Electrochemistry, $v$. 36, p. 1271-1279, 2006.

100 HAN, L.; JU, H.; XU, Y. Ethanol electro-oxidation: cyclic voltammetry, electrochemical impedance spectroscopy and galvanostatic oscillation. International Journal of Hydrogen Energy, v. 37, n. 20, p. 15156-15163, 2012.

101 CHEN, S.; SCHELL, M. Bistability and excitability in the electrochemical oxidation of ethanol. Electrochimica Acta, v. 44, n. 26, p. 4773-4780, 1999.

102 LAMY, C.; COUTANCEAU, C. Electrocatalysis of alcohol oxidation reactions at platinum group metals. In: LIANG, Z.-X.; ZHAO, T.S., (Eds.). Catalysts for Alcohol-Fuelled Direct Oxidation Fuel Cells. Cambridge, Reino Unido: Royal Society of Chemistry, 2012. p. 1-70.

103 CANTANE, D.A.; GONZALEZ, E.R. Chemical selectivity during the electro-oxidation of ethanol on unsupported Pt nanoparticles. Journal of The Electrochemical Society, v. 159, n. 3, p. B355-B359, 2012.

104 KUTZ, R.B.; BRAUNSCHWEIG, B.; MUKHERJEE, P.; BEHRENS, R.L.; DLOTT, D.D.; WIECKOWSKI, A. Reaction pathways of ethanol electrooxidation on polycrystalline platinum catalysts in acidic electrolytes. Journal of Catalysis, v. 278, n. 2, p. 181-188, 2011.

105 DEL COLLE, V.; SOUZA-GARCIA, J.; TREMILIOSI-FILHO, G.; HERRERO, E.; FELIU, J.M. Electrochemical and spectroscopic studies of ethanol oxidation on Pt stepped surfaces modified by tin adatoms. Physical Chemistry Chemical Physics, v. 13, n. 26, p. 12163-12172, 2011. 
106 ABD-EL-LATIF, A.A.; MOSTAFA, E.; HUXTER, S.; ATTARD, G.; BALTRUSCHAT, H.

Electrooxidation of ethanol at polycrystalline and platinum stepped single crystals: A study by differential electrochemical mass spectrometry. Electrochimica Acta, v. 55, n. 27, p. 79517960, 2010.

107 IWASITA, T.; RASCH, B.; CATTANEO, E.; VIELSTICH, W. A SNIFTIRS study of ethanol oxidation on platinum. Electrochimica Acta, v. 34, n. 8, p. 1073-1079, 1989.

108 CAMARA, G.A.; IWASITA, T. Parallel pathways of ethanol oxidation: The effect of ethanol concentration. Journal of Electroanalytical Chemistry, v. 578, n. 2, p. 315-321, 2005.

109 WANG, H.; JUSYS, Z.; BEHM, R.J. Ethanol electrooxidation on a carbon-supported Pt catalyst: reaction kinetics and product yields. Journal of Physical Chemistry B, v. 108, n. 50, p. 19413-19424, 2004.

110 PACHECO SANTOS, V.; DEL COLLE, V.; BATISTA DE LIMA, R.; TREMILIOSI-FILHO, G. FTIR study of the ethanol electrooxidation on $\mathrm{Pt}(100)$ modified by osmium nanodeposits. Langmuir, v. 20, n. 25, p. 11064-11072, 2004.

111 HITMI, H.; BELGSIR, E.M.; LÉGER, J.M.; LAMY, C.; LEZNA, R.O. A kinetic analysis of the electro-oxidation of ethanol at a platinum electrode in acid medium. Electrochimica Acta, $\mathrm{v}$. 39, n. 3, p. 407-415, 1994.

112 WILLSAU, J.; HEITBAUM, J. Elementary steps of ethanol oxidation on Pt in sulfuric acid as evidenced by isotope labelling. Journal of Electroanalytical Chemistry and Interfacial Electrochemistry, v. 194, n. 1, p. 27-35, 1985.

113 GOMES, J.F.; BERGAMASKI, K.; PINTO, M.F.S.; MIRANDA, P.B. Reaction intermediates of ethanol electro-oxidation on platinum investigated by SFG spectroscopy. Journal of Catalysis, v. 302, p. 67-82, 2013.

114 PRIETO, M.J.; TREMILIOSI-FILHO, G. The influence of acetic acid on the ethanol electrooxidation on a platinum electrode. Electrochemistry Communications, v. 13, n. 6, p. 527-529, 2011. 


\section{APÊNDICE A}

A posição, $v_{i}$, das bandas de espécies adsorvidas $i$ presentes nos espectros coletados durante a eletro-oxidação galvanostática de $\mathrm{H}_{2} \mathrm{SO}_{4} 0,5 \mathrm{M}+\mathrm{C}_{2} \mathrm{H}_{5} \mathrm{OH} 0,05 \mathrm{M}$ a 0,183 mA cm${ }^{-2}$, Fig. 32, foram encontradas usando-se uma rotina no aplicativo Mathematica 9, assumindo $v_{i}$ como a posição do máximo de intensidade da banda. Inicialmente, uma função de interpolação $f$ foi criada a partir dos pares ordenados $\{v, l\}=\{$ número de onda, intensidade de absorção\} experimentalmente obtidos e que compõem os espectros de radiação infravermelha. Então, o comando FindMaximum $\left[f(x),\left\{x, x_{0}\right\}\right]$, onde $x_{0}$ é valor do número de onda usado para dar início à busca numérica do máximo, foi usado para uma primeira estimativa da posição da banda. Contudo, devido ao ruído presente nos dados, consequência da necessidade de se empregar alta resolução temporal a fim de definir as mudanças nas características dos adsorbatos numa escala de tempo inferior ao período das oscilações, múltiplos máximos locais podem estar presentes nas bandas, induzindo a erro. Assim, após uma primeira estimativa da posição do máximo, um intervalo de 35 unidades de número de onda inferiores e superiores a ele foi tomado para realizar a seguinte média entre eles:

$$
\left\{v_{n}, f\left(v_{n}\right)\right\}=\frac{1}{15} \sum_{i=n}^{n+15}\left\{v_{i}, f\left(v_{i}\right)\right\}
$$

visando suavizar o ruído em torno da posição provável do máximo. Então, é criada uma nova função de interpolação $g$ em torno do novo conjunto de pares ordenados $\left\{v_{n}, f\left(v_{n}\right)\right\}$ e usando o comando FindMaximum sobre ela foi encontrado o que se supôs ser a posição da banda. Na Fig. A1 abaixo são apresentados exemplos da aplicação deste método para a determinação da posição da banda de $\mathrm{CO}_{\llcorner}$. O ponto em vermelho corresponde à primeira estimativa de posição da banda, a curva tracejada em laranja é a função de interpolação $g$ e o ponto em azul corresponde ao seu máximo. 

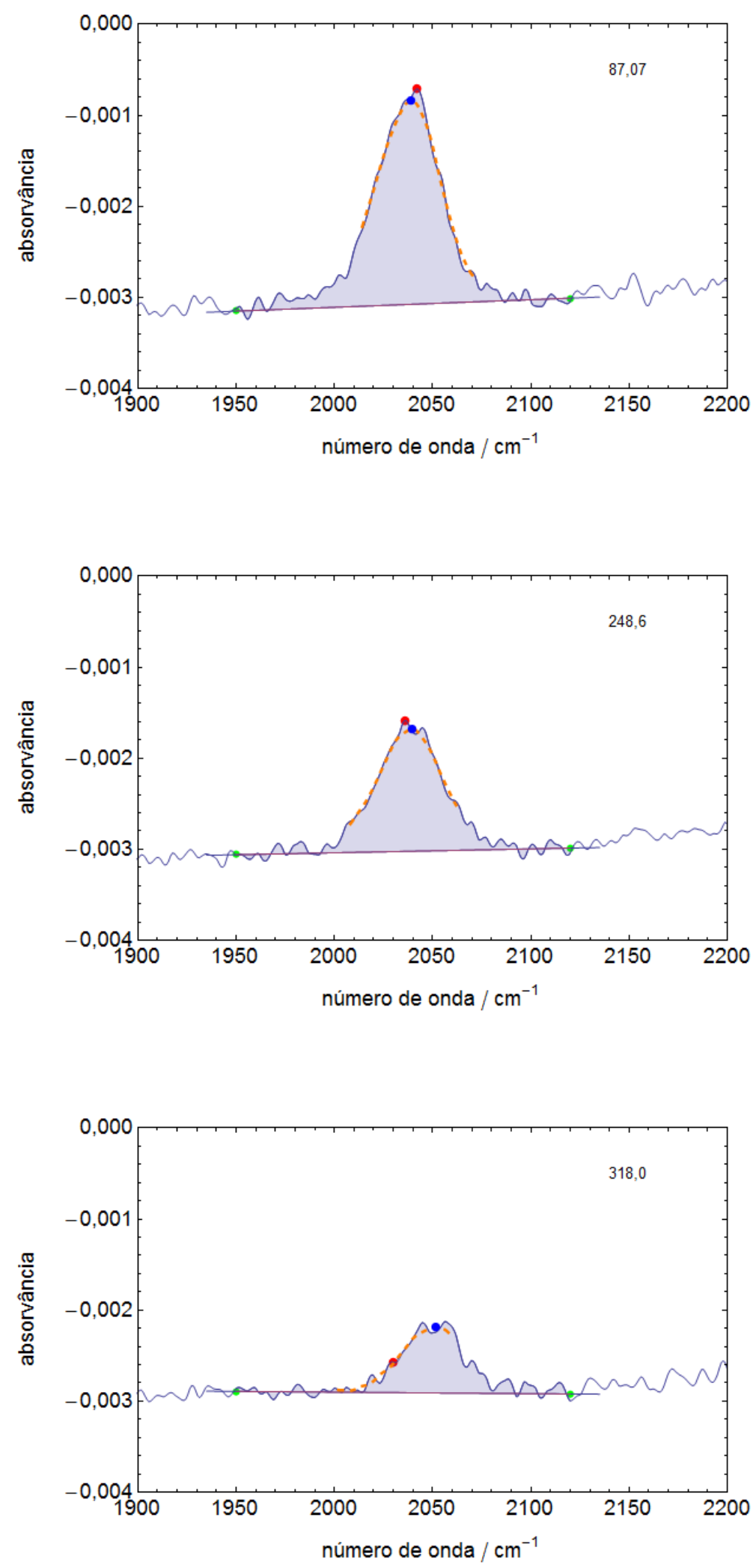

Figura $\mathrm{A} \mathbf{1}$ - Espectros na região da banda de $\mathrm{CO}_{\mathrm{L}}$ em três diferentes tempos, indicados no canto superior direito das figuras. Mais detalhes podem ser encontrados no texto. 